\title{
Title: Distinguishing and understanding thermogenic and biogenic sources of methane using multiply substituted isotopologues
}

\author{
Authors: D.A. Stolper ${ }^{\mathrm{a}}$, A.M. Martini ${ }^{\mathrm{b}}, \mathrm{M} \mathrm{Clog}^{\mathrm{a}}$, P.M. Douglas ${ }^{\mathrm{a}}$, S.S. Shusta ${ }^{\mathrm{c}}$, D.L. Valentine ${ }^{\mathrm{c}}$, \\ A.L. Sessions ${ }^{\mathrm{a}}$, J.M. Eiler ${ }^{\mathrm{a}}$ \\ Affiliations: ${ }^{a}$ Division of Geological and Planetary Sciences, California Institute of Technology, Pasadena, CA, \\ USA \\ ${ }^{b}$ Department of Geology, Amherst College, Amherst, MA, USA \\ ${ }^{c}$ Department of Earth Science and Marine Science Institute, University of California, Santa Barbara, CA 93106, \\ USA
}

\begin{abstract}
Sources of methane to sedimentary environments are commonly identified and quantified using the stable-isotopic compositions of methane. The methane "clumped-isotope geothermometer", based on the measurement of multiply substituted methane isotopologues $\left({ }^{13} \mathrm{CH}_{3} \mathrm{D}\right.$ and $\left.{ }^{12} \mathrm{CH}_{2} \mathrm{D}_{2}\right)$, shows promise in adding new constraints to the sources and formational environments of both biogenic and thermogenic methane. However, questions remain about how this geothermometer behaves in systems with mixtures of biogenic and thermogenic gases and different biogenic environments. We have applied the methane clumped-isotope thermometer to a mixed biogenic-thermogenic system (Antrim Shale, USA) and to biogenic gas from gas seeps (Santa Barbara and Santa Monica Basin, USA), a pond on the Caltech campus, and methanogens grown in pure-culture. We demonstrate that clumped-isotope based temperatures add new quantitative constraints to the relative amounts of biogenic vs. thermogenic gases in the Antrim Shale indicating a larger proportion $(\sim 50 \%)$ of thermogenic gas in the system than previously thought. Additionally, we find that the clumped-isotope temperature of biogenic methane appears related to the environmental settings in which the gas forms. In systems where methane generation rates appear to be slow (e.g., the Antrim Shale and gas seeps), microbial methane forms in or near both internal isotopic equilibrium and hydrogen-isotope equilibrium with environmental waters. In systems where methane forms rapidly, microbial methane is neither in internal isotopic equilibrium nor hydrogen-isotope equilibrium with environmental waters. A quantitative model of microbial methanogenesis that incorporates isotopes is proposed to explain these results.
\end{abstract}

\footnotetext{
${ }^{1}$ Corresponding author: 1200 E. California Blvd, Pasadena, CA 91125, dstolper@caltech.edu, 626-395-3753
} 


\section{Introduction}

Understanding and quantifying the sources of methane in sedimentary environments is critical for studies of climate change, biogeochemical cycling, and energy exploration. The two dominant processes that generate methane in nature are (Wuebbles and Hayhoe, 2002): (i) methane generated by methanogenic archaea, known as 'biogenic' methane; and (ii) methane generated during the thermally-activated breakdown of larger organic molecules, termed 'thermogenic' methane. Identifying the relative contributions of these sources to a given accumulation of methane can be challenging because gases tend to migrate and mix in the subsurface (Tissot and Welte, 1978; England et al., 1987; Price and Schoell, 1995; Hunt, 1996). However, this identification is the necessary first step in understanding the (bio)geochemistry of methane formation, gas flow, and ecology of microorganisms in the subsurface.

In many environments, thermogenic and biogenic gases can be distinguished using average or 'bulk' carbon and hydrogen isotope compositions combined with the relative abundances of methane to other hydrocarbon gases (e.g., Bernard et al., 1976; Schoell, 1980, 1983; Whiticar et al., 1986; Chung et al., 1988; Whiticar, 1999). These molecular and isotopic 'fingerprints' are a powerful and important starting point for establishing the origin of methane in nature, but they are not foolproof - some gases can appear both thermogenic and biogenic in these frameworks (Martini et al., 1996, 1998). Additionally, the end-member compositions of thermogenic and biogenic gases are sufficiently variable that it can be difficult to quantify their contributions to mixtures solely using isotopic and compositional parameters. Furthermore, the fundamental controls of the isotopic composition - especially the hydrogen isotopic composition - of biogenic and thermogenic methane remains poorly understood (Burke Jr, 1993; Sugimoto and Wada, 1995; Whiticar, 1999; Valentine et al., 2004; Schimmelmann et al., 2006; Yoshioka et al., 2008; Ni et al., 2011; Hattori et al., 2012; Kawagucci et al., 2014). Important questions to consider when interpreting the meaning of the isotopic composition of biogenic methane are the importance of kinetic vs. equilibrium isotope effects during methanogenesis and, by extension, how reversible are the enzymatic processes involved in methane generation (Blair, 1998; Whiticar, 1999; Valentine et al., 2004; Penning et al., 2005).

\subsection{New techniques to identify the source of methane in in the environment}

A potentially powerful way to distinguish biogenic from thermogenic methane is through the direct determination of a gas's formation temperature. For example, based on observations from environmental systems, biogenic gases in nature are generally thought to form below $\sim 80^{\circ} \mathrm{C}$ (Wilhelms et al., 2001; Valentine, 2011) - although laboratory methanogenic cultures can grow up to at least $122^{\circ} \mathrm{C}$ (Takai et al., 2008). In contrast, based on both experiments and comparison to observations from sedimentary basins, thermogenic gases are thought to form above $\sim 60^{\circ} \mathrm{C}$ (Tissot and Welte, 1978; Quigley and Mackenzie, 1988; Hunt, 1996; Seewald et al., 1998; Seewald, 2003), and many models predict that most natural gases form at temperatures greater than $\sim 150{ }^{\circ} \mathrm{C}$ (Quigley and Mackenzie, 1988; Seewald et al., 1998). Thus, knowledge of the formation temperature of a sample of methane could provide a fingerprint for its original formational environment and by extension, its source. Formation temperatures may be

76 particularly distinctive and useful when combined with the established molecular and isotopic 77 
New geothermometers based on the measurement of multiply substituted ('clumped') methane isotopologues (Ma et al., 2008; Tsuji et al., 2012; Stolper et al., 2014a; Stolper et al., 2014b; Ono et al., 2014a; Wang et al., in press) can constrain formation temperatures of methane. This is possible because the degree of clumped isotopic ordering, i.e., the clumped-isotope composition/distribution of a sample of methane (or any other molecule) that formed in isotopic equilibrium without further isotopic exchange after formation is a function of its formation temperature (e.g., Urey and Rittenberg, 1933; Wang et al., 2004; Eiler and Schauble, 2004; Schauble et al., 2006; Eiler, 2007; Ma et al., 2008; Yeung et al., 2012; Eiler, 2013; Eiler et al., 2014a; Stolper et al., 2014a; Stolper et al., 2014b; Webb and Miller III, 2014; Ono et al., 2014a). The potential to use clumped isotopes to measure methane formation temperatures has been demonstrated theoretically in several studies (Ma et al., 2008; Cao and Liu, 2012; Stolper et al., 2014a; Webb and Miller III, 2014; Ono et al., 2014a).

The first demonstration that clumped-isotope distributions of methane could be measured at the sub-per-mil precisions necessary for geothermometry along with an experimentally generated temperature calibration was by Stolper et al. (2014a) using mass spectrometry. Stolper et al. (2014a) also provided evidence that thermogenic methane can yield clumped-isotope temperatures related to its formation temperatures. Following this, Stolper et al. (2014b) showed that clumped-isotope temperatures of biogenic and thermogenic methane from sedimentary basins are consistent with expected gas formation temperatures. Additionally, Stolper et al. (2014b) discussed (and showed in the supplementary materials) that biogenic methane can form without achieving an equilibrium distribution of clumped-isotopes, i.e., out of clumped-isotope equilibrium. They hypothesized that biogenic methane that resulted in reasonable clumpedisotope temperatures (and thus, by inference, formation in clumped isotopic equilibrium) resulted from the partial reversibility of enzymes involved in methanogenesis. Using an independent infrared spectroscopic method for measuring methane clumped-isotope distributions, Ono et al. (2014a) confirmed the results of the mass spectrometric measurements of Stolper et al. (2014a) and Stolper et al. (2014b) that thermogenic methane yields clumped-isotope temperatures consistent with their formational environments. This demonstration that two different analytical techniques yield similar quantitative determinations of clumped-isotope distributions and inferred temperatures is an important demonstration of the validity of the application of clumped-isotope thermometry to natural systems.

Although clumped-isotope distributions of methane appear to reflect equilibrium distributions imprinted at the time of formation in many settings, including for some microbially sourced gases, in addition to the results of Stolper et al. (2014b) discussed above, Stolper et al. (2014c), Gruen et al. (2014), and Ono et al. (2014b) all presented preliminary results indicating that biogenic methane forms out of clumped-isotope equilibrium such that the clumped-isotope temperatures yield apparent temperatures that are too high to be formation temperatures. Stolper et al. (2014c) suggested that this disequilibrium reflects the methane's formation environment. Specifically, disequilibrium was suggested to occur in environments where methane generation rates are high, such as in organic-carbon-rich environments (like a pond). Conversely, in subsurface environments such as sedimentary basins, where methane generation rates are slower, methane was suggested to form in clumped isotopic equilibrium. Stolper et al. (2014c) also showed that the clumped isotopic composition of biogenic methane was linked to the difference 
in $\mathrm{D} / \mathrm{H}$ ratios of methane vs. the water it formed in: Specifically, when methane was found to be in clumped isotopic equilibrium and yielded reasonable clumped-isotope temperatures, it was also in $\mathrm{D} / \mathrm{H}$ equilibrium with its formational waters. However, when the methane appeared to be out of clumped isotopic equilibrium, it was out of $\mathrm{D} / \mathrm{H}$ isotopic equilibrium with its source waters. Following this, Eiler et al. (2014) presented a quantitative model of microbial methanogenesis based on the hypothesis of a Stolper et al. (2014b) that the degree of enzymatic reversibility during methanogenesis controls the clumped isotopic composition of methane. This model successfully linked the clumped isotopic composition of methane and the isotopic difference between methane, water and $\mathrm{CO}_{2}$ to the overall reversibility of enzymes involved in methanogenesis. This preliminary work is developed and presented more fully here. Alternative hypotheses are that the generation of biogenic methane out of clumped isotopic equilibrium arises from kinetic isotope effects created via tunneling of hydrogen and deuterium atoms and/or other forms of kinetic isotope effect during hydrogenation reactions or reflect inheritance from substrates (Gruen et al., 2014; Ono et al., 2014b). In more recent work this same group (Wang et al., in press), confirmed that biogenic gases in some systems yield apparent methane clumpedisotope-based temperatures that are sensible, but that other biogenic systems yield apparent temperatures that represent methane formation of out of isotopic equilibrium. They additionally confirmed the correlation of $\mathrm{D} / \mathrm{H}$ ratios of methane water vs. methane clumped-isotope compositions first reported by Stolper et al. (2014c) and developed a quantitative model similar to that shown by Eiler et al. (2014) that also relates the generation of biogenic methane to enzymatic reversibility.

\subsection{This study}

Although initial results demonstrate promise in identifying the environment where methane forms, including distinguishing biogenic from thermogenic methane, clumped-isotope techniques have so far only been applied to methane from a small number of natural environments, most of which were dominantly either biogenic or thermogenic in origin (Stolper et al., 2014b; Wang et al., in press). Thus, it remains unclear whether these temperature constraints can yield quantitative insights into systems that contain a mixture of thermogenic and biogenic gases. Such mixtures could be difficult to untangle due to non-linear and unintuitive 'mixing effects' on the clumped isotope systematics of many gases [discussed below and more broadly in Eiler and Schauble (2004) and Eiler (2013)]. Additionally, distinguishing biogenic methane that forms out of isotopic equilibrium from thermogenic methane might be challenging (Stolper et al., 2014b; Stolper et al., 2014c; Gruen et al., 2014; Eiler et al., 2014b; Wang et al., in press).

To explore these issues, we have measured abundances of clumped isotopologues of methane in gases from the northern and western margin of the Antrim Shale in the Michigan Basin, which is known to contain a mixture of biogenic and thermogenic gases (Martini et al., 1996; Martini et al., 1998; Martini et al., 2003). We demonstrate that the measurements provide quantitative, novel insights into the origin of gases in the system. Specifically, the results indicate a higher abundance of thermogenic gases than previously inferred and add geologically grounded constraints to the source of the thermogenic component.

To place our results from the Antrim Shale system into a broader context, we also measured biogenic gases from laboratory cultures of methanogens and two other natural environments (gas 
seeps from the Santa Barbara and Santa Monica Basins and a pond from the Caltech campus). We demonstrate that the measured difference in the $\mathrm{D} / \mathrm{H}$ ratio of biogenic methane versus that of the water in which the methane forms is correlated to the clumped-isotope composition. Using this relationship, we demonstrate that when methane is in clumped isotopic equilibrium, it is in heterogeneous equilibrium with water as well. We argue that this relationship is indicative of the importance of enzymatic reversibility in setting the isotopic composition of biogenic methane. The combined results from the Antrim Shale and these other settings indicate that the clumped isotopic composition of biogenic methane is sensitive to the environment in which the organisms grow. Specifically, as hypothesized by Stolper et al. (2014c), in systems where rates of microbial methanogenesis appear to be low, methane is formed in isotopic equilibrium with itself and other phases such as water. In contrast, rapid methane generation rates promote the formation of methane out of isotopic equilibrium with both itself and with other phases.

Based on these findings, following the initial work of Eiler et al. (2014), we develop a quantitative model linking the physiology of methanogens to the measured clumped-isotope abundances of biogenic gases through the assumption that the enzymes involved in methanogenesis can operate reversibly. This model considers both kinetic- and equilibriumbased controls on the generation and isotopic composition of methane. We show that for fully reversible enzymatic conditions methane is generated in both internal isotopic (homogenous phase) and heterogeneous phase equilibrium with water and $\mathrm{CO}_{2}$. In contrast, for partially irreversible enzymatic conditions, methane is formed out of both internal isotopic equilibrium and out of equilibrium with water and $\mathrm{CO}_{2}$. This work highlights the key role clumped-isotope measurements can play in elucidating the thermodynamic conditions under which biogenic methane is generated.

\section{Geological and geochemical context of the Antrim Shale}

The Antrim Shale subcrops below glacial drift deposits in the Michigan Basin (Figure 1). It is Devonian in age, having formed during the Acadian orogeny as a distal facies of the Catskills delta complex (Gutschick and Sandberg, 1991). The northern margin of the shale contains economically significant accumulations of natural gas (Martini et al., 1996; Martini et al., 1998) with over 12,000 wells drilled (Martini et al., 2008). It is considered to be an 'unconventional' shale-gas system in which the gases were formed and are stored in situ. There is evidence based on both isotopic and chemical constraints for extensive fluid migration within the northern margin of the Antrim Shale: specifically water from basinal brines is thought to have mixed in the northern margin with meteoric waters (Wilson and Long, 1993; Martini et al., 1998; McIntosh and Walter, 2005). This mixing is facilitated by fluid migration along extensive vertical fracture networks (Apotria and Kaiser, 1994; Martini et al., 1998) that are potentially important conduits for gas migration.

A key distinguishing feature of the northern margin Antrim Shale gases is that they are thought to be dominantly $(>80 \%)$ microbial in origin with the remaining fraction $(<20 \%)$ thermogenic (Martini et al., 1996; Martini et al., 1998). In fact, the Antrim Shale has been used as a model for microbially generated, unconventional shale-gas systems (Curtis, 2002). In addition to their economic importance, these systems have been proposed to play a role in regulating climate between glacial/interglacial cycles via storage and release of methane to the atmosphere 
(Formolo et al., 2008). There are three key pieces of evidence for the biological character of the northern margin gases: (i) Methanogens are present in formation waters (Waldron et al., 2007; Formolo et al., 2008; Kirk et al., 2012; Wuchter et al., 2013); (ii) $\delta$ D values (footnote 2) of methane and water extracted (co-produced) with the methane are linearly correlated. Following Schoell (1980), this correlation was interpreted to indicate a biological origin for most $(>80 \%)$ of the gas (Martini et al., 1996, 1998); And (iii) $\delta^{13} \mathrm{C}$ values of co-produced $\mathrm{CO}_{2}$ methane are high (>20\% ; Martini et al., 1996, 1998, and 2003), indicative of active hydrogenotrophic $\left(\mathrm{CO}_{2}+\mathrm{H}_{2}\right)$ methanogenesis in a closed system (e.g., Claypool and Kaplan, 1974). It is important to note that only the biogenic methane is hypothesized to have formed within the shales. The original formational site of the thermogenic component of the gases is poorly constrained. Proposed sources of thermogenic gases include the northern margin itself (i.e., that it is self-sourced) or migration of gases into the northern margin along the fracture networks discussed above from more deeply buried expressions of the Antrim Shale in the mid-basin or older source rocks in the Michigan Basin (Martini et al., 1996; Martini et al., 1998; Martini et al., 2003). Consequently, the Antrim Shale provides a type example for studying both the mixing of thermogenic and biogenic gases in a relatively simple system and the behavior of methanogenic archaea in the 'deep biosphere' (Edwards et al., 2012).

Measurements of clumped isotopes provide an independent method to quantify the ratio of thermogenic and biogenic gases in the northern margin and thus test the proposal that the gases are dominantly microbial in origin. Specifically, if northern and western margin gases are dominantly biogenic and formed in internal isotopic equilibrium, the clumped isotope temperatures should reflect current ambient temperatures in the shale $\left(\sim 10-30^{\circ} \mathrm{C}\right.$; Martini et al., 1998).

\section{Methods}

\subsection{General methods and sample collection}

We studied methane samples from a variety of economic wells from the northern margin of the Antrim Shale, and one sample from the western margin (Table 1). For each sample, we measured the $\delta \mathrm{D}$ and $\delta^{13} \mathrm{C}$ values of methane $\left(\delta^{13} \mathrm{C}_{\mathrm{CH} 4}\right.$ and $\left.\delta \mathrm{D}_{\mathrm{CH} 4}\right)$, relative abundances of $\mathrm{C}_{1}-\mathrm{C}_{4}$ alkanes, $\delta \mathrm{D}$ and $\delta^{18} \mathrm{O}$ values of co-produced waters $\left(\delta \mathrm{D}_{\mathrm{H} 20 \text {, liquid }}\right.$ and $\left.\delta^{18} \mathrm{O}_{\mathrm{H} 20 \text {,liquid }}\right)$, and $\delta^{13} \mathrm{C}$ values of $\mathrm{CO}_{2}$ $\left({ }^{13} \mathrm{C}_{\mathrm{CO} 2}\right)$ in the gas phase. Clumped-isotope compositions of methane were also measured, and are reported as the combined signal of the mass-18 isotopologues $\left({ }^{13} \mathrm{CH}_{3} \mathrm{D}[\sim 98 \%]\right.$ and ${ }^{12} \mathrm{CH}_{2} \mathrm{D}_{2}$ $[\sim 2 \%])$. We also measured $\delta^{13} \mathrm{C}$ values of ethane $\left(\delta^{13} \mathrm{C}_{\mathrm{C} 2 \mathrm{H} 6}\right)$ for some samples.

Antrim Shale gases were sampled in duplicate directly from wellheads in stainless steel containers. One set was sent to Isotech Labs (Champaign, IL) and the other set sent to the Caltech. At Isotech, $\delta^{13} \mathrm{C}$ values of $\mathrm{CO}_{2}$ were measured using dual-inlet mass spectrometry with an external precision of $\sim 0.1 \%$. Gas compositions $\left(\mathrm{C}_{1} / \mathrm{C}_{2-4}\right.$ ratios $)$ were also measured at Isotech

\footnotetext{
${ }^{2} \delta=\left(\mathrm{R} / \mathrm{R}_{\text {std }}-1\right) \times 1000$ where ${ }^{13} \mathrm{R}=\left[{ }^{13} \mathrm{C}\right] /\left[{ }^{12} \mathrm{C}\right],{ }^{\mathrm{D}} \mathrm{R}=[\mathrm{D}] /[\mathrm{H}],{ }^{18} \mathrm{R}=\left[{ }^{18} \mathrm{O}\right] /\left[{ }^{16} \mathrm{O}\right]$, and 'std' denotes the standard to which all measurements are referenced. For this paper all carbon measurements are referenced to VPDB and all hydrogen and oxygen measurements to VSMOW.
} 
laboratories via gas chromatography using a Shimadzu 2014 and 2010 gas chromatographs equipped with flame ionization and thermal conductivity detectors. Relative precision was typically $\pm 5 \%$ for $\mathrm{C}_{1-3}$ hydrocarbons and $\pm 10 \%$ for larger hydrocarbons. $\delta \mathrm{D}_{\text {н2о,liquid }}$ and $\delta^{18} \mathrm{O}_{\text {H2O,liquid }}$ of co-produced waters were measured at Smith College using a Picarro L1102-i cavity ring-down spectroscopy analyzer. Precision was $0.2 \%$ for $\delta^{18} \mathrm{O}_{\text {нго,liquid }}$ and $0.5 \%$ for $\delta \mathrm{D}_{\mathrm{H} 20 \text {,liquid }}$.

For Santa Barbara and Santa Monica Basin samples, gases were collected at the sea floor using an inverted funnel equipped with a stainless steel cylinder, using the ROV Jason during cruise AT26-06 of the $R / V$ Atlantis. Seeping gases were trapped using the inverted funnel and sealed in the cylinder for transport to the $R / V$ Atlantis where they were subsampled for subsequent analyses. One subsample was used to measure gas composition at the University of California, Santa Barbara using the method described by Duffy et al. (2007). Another subsample was shipped to Caltech for analysis of clumped isotopes.

One sample of methane was extracted from a pond on Caltech's campus. A vacuum-evacuated 1 L Pyrex flask was connected to a vessel for collecting gas from sedimentary systems. Gases were released from the pond sediments manually through agitation and collected in the headspace of the initial vessel. Atmospheric gases were eliminated by first filling the vessel with pond water. The evacuated flask was then connected to the vessel via a rubber tube and opened, filling with pond-derived gas.

\subsection{Description of clumped-isotope and ethane analyses and external reproducibility}

Prior to isotopic analyses, methane and ethane were purified on a glass vacuum line as described in Stolper et al. (2014a), Stolper et al. (2014b), and Clog et al. (2014). $\delta^{13} \mathrm{C}, \delta \mathrm{D}$, and clumpedisotope compositions of methane and $\delta^{13} \mathrm{C}$ of ethane were measured via mass spectrometry on a prototype, high-resolution isotope-ratio mass spectrometer, the MAT 253 Ultra (Eiler et al., 2013), at Caltech as described in Stolper et al. (2014a) and Stolper et al. (2014b) for methane and Clog et al. (2014) for ethane. External precisions for $\delta \mathrm{D}_{\mathrm{CH} 4}$ measurements were typically $0.13 \%$, $0.06 \%$ for $\delta^{13} \mathrm{C}_{\mathrm{CH} 4}$ measurements and $0.03 \%$ for $\delta^{13} \mathrm{C}_{\mathrm{C} 2 \mathrm{H} 6}$ measurements.

Clumped-isotope compositions are expressed using $\Delta_{18}$ notation (Stolper et al., 2014a) where

$$
\Delta_{18}=\left({ }^{18} \mathrm{R} /{ }^{18} \mathrm{R}^{*}-1\right) \times 1000,
$$

and

$$
{ }^{18} \mathrm{R}=\left(\left[{ }^{13} \mathrm{CH}_{3} \mathrm{D}\right]+\left[{ }^{12} \mathrm{CH}_{2} \mathrm{D}_{2}\right]\right) /\left[{ }^{12} \mathrm{CH}_{4}\right] .
$$

The brackets denote the molar concentration of the isotopologue as a fraction of all molecules of the compound of interest. $\mathrm{R}^{*}$ is the ratio expected for a random distribution of isotopes amongst all isotopologues (Stolper et al., 2014a). $\Delta_{18}$ values are reported in a reference frame in which $0 \%$ represents a random isotopic distribution. All samples are compared to (i.e., referenced against) a laboratory standard with a $\Delta_{18}$ value in this reference frame of $2.981 \%$, which was 
previously calibrated in the study of Stolper et al. (2014a). $\Delta_{18}$ values are converted into

$$
\Delta_{18}=-0.0117\left(\frac{10^{6}}{\mathrm{~T}^{2}}\right)^{2}+0.708\left(\frac{10^{6}}{\mathrm{~T}^{2}}\right)-0.337 \text {. }
$$

306

307

308

309

310

311

312

313

314

315

316

317

318

319

320

321

322

323

324

325

326

327

328

329

330

331

332

333

334

335

336

337

338

339

340

341

Samples were measured over 8 analytical sessions spanning 10 months including some overlap with measurement sessions for data reported in Stolper et al. (2014b). External precision of measurements was monitored three ways. First, a standard differing in $\delta \mathrm{D}(+56 \%), \delta^{13} \mathrm{C}$ $(+33 \%)$, and $\delta^{18}(+92 \%$; footnote 3$)$ as compared to the laboratory internal standard was measured multiple times in each analytical session. External precision for the $\Delta_{18}$ value across all measurements is $\pm 0.23 \%$ ( 1 standard deviation, $\sigma ; n=19$ ), and differs in $\Delta_{18}$ by $<0.04 \%$ o from the long-term average of the standard over 2.5 years of measurements (being slightly too positive). Second, gases equilibrated on nickel catalysts at $500^{\circ} \mathrm{C}$ were measured in all sessions (Stolper et al., 2014a). External precision across the sessions is $\pm 0.28 \%$ o $(1 \sigma ; n=17)$ and differs by $<0.06 \%$ in $\Delta_{18}$ from the long-term (2.5 year) average (again being slightly too positive). Additionally, no statistically significant dependence of $\Delta_{18}$ values on the bulk isotopic composition of the heated gases (monitored using a 300\% range in $\delta^{18}$ values) was observed (Figure A1). Third, 8 Antrim Shale gases and 1 Santa Monica Basin gas were measured multiple times in different sessions. Additionally, the Antrim Shale samples were purified by different users and contain significant quantities of gases other than methane. Thus, replicate analysis of these samples should provide constraints on the overall reproducibility of the $\Delta_{18}$ measurements that incorporates both sample preparation and mass-spectrometric measurements. The external precision for $\Delta_{18}$ for the samples is $\pm 0.24 \%$ o $(1 \sigma, n=20)$. One Antrim sample (North Charlton A1-18), measured 3 times, yielded a single outlier $\Delta_{18}$ value compared to the others and this value is excluded from all further discussion. Exclusion of this outlier yields an external precision for $\Delta_{18}$ measurements of $0.17 \%$ o $(1 \sigma, n=19)$.

We thus conclude that $\Delta_{18}$ external precisions are $\sim 0.25 \%$, consistent with internal, countingstatistics-derived errors for a single measurement of 0.24-0.27\%o (Stolper et al., 2014a). In two sessions, drift in the standard used to normalize data from a measurement session to a unified $\delta \mathrm{D}$ and $\Delta_{18}$ reference frame (as described in Stolper et al., 2014a) was observed. We corrected for this drift by measuring the standard used for the correction multiple times over the course of these sessions and assumed the values required for the correction for a sample measured on a different day changed linearly with time between observations of the standard. The quality of the correction was checked through multiple measurements of a secondary standard (the one described above which differs in $\delta \mathrm{D}, \delta^{13} \mathrm{C}$ and $\delta^{18}$ as compared to the laboratory reference standard) in all sessions and re-analysis of at least some samples in other sessions. For both sessions, final average $\Delta_{18}$ values of the secondary standard were within 1 standard error (s.e.) of its long-term average (longer term average $\left.\Delta_{18}=1.71\right): 1.79 \pm 0.07(1$ s.e., $n=2)$ and $1.56 \pm 0.15$ ( 1 s.e., $n=4)$. Additionally, the overall external precision of the Antrim Shale samples, including

\footnotetext{
${ }^{3} \delta^{18}=\left({ }^{18} \mathrm{R}_{\text {sample }} /{ }^{18} \mathrm{R}_{\text {standard }}-1\right) \times 1000$ where ${ }^{18} \mathrm{R}=\left(\left[{ }^{13} \mathrm{CH}_{3} \mathrm{D}\right]+\left[{ }^{12} \mathrm{CH}_{2} \mathrm{D}_{2}\right]\right) /\left[{ }^{12} \mathrm{CH}_{4}\right]$
} 
those observed in these sessions, does not differ from the external precision of other measured standards and $500{ }^{\circ} \mathrm{C}$ heated gases.

\subsection{Methanogen pure-culture growth conditions and considerations}

Pure cultures of Methanothermobacter marburgensis and Methanosarcina barkeri (species of methanogens) were grown at the University of California, Santa Barbara in an $\mathrm{H}_{2} / \mathrm{CO}_{2}$ atmosphere following Boone et al. (1989), at constant temperatures from $30-70^{\circ} \mathrm{C}$. Samples were shaken to ensure mixing of $\mathrm{H}_{2}$ into the solution. Before sampling of methane, culture media was removed from the culture bottles. Methane was removed from the culture bottles with a gas-tight syringe (Vici), injected onto a vacuum glass line, and then purified as described in Stolper et al. (2014a) and Stolper et al. (2014b). These samples are more depleted in $\delta^{18}$ relative to our working gas standard by $\sim 200$ to $400 \%$ and are outside of the normal range of bulk isotopic composition of samples usually measured. To ensure no measureable bias exists for measurements of gases with significantly more depleted $\delta^{18}$ values than the standards, two biogenic gases $\left(\delta^{18}=-180\right.$ to $-200 \%$ ) were heated in the presence of nickel catalysts to promote internal isotopic equilibrium at $500{ }^{\circ} \mathrm{C}$ following Stolper et al. (2014a). These gases yielded a $\Delta_{18}$ value of $1.03 \pm 0.28$ ( 1 s.e.), identical within error to the long term average for $500{ }^{\circ} \mathrm{C}$ heated gases, $1.06 \pm 0.05$ ( $n=21,1$ s.e.). However we note that two samples measured were significantly more depleted in $\delta^{18}$ (by $\sim 200 \%$ ) than the biogenic gases catalytically equilibrated at $500^{\circ} \mathrm{C}$ (the $30^{\circ} \mathrm{C}$ and $37^{\circ} \mathrm{C}$ experiments). Thus there is the potential that an analytical artifact for these very low $\delta^{18}$ samples exists that was not tested for by our study of heated, low $\delta^{18}$ gases. Regardless, any inaccuracies up to $\sim \pm 2 \%$ o for these samples, i.e., an order of magnitude larger than the stated $1 \sigma$ error bars, would not affect any interpretation of these measurements.

$\delta \mathrm{D}_{\mathrm{H} 2 \mathrm{O} \text {,liquid }}$ for one pure culture experiment $\left(65^{\circ} \mathrm{C} M\right.$. marburgensis experiment $)$ and the Caltech Pond samples were measured at Caltech using a spectroscopic Liquid-Water Isotope Analyzer (Los Gatos Research Inc.) as described in Feakins and Sessions (2010). Samples were standardized to the VSMOW/VSLAP scale by measuring standards of known isotopic composition that bracketed the $\delta \mathrm{D}$ values of the samples. Typical precision for $\delta \mathrm{D}_{\mathrm{H} 2 \mathrm{O} \text {,iquid }}$ measurements for this instrument is $\sim<1 \%$ (Feakins and Sessions, 2010). $\delta D_{\mathrm{H} 20 \text {,liquid }}$ values were not measured for all culture media, which were prepared with the same water source but at different times. We assume that all media had the same $\delta D$ value with a conservative $1 \sigma$ error of $25 \%$ for the instances where the value was not measured.

\subsection{Calculations of expected differences in $\delta D_{H 2 O} v s . \delta D_{C H 4}$}

We calculated the expected equilibrium isotopic difference between $\delta \mathrm{D}_{\mathrm{CH} 4}$ and $\delta \mathrm{D}_{\mathrm{H} 2 \mathrm{O} \text {,liquid, }}$, i.e., $\alpha_{\mathrm{CH} 4-\mathrm{H} 2 \mathrm{O} \text {,liquid }}$, where $\alpha_{\mathrm{A}-\mathrm{B}}=\left(\mathrm{R}_{\mathrm{A}} / \mathrm{R}_{\mathrm{B}}\right)$. To do this, we first calculated $\alpha_{\mathrm{CH} 4 \text {-H2O,vapor }}$ (where ' $\mathrm{H}_{2} \mathrm{O}$,vapor' refers to water in the vapor phase) as a function of temperature using the theoretically derived data from Richet et al. (1977). The derived equations are given in Table 2. In Richet et al. (1977), two theoretical datasets are available to calculate $\alpha_{\mathrm{CH} 4-\mathrm{H} 2 \mathrm{O}, \mathrm{vapor}}$, one that incorporates anharmonicity in the reduced partition functions of methane and one that does not (i.e., is harmonic). These models disagree strongly at low temperatures, yielding, for example, a 70\%o difference in $\alpha_{\mathrm{CH} 4-\mathrm{H} 2 \mathrm{O} \text {,vapor }}$ at $20^{\circ} \mathrm{C}$. Perhaps surprisingly, there are no independent experimentally 
or environmentally derived constraints to indicate which is correct. In the face of these uncertainties, we simply used the average of the two model estimates at a given temperature to calculate $\alpha_{\mathrm{CH} 4-\mathrm{H} 2 \mathrm{O} \text {,vapor. }}$. This estimate was then combined with the experimentally derived fractionation factor between liquid water and vapor from Horita and Wesolowski (1994), resulting in an estimated value for $\alpha_{\mathrm{CH} 4-\mathrm{H} 2 \mathrm{O} \text {,liquid }}$. We did not use the experimentally calibrated $\alpha_{\mathrm{CH} 4-\mathrm{H} 2}$ calibration provided by Horibe and Craig (1995) (in combination with other fractionation factors to arrive at $\alpha_{\mathrm{CH} 4-\mathrm{H} 2 \mathrm{O} \text {,liquid }}$ ) as it is only calibrated at temperatures greater than $200^{\circ} \mathrm{C}$. As our interest in using this calibration (see below) is for microbial environments, which range in temperature from $\sim 0$ to $120^{\circ} \mathrm{C}$ (all samples examined here were generated below $70^{\circ} \mathrm{C}$ ), we consider it more accurate to use the theoretical forms given in Richet et al. (1977). We note though, that the calibration of $\alpha_{\mathrm{CH} 4-\mathrm{H} 2}$ from Horibe and Craig (1995) combined with the calibration for $\alpha_{\mathrm{H} 2-\mathrm{H} 2 \mathrm{O} \text {,vapor }}$ from Richet et al. (1977) and $\alpha_{\mathrm{H} 2 \mathrm{O} \text {,liquid-H2O,vapor from }}$ Horita and Wesolowski (1994) results in a calibration that falls between those derived using the harmonic and anharmonic calculations for $\alpha_{\mathrm{CH} 4-\mathrm{H} 2 \mathrm{O} \text {,vapor }}$ from Richet et al. (1977) with $\alpha_{\mathrm{H} 2 \mathrm{O} \text {,liquid-H2O,vapor }}$ from Horita and Wesolowski (1994) discussed above.

\section{Mixed-source gases of the Antrim Shale}

\section{Stable-isotope systematics and chemical/physical measurements of the Antrim Shale}

Measured isotopic and physical/chemical values for Antrim Shale gases are provided in Table 3 and Figure 2. Samples measured in this study are similar in isotopic composition and $\mathrm{C}_{1} / \mathrm{C}_{2-4}$ ratios to those measured previously by others (Figure 2a, c, and e; Martini et al., 1996, 1998, 2003). Gas-well temperatures range from 16 to $24{ }^{\circ} \mathrm{C}$ (Table 3 ).

The $\delta^{13} \mathrm{C}_{\mathrm{CH} 4}$ values of all measured gases vary by less than $3 \%$, ranging from -50 to $-53 \%$ o (Figure $2 \mathrm{c}$ and $\mathrm{d}$ ). Historically, $\delta^{13} \mathrm{C}_{\mathrm{CH} 4}$ values $<-60 \%$ o have often been considered indicative of biogenic gases, while those $\sim-50 \%$ indicative of thermogenic gases (Schoell, 1980; Whiticar, 1999), though the actual ranges in nature may have a larger overlap (e.g., Tang et al., 2000; Valentine et al., 2004). Regardless, the $\delta^{13} \mathrm{C}$ values observed in the Antrim Shale gases fall between these historic ranges and, as discussed by others, do not yield strong constraints on the origin of the methane (Martini et al., 1996; Martini et al., 1998; Whiticar, 1999). As observed in other northern margin gases, all $\delta^{13} \mathrm{C}_{\mathrm{CO} 2}$ values are $>20 \%$ (Table 2; Martini et al., 1996, 1998, 2003). Also, $\delta \mathrm{D}_{\mathrm{CH} 4}$ and $\delta \mathrm{D}_{\mathrm{H} 2 \mathrm{O} \text {,iquid }}$ values are correlated, following a similar linear trend as observed previously (Figure 2e). As discussed above, these two observations were previously used by Martini et al. (1996) to hypothesize that the northern margin gases are dominantly biogenic in origin. However, a proportion of thermogenic gases must be present in the samples because some contain significant quantities of $\mathrm{C}_{2-4}$ alkanes with $\mathrm{C}_{1} / \mathrm{C}_{2-4}$ ratios as low as 8 (i.e., $11 \% \mathrm{C}_{2-4}$ alkanes relative to all $\mathrm{C}_{1-4}$ alkanes; Table 2). This is because $\mathrm{C}_{2-4}$ alkanes are thought to be of thermogenic origin in the Antrim Shale (Martini et al., 2003). Similarly low $C_{1} / C_{2-4}$ ratios $\left(\mathrm{C}_{1} / \mathrm{C}_{2-4}=12\right.$; Figure $2 \mathrm{a}$ and $\left.\mathrm{b}\right)$ occur in other northern margin gases (Martini et al., 1998). Finally, as observed in previous studies (Martini et al., 1996; Martini et al., 1998), the $\mathrm{C}_{1} / \mathrm{C}_{2-4}$ ratio is related to $\delta D_{\mathrm{CH} 4}$ values, such that gases with more enriched $\delta \mathrm{D}_{\mathrm{CH} 4}$ values have lower $\mathrm{C}_{1} / \mathrm{C}_{2-4}$ ratios (Figure 2a). This relationship is consistent with gases with more enriched $\delta D_{C H 4}$ values having a greater proportion of thermogenic gas. 


\section{$4.1 \Delta_{18}$-based temperatures}

Measured $\Delta_{18}$ temperatures average $67^{\circ} \mathrm{C}$, range from $40-115^{\circ} \mathrm{C}$ (Table 2), and correlate with many of the other measured parameters. For example, a hyperbolic relationship exists between $\Delta_{18}$ temperatures and $\mathrm{C}_{1} / \mathrm{C}_{2-4}$ ratios, with hotter temperatures corresponding to lower $\mathrm{C}_{1} / \mathrm{C}_{2-4}$ values (Figure $2 \mathrm{~b}$ ). $\Delta_{18}$ temperatures are also linearly correlated with $\delta \mathrm{D}_{\mathrm{H} 2 \mathrm{O} \text {,liquid }}$ (Figure $2 \mathrm{f}$ ) and $\delta \mathrm{D}_{\mathrm{CH} 4}$ (Figure $2 \mathrm{~g}$ ), with hotter temperatures corresponding to more enriched $\delta \mathrm{D}_{\mathrm{H} 2 \mathrm{O} \text {,liquid }}$ and $\delta \mathrm{D}_{\mathrm{CH} 4}$ values. Despite the relatively small variation of $\delta^{13} \mathrm{C}_{\mathrm{CH} 4}$ in Antrim shale gases (and a general lack of correlation with other geochemical properties), we note a weak linear relationship between $\delta^{13} \mathrm{C}_{\mathrm{CH} 4}$ and $\Delta_{18}$ temperatures $\left(\mathrm{r}^{2}=0.31\right.$; Figure $\left.2 \mathrm{~d}\right)$. This relationship or lack thereof is discussed in more detail below in the context of a quantitative mixing model (Section 4.2).

The relationships between $\Delta_{18}$ temperatures and various other isotopic and compositional parameters support the hypothesis that the northern margin gases are a mixture of lower temperature biogenic gases with higher temperature thermogenic gases. For example, samples previously interpreted to be dominantly biogenic, those with more depleted $\delta \mathrm{D}_{\mathrm{CH} 4}$ values and higher $\mathrm{C}_{1} / \mathrm{C}_{2-4}$ ratios (Martini et al., 1996; Martini et al., 1998; Martini et al., 2003) yield the lowest $\Delta_{18}$ temperatures while samples with lower $\mathrm{C}_{1} / \mathrm{C}_{2-4}$ ratios yield the highest temperatures. The meaning of the $\Delta_{18}$ values of the samples, which, based on previous criteria, should contain significant quantities of biogenic methane is not straightforward. For example, the $\Delta_{18}$ temperatures of the thermogenic and biogenic end members could reflect the actual gas formation temperatures (Stolper et al., 2014b). Alternatively, the $\Delta_{18}$ temperatures of the biogenic end member could be influenced by kinetic isotope effects that have been observed in some microbial systems (Stolper et al., 2014b; Stolper et al., 2014c; Gruen et al., 2014; Ono et al., 2014b; Eiler et al., 2014b; Wang et al., in press). Thus, it is not clear whether we should interpret the low measured $\Delta_{18}$ temperatures of biogenic gases as an indication of their actual formation temperatures, or instead as some non-equilibrium isotopic signature. As will be discussed and developed in the following sections, multiple lines of evidence indicate that the $\Delta_{18}$-based temperatures of the biogenic end-member gases are $\sim 20^{\circ} \mathrm{C}$, the current temperature of the shales, and thus that the biogenic component of the gases was formed in clumped isotopic equilibrium.

\subsection{Mixing Model}

The relationship between $\Delta_{18}$ temperatures and $\delta \mathrm{D}_{\mathrm{CH} 4}, \delta \mathrm{D}_{\mathrm{H} 20 \text {,liquid, }}$ and $\mathrm{C}_{1} / \mathrm{C}_{2-4}$ values suggests that the $\Delta_{18}$ temperatures relate to the amount of thermogenic and biogenic gas in the system. In order to explore the feasibility of this quantitatively, a mixing model was created. This model assumes that there are two end members of gases mixed together, one a biogenic gas formed at lower temperatures and the other a thermogenic gas formed at higher temperatures. In order to create this model, end-member values for the $\Delta_{18}$ temperature, $\delta \mathrm{D}_{\mathrm{CH} 4}, \delta \mathrm{D}_{\mathrm{H} 2 \mathrm{O}}$, and $\mathrm{C}_{1} / \mathrm{C}_{2-4}$ ratios had to be assigned. In choosing these end member values, we incorporated as many external constraints as possible. Thus the model can serve as a test of the plausibility of the measured $\Delta_{18}$ temperatures. I.e., we can ask whether the mixing model is both self-consistent with one or more of the trends 
defined by the samples studied here and, more broadly, with the other measured properties of these and related gases.

Assumed compositions for the thermogenic and biogenic end-member components of our mixing model are given in Table 3. Of these, two compositional parameters $\left(\delta^{13} \mathrm{C}_{\mathrm{CH} 4}\right.$ and $\Delta_{18}$ of both end members) are discussed in detail here. $\delta^{13} \mathrm{C}_{\mathrm{CH} 4}$ end member values were chosen assuming, as observed by the weak linear relationship between $\delta^{13} \mathrm{C}_{\mathrm{CH} 4}$ and $\Delta_{18}$-temperature (Figure 2d), that the biogenic end member has a more enriched $\delta^{13} \mathrm{C}_{\mathrm{CH} 4}$ value than the thermogenic end member. Then, the highest measured $\delta^{13} \mathrm{C}_{\mathrm{CH} 4}$ value of a northern margin gas with $\mathrm{C}_{1} / \mathrm{C}_{2-4}$ ratios $>500$ was taken for the biogenic component and lowest $\delta^{13} \mathrm{C}_{\mathrm{CH} 4}$ value of gases with $\mathrm{C}_{1} / \mathrm{C}_{2-4}<100$ for the thermogenic component (Table 3). However, the potential range of $\delta^{13} \mathrm{C}_{\mathrm{CH} 4}$ end-member values varies by $9 \%$, significantly larger than the range of samples measured here (3\%; Figure A2). Thus, our choice of end-member $\delta^{13} \mathrm{C}_{\mathrm{CH} 4}$ values can be thought of as plausible but non-unique. Importantly, the $\delta^{13} \mathrm{C}_{\mathrm{CH} 4}$ variations among Antrim methane samples are sufficiently small and poorly correlated with other isotopic and molecular indices that this uncertainty has little bearing on other elements of our model: Any choice of $\delta^{13} \mathrm{C}_{\mathrm{CH} 4}$ values from the possible range has no significant quantitative impact on the resultant model (Figure A2). For these reasons we include $\delta^{13} \mathrm{C}$ values in Table 3 in the interest of completeness but do not discuss them further.

For this model, we have assumed that the biogenic $\Delta_{18}$ temperature reflects current temperatures in the Antrim Shale $\left(\sim 20^{\circ} \mathrm{C}\right)$. We will validate this in a variety of ways in the following sections, but in first constructing this mixing model, we simply adopt it as an assumption. We do not know of any independent constraints on the maximum formation temperature of the thermogenic end member, because its source is not known (Martini et al., 1996; Martini et al., 1998). We estimated this temperature $\left(\mathrm{T}_{118}\right)$ using observed linear relationship between $\delta \mathrm{D}_{\mathrm{CH} 4}$ and $\Delta_{18}$ temperature (Figure $2 \mathrm{~g} ; \mathrm{T}_{\Delta 18}\left({ }^{\circ} \mathrm{C}\right)=2.33 \times \mathrm{\delta D}+626$ ) with independent constraints on the maximum $\delta \mathrm{D}_{\mathrm{CH} 4}$ of the thermogenic end member, $-207 \%$ (from the northern margin; Martini et al., 1998). For this analysis, we excluded the one significant outlier point in Fig $2 \mathrm{~g}$ (State Charlton $\left.\mathrm{A} 3-32, \delta \mathrm{D}=-211 \%, \mathrm{~T}_{\Delta 18}=67^{\circ} \mathrm{C}\right)$. Application of our regression then implies a maximum $\Delta_{18}$ temperature of $144^{\circ} \mathrm{C}\left( \pm 11^{\circ} \mathrm{C}, 1 \sigma\right)$. Although this temperature is higher than those estimated for maximum burial temperatures of the northern margin of the Antrim Shale (see below), it is consistent with previously measured peak temperatures (based on fluid inclusions) of $\sim 150^{\circ} \mathrm{C}$ (and perhaps as high as $175^{\circ} \mathrm{C}$ ) in the deeper-buried Devonian-aged, oil-producing Dundee Formation in the Michigan Basin (Luczaj et al., 2006) and previous suggestions that the thermogenic gases could have formed outside of the northern margin (Martini et al., 1996; Martini et al., 1998).

A key aspect of mixing of clumped isotopic compositions to consider is that $\Delta_{18}$-based temperatures of a mixture are not linear functions of the $\Delta_{18}$-based temperatures of the end members. This non-linearity occurs because: (i) $\Delta_{18}$ values have a non-linear dependence on temperature (equation 3 above) - thus, although $\Delta_{18}$ values can be linear mixtures of end members, $\Delta_{18}$-based temperatures need not; And (ii), $\Delta_{18}$ values of mixtures depend not only on the $\Delta_{18}$ value of the end members, but the $\delta \mathrm{D}_{\mathrm{CH} 4}$ and $\delta^{13} \mathrm{C}_{\mathrm{CH} 4}$ values as well (Stolper et al., 2014a and c). In the Antrim Shale, the $\delta^{13} \mathrm{C}_{\mathrm{CH} 4}$ and $\delta \mathrm{D}_{\mathrm{CH} 4}$ values of the biogenic and thermogenic end 
members do not differ enough for this second non-linearity to matter: for example, the differences in $\Delta_{18}$ values of the mixtures using the approximation that $\Delta_{18}$ values mix linearly vs. doing the calculation precisely are less than $0.1 \%$. This is less than half the analytical precision of a single measurement and thus unimportant for all conclusions made here - for the calculations here, all mixing is done exactly and all non-linearities included.

Modeled isotopic compositions for mixtures of these two end-member gases are shown in Figure 3. The model agrees well with measured data for $\delta \mathrm{D}_{\mathrm{CH} 4} \mathrm{vs}$. $\delta \mathrm{D}_{\mathrm{H} 2 \mathrm{O}}$ (Figure $3 \mathrm{c}$ ), $\Delta_{18}$ temperatures vs. $\delta \mathrm{D}_{\mathrm{H} 2 \mathrm{O}}$ (Figure $3 \mathrm{~d}$ ), and $\delta \mathrm{D}_{\mathrm{CH} 4}$ vs. $\Delta_{18}$ temperature (Figure $3 \mathrm{e}$ ). Poorer matches between the mixing model and the measured data occur for $\mathrm{C}_{1} / \mathrm{C}_{2-4}$ vs. $\delta \mathrm{D}_{\mathrm{CH} 4}$ (Figure $3 \mathrm{a}$ ) and vs. $\Delta_{18}$ temperature (Figure $3 b$ ). The poor match of $\mathrm{C}_{1} / \mathrm{C}_{2-4}$ ratios vs. the isotopic values was expected because the abundances of ethane, propane, and butane are not thought to be controlled solely by mixing of end members in the Antrim Shale, but instead by a combination of mixing and microbial oxidation (Martini et al., 2003). The oxidation of ethane and propane is supported by the correlation of $\delta^{13} \mathrm{C}_{\mathrm{C} 2 \mathrm{H} 6}$ values with the concentration of ethane such that as ethane concentrations decrease $\left(\mathrm{C}_{1} / \mathrm{C}_{2-4}\right.$ rises), $\delta^{13} \mathrm{C}_{\mathrm{C} 2 \mathrm{H} 6}$ values increase (Figure 4; Martini et al., 2003). A significant change in the $\delta^{13} \mathrm{C}$ value of ethane cannot occur solely due to mixing when one end member contains no or very little ethane. Oxidative consumption of ethane, on the other hand, will cause $\delta^{13} \mathrm{C}_{\mathrm{C} 2 \mathrm{H} 6}$ values to increase (Kinnaman et al., 2007; Kniemeyer et al., 2007; Valentine et al., 2010).

We incorporated this microbial hydrocarbon oxidation into the mixing model by assuming that its extent is correlated with the amount of biogenic gas in the mixture. We have modeled this by assuming that the amount of microbial oxidation is equal to the mixing ratio of biogenic gas raised to a power (with maximum and minimum mixing ratios of 0 and 1 respectively). We found the power, 2.1, that best fit the data by minimizing the combined residuals of the modeled and measured $\log \left(\mathrm{C}_{1} / \mathrm{C}_{2-4}\right)$ values as a function of $\delta \mathrm{D}_{\mathrm{CH}_{4}}$ and $\Delta_{18}$ temperature (Figure $3 \mathrm{a}$ and b). Importantly, both the $\mathrm{C}_{1} / \mathrm{C}_{2-4}$ vs. $\delta \mathrm{D}_{\mathrm{CH} 4}$ and vs. $\Delta_{18}$ temperature can be fit with the same amount of oxidation as a function of the biogenic mixing ratio. Although this is an arbitrary parameterization of microbial oxidation, the essential point is that the data are consistent with increasing $\mathrm{C}_{2+}$ oxidation at the same time more microbial gas is added. Importantly, both the $\mathrm{C}_{1} / \mathrm{C}_{2-4}$ vs. $\delta \mathrm{D}_{\mathrm{CH} 4}$ and vs. $\Delta_{18}$ temperature relationships can be fit with the same parameterization.

In contrast to ethane and propane, we have assumed that methane oxidation is not significant in the northern margin following Martini et al. (2003). This is based on the relatively small range of $\delta^{13} \mathrm{C}_{\mathrm{CH} 4}$ values $(<3 \%)$ and on the absence of covariation between $\delta \mathrm{D}_{\mathrm{CH} 4}$ and $\delta^{13} \mathrm{C}_{\mathrm{CH} 4}$ (figure 2c). Significant amounts of methane oxidation generally result in measurable increases in both the $\delta^{13} \mathrm{C}$ and $\delta \mathrm{D}$ values of the residual methane (Whiticar, 1999). Additionally, $\mathrm{C}_{2-4}$ alkanes are often oxidized orders of magnitude more rapidly than methane in natural systems (Valentine et al., 2010). However, we note that recent laboratory manipulations suggest that anaerobic microbial oxidation of methane may be occurring within the Antrim Shale (Wuchter et al., 2013). Regardless, the effect of microbial oxidation on $\Delta_{18}$ values of residual methane is unknown and thus currently difficult to incorporate into our model.

\subsection{A Test of the Mixing Model}


Importantly, the model can be tested using an entirely independent constraint, the $\delta^{13} \mathrm{C}$ of ethane. Specifically, the model calculates the amount of ethane oxidation occurring as a function of the mixing ratio of biogenic relative to thermogenic gases (or $\mathrm{C}_{1} / \mathrm{C}_{2-4}$ ratios). Therefore, if the carbon isotopic fractionation associated with microbial ethane oxidation is known, the model explicitly predicts the $\delta^{13} \mathrm{C}_{\mathrm{C} 2 \mathrm{H} 6}$ of the residual ethane. We performed this test using a Rayleigh distillation model (Criss, 1999) with a range of independently measured carbon-isotope fractionation factors for microbial ethane oxidation from Kinnaman et al. (2007), an initial $C_{1} / C_{2-4}$ ratio of 5.8 for the thermogenic end member (as in the model above), and initial $\delta^{13} \mathrm{C}_{\mathrm{C} 2 \mathrm{H} 6}$ value of -52.9 , the lowest observed $\delta^{13} \mathrm{C}_{\mathrm{C} 2 \mathrm{H} 6}$ from the northern margin gases. We note that the fractionation factors used here are for aerobic ethane oxidation as these are the only known isotopic fractionation factors for microbial ethane oxidation.

The model's predicted $\delta^{13} \mathrm{C}_{\mathrm{C} 2 \mathrm{H} 6}$ vs. $\mathrm{C}_{1} / \mathrm{C}_{2-4}$ values are consistent with the measured values from wells sampled in this study and other measured wells (Figure 4). Although some measurements fall outside of the predicted envelope of values (Figure 4), these divergences are not surprising as it is unlikely that all samples start with the exact same $C_{1} / C_{2-4}$ ratio or ethane $\delta^{13} \mathrm{C}$ value. Regardless, the agreement between the modeled vs. measured $\delta^{13} \mathrm{C}_{\mathrm{C} 2 \mathrm{H} 6}$ values further demonstrates the plausibility of the mixing/oxidation model we present and provides an independent check on the calculated amount of oxidation occurring in the samples. The model also helps to validate our assumption that methanogens in the Antrim Shale generate methane with a $\Delta_{18}$-based temperature near $\sim 20^{\circ} \mathrm{C}$. If that temperature was 40 to $45^{\circ} \mathrm{C}$, with no microbial oxidation of $\mathrm{C}_{2-4}$ gases, then the measured $\mathrm{T}_{418}$ vs. $\mathrm{C}_{1} / \mathrm{C}_{2-4}$ data could be reproduced by the model, but the $\delta \mathrm{D}_{\mathrm{CH} 4}$ vs. $\mathrm{C}_{1} / \mathrm{C}_{2-4}$ would still result in a misfit. Adding microbial oxidation to the model

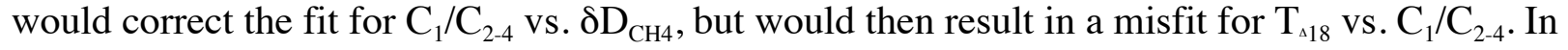
other words, only model parameters with biogenic methane at or near internal isotopic equilibrium at $\sim 20^{\circ} \mathrm{C}$ can satisfy all of the measured isotopic and compositional relationships.

\subsection{A discrepancy between $\Delta_{18}$ temperatures and previous estimates of the amount of} thermogenic gas in the Antrim Shale?

Although the model describes the observed trends in both the isotopic and compositional parameters, it contrasts with previous studies in that it requires a larger thermogenic contribution (20-80\% thermogenic) to gases from the northern margin of the Antrim Shale (Table 4) than previously proposed (<20\%; Martini et al., 1996; Martini et al., 1998; Martini et al., 2003). It is important to consider that the values in Table 4 are modeled results and depend on the assumed

$601 \Delta_{18}$ and $\delta \mathrm{D}_{\mathrm{CH} 4}$ value of the thermogenic end member, with higher $\Delta_{18}$-based temperatures and/or 602 more depleted $\delta \mathrm{D}_{\mathrm{CH} 4}$ values resulting in lower required amounts of the thermogenic component 603 or vice-versa. For example, choosing the formation temperature for the thermogenic end member 604 to be the maximum $\Delta_{18}$ temperature observed, $115^{\circ} \mathrm{C}$, changes the average thermogenic content 605 of the gases to $50 \%( \pm 28 \%, 1 \sigma)$. Regardless, the higher-than-expected proportions of 606 thermogenic gas $(>20 \%)$ for some samples are an inescapable conclusion of the $\Delta_{18}$ temperatures: 607 Even if the thermogenic component gases formed at infinite temperatures $\left(\Delta_{18}=0\right)$, mixing with 608 a low temperature $\left(\sim 20^{\circ} \mathrm{C}\right)$ gas would result in the average $\Delta_{18}$ temperature for the northern 609 margin gases measured here, $67^{\circ} \mathrm{C}$, to be $25 \%$ thermogenic. 
Furthermore, the maximum amount of $\mathrm{C}_{2-4}$ relative to $\mathrm{C}_{1-4}$ alkanes measured in the northern margin gases supports a higher-than-expected proportion of thermogenic gases. Specifically, in the northern margin, $\mathrm{C}_{2-4}$ alkanes can represent up to $\sim 10 \%$ of all $\mathrm{C}_{1-4}$ alkanes (Table 2). If all gases were $>80 \%$ biogenic, then the original thermogenic end member would need to be at least $50 \% \mathrm{C}_{2-4}$ (assuming pure mixing without oxidation, which only compounds the problem). However, $\mathrm{C}_{2-4}$ abundances relative to total $\mathrm{C}_{1-4}$ abundances of thermogenic gases in the Michigan Basin range from 10-30\%, with an average of 15\% (Martini et al., 1998; Martini et al., 2003). A higher relative concentration of thermogenic vs. biogenic gases would lower the necessary $\mathrm{C}_{2-}$ ${ }_{4} / \mathrm{C}_{1-4}$ value of the end member, bringing it closer to observed values in the Michigan Basin.

Thus, a significant question is why the original estimate for the amount of thermogenic relative to biogenic gas differs from those based on the constraints provided by the $\Delta_{18}$ temperatures and $\delta \mathrm{D}_{\mathrm{CH} 4}$ values in the mixing/oxidation model. The previous estimation was based on the linear relationship observed between $\delta \mathrm{D}_{\mathrm{CH} 4}$ and $\delta \mathrm{D}_{\mathrm{H} 2 \mathrm{O}}$. Because this slope was similar to those observed in some natural settings dominated by hydrogenotrophic methanogens (e.g., Schoell, 1980), it was assumed that most of the gases were biogenic in origin, with a minor thermogenic component included to accommodate the presence of $\mathrm{C}_{2+}$ alkanes. This is a straightforward interpretation of the cause of the relationship between $\delta \mathrm{D}_{\mathrm{CH} 4}$ and $\delta \mathrm{D}_{\mathrm{H} 2 \mathrm{O}}$. However, this relationship is not unique and can also be interpreted as a mixing line as above. When the additional constraints provided by the $\mathrm{C}_{1-4}$ concentrations and $\Delta_{18}$ temperatures are also included in the analysis, significant proportions of thermogenic gases become required in many of the samples. We stress that despite this greater-than-expected proportion of thermogenic gas in the samples, the $\Delta_{18}$ values indicate that biogenic gases also represent a significant, and in many cases dominant proportion of gases in the Antrim Shale (Table 4; Martini et al., 1996; Martini et al., 1998; Martini et al., 2003).

\subsection{Potential implications of measured $\Delta_{18}$ values and the mixing/oxidation model for the generation and source of hydrocarbon gases in the Antrim Shale}

If this mixing/oxidation model is correct, it has significant implications for the history of gas generation and migration in the Antrim Shale. Specifically, the formation temperature of the thermogenic component is, at a minimum, $115^{\circ} \mathrm{C}$, and, as modeled here, $\sim 140^{\circ} \mathrm{C}$. The northern margin of the Antrim Shale, based on vitrinite reflectance data $\left(\mathrm{R}_{0}\right.$ between 0.4 and $0.6 \%$; Cercone and Pollack, 1991) has remained below $\sim 60^{\circ} \mathrm{C}$ (Hunt, 1996). The $\Delta_{18}$ temperatures, therefore, demonstrate that the thermogenic components are unlikely to be locally sourced. Formations that could have reached these elevated temperatures include $(i)$ the Antrim Shale in the central basin, which has vitrinite reflectance values as high as 1.0\% (Martini et al., 2003), consistent with maximum temperatures of $\sim 160^{\circ} \mathrm{C}$ (Hunt, 1996); And (ii) more deeply buried Silurian and older strata underlying the Antrim Shale, that likely reached maximum burial temperatures above $100^{\circ} \mathrm{C}$ (Cercone and Pollack, 1991) to $150^{\circ} \mathrm{C}$ (Luczaj et al., 2006).

An additional constraint on the origin of the thermogenic gases in the northern margin is the predicted minimum $\delta \mathrm{D}_{\mathrm{CH} 4}$ value of $-207 \%$ o for the thermogenic component. This value may eliminate the central basin of the Antrim Shale as a potential source because gases there exhibit 
$\delta \mathrm{D}_{\mathrm{CH} 4}$ values between -270 to $-280 \%$, though only two gases have been measured (Martini et al., 2003). Silurian-aged (or older) thermogenic gases derived from below the Antrim Shale are also plausible sources: stratigraphically equivalent formations from the Appalachian Basin in other Devonian, Silurian, and Ordovician aged formations commonly contain methane with $\delta \mathrm{D}$ values greater than -200\%o (Osborn and McIntosh, 2010).

Large scale mixing of gases from deeper portions of the basin, whether from the Antrim Shale or other units, could be reflected not only in the hydrocarbon composition of the gases, but in the chemical and isotopic compositions of the co-produced waters. This is because mixing of biogenic and thermogenic gases may and perhaps should co-occur with mixing of deeper basinal brines, which carry thermogenic gas, and fresher surficial waters, which contain biogenic gas. This prediction is borne out: the $\Delta_{18}$-based temperatures correlate strongly with the $\delta \mathrm{D}$ values of the co-produced waters (figure $2 \mathrm{f}$ and $3 \mathrm{~d}$ ), with hotter temperatures correlating to enriched $\delta \mathrm{D}_{\mathrm{H} 2 \mathrm{O}}$ values. As demonstrated by Wilson and Long (1993) and Martini et al. (1998), $\delta \mathrm{D}_{\mathrm{H} 2 \mathrm{O}}$ values of waters in the Michigan Basin and northern margin of the Antrim Shale correlate with the salt composition of the waters. Specifically, more depleted $\delta \mathrm{D}_{\mathrm{H} 2 \mathrm{O}}$ values correlate with a low salt, meteoric water end member while more enriched $\delta \mathrm{D}_{\mathrm{H} 2 \mathrm{O}}$ correspond to waters with a higher salt content. Wilson and Long (1993) and Martini et al. (1998) interpreted this relationship to indicate the mixing of basinal brines with meteoric water in the Michigan Basin, which consistent with hydrological models of the Michigan Basin (e.g., McIntosh et al., 2011) and tracer studies using radiogenic isotopes (e.g., Ma et al., 2005). Thus, the relationship between $\Delta_{18}$ temperatures and $\delta \mathrm{D}_{\mathrm{H} 2 \mathrm{O}}$ values is consistent with previous geological, geochemical, and hydrological studies of Michigan Basin fluids and demonstrates the importance of interpreting clumped-isotope compositions of gases in both an environmental and geological context.

In summary, our finding of relatively high apparent temperatures for methane in Antrim Shale gases leads to two key conclusions: $(i)$ There is more thermogenic gas in the system than previously proposed and (ii) that thermogenic component of the gas is probably derived from depth (from the basin center or below the northern margin of the Antrim Shale) and migrated to the shallow depths the Antrim Shale currently occupies on the basin rim. This is significant because the Antrim Shale is considered an end member of unconventional gas reservoirs in which the vast majority of gas formed in situ via microbial methanogenesis (Curtis, 2002) with the thermogenic component largely sidelined in subsequent interpretations. We interpret the $\Delta_{18}$ temperatures to indicate a different story: the biogenic gases are indeed derived in situ and represent $\sim 50 \%$ of the gas. However the thermogenic component is an important contributor to the system (also $\sim 50 \%$ ) and formed elsewhere, mixing with the biogenic gas via migration. Thus the northern margin of the Antrim Shale can be considered a pseudo unconventional system about half of the gas formed in situ while the other half formed elsewhere and migrated to the shale. Thus care should be taken in using of the Antrim Shale as the type model for biogenic natural gas deposits (Curtis, 2002). Additionally, the importance of the relative amounts of biogenic and thermogenic gases in the Antrim Shale should factor in to future calculations that suggest such deposits are major contributors of methane to the inventory of greenhouse gases in the atmosphere (Formolo et al., 2008). This alternative conclusion demonstrates the potential of $\Delta_{18}$ temperatures in untangling and quantifying the sources of gas to economically important gas reservoirs. 


\section{The meaning of $\Delta_{18}$ temperatures for naturally occurring biogenic samples}

In the Antrim Shale, samples that yielded the lowest $\Delta_{18}$ temperatures have properties consistent with a dominantly biogenic origin. Similarly low $\Delta_{18}$ temperatures for biological samples were previously observed in biogenic methane derived from biodegraded oils in the Gulf of Mexico (Stolper et al., 2014b) and other sedimentary systems (Wang et al., in press). A simple interpretation of these measurements is that, in these environments, methanogens generate methane in or close to internal isotopic equilibrium. Two key questions brought up by these results are: ( $i$ ) What are the driving biochemical reasons that biogenic methane in many natural settings are near internal isotopic equilibrium; And (ii) how common is this result and is it dependent on the environmental setting. To probe these questions, and thus help inform our interpretation of the measured composition of the Antrim biogenic component, we additionally measured methane created by methanogens from low-temperature seep environments (Santa Barbara and Santa Monica Basins), a pond from the Caltech campus, and methane generated by methanogens in pure-culture incubations (Table 6, Figure 5).

Methane samples from Santa Barbara and Santa Monica Basins yield $\Delta_{18}$-based temperatures from 6 to $16^{\circ} \mathrm{C}$ (Table 6) and are within $2 \sigma$ error in all cases of their present bottom-water temperatures $\left(5-9^{\circ} \mathrm{C}\right.$; Table 6$)$. We consider these samples to be nearly pure biogenic gas because they have low $\delta^{13} \mathrm{C}$ values (-66 to $-70 \%$ ), generally indicative of microbially derived methane (Whiticar, 1999), and are nearly pure methane (>99.5\%).

In contrast, the pond sample yielded a negative $\Delta_{18}$ value (Figure 5; Tables 6 and 7), which is not thermodynamically possible for any sample in internal isotopic equilibrium at any temperature. This sample demonstrates that natural biogenic methane can yield $\Delta_{18}$ values strongly out of equilibrium. Data from laboratory cultures confirm this observation: all methane from cultured methanogens yield $\Delta_{18}$ values that differ from those predicted by their known growth temperatures, and also yield, in some cases, samples with negative $\Delta_{18}$ values. As discussed above, that such disequilibrium can occur was previously discussed and demonstrated in Stolper et al. (2014b) and presented in preliminary reports by this group (Stolper et al., 2014c; Eiler et al., 2014b) and preliminary reports by others (Gruen et al., 2014). Such observations have also recently been confirmed by Wang et al. (in press).

The interpretation of $\Delta_{18}$ values for methane from pure culture experiments is ambiguous because the observed disequilibrium could result from several different processes. For example, production of methane with continuously changing $\delta D$ and $\delta^{13} \mathrm{C}$ values due to Rayleigh distillation or changes in isotopic fractionation factors (Valentine et al., 2004), even if $\Delta_{18}$ values represented internal isotopic equilibrium, could result in disequilibrium $\Delta_{18}$ values due to the potential non-linear mixing effects on $\Delta_{18}$ values (Eiler and Schauble, 2004; Eiler, 2007; Eiler, 2013; Stolper et al., 2014a; Stolper et al., 2014b). Alternatively, kinetic isotope effects during methane generation could create disequilibrium $\Delta_{18}$ values. It is thus significant that methane from a natural setting also exhibits a disequilibrium $\Delta_{18}$ value, indicating that such effects cannot be due solely to culturing artifacts. 
5.1 Comparison of $\Delta_{18}$ temperatures to the $\delta D_{C H 4^{-}} \delta D_{H 2 O, \text { iquid }}$ heterogeneous-phase geothermometer

Other geothermometers can be used to calculate 'apparent equilibrium temperatures' (Zhang, 1994) of methane formation. For example, equilibrium $\mathrm{D} / \mathrm{H}$ fractionations between methane and water (i.e., $\left.\alpha_{\mathrm{CH} 4-\mathrm{H} 2 \mathrm{Oliquid}}\right)$ are a function of temperature (Bottinga, 1969; Richet et al., 1977; Horibe and Craig, 1995). We calculated the departure of $\alpha_{\text {Сн4-н2о,liquid }}$ from the expected value for equilibrium at the given environmental or experimental temperature as discussed in the methods section above (section 3.4). This departure is given by the quantity, ([measured $\alpha_{\mathrm{CH} 4-}$ н20,liquid $] /\left[\right.$ predicted equilibrium $\left.\left.\alpha_{\text {Сн4-н2о,liquid }}\right]-1\right)$ x 1000. We also calculated departure from equilibrium for $\Delta_{18}$ values as $\left(\left[\right.\right.$ measured $\left.{ }^{18} \mathrm{R} /{ }^{18} \mathrm{R}^{*}\right] /\left[\right.$ predicted equilibrium $\left.\left.{ }^{18} \mathrm{R} /{ }^{18} \mathrm{R}^{*}\right]-1\right)$ x 1000 . As given in equation $1,{ }^{18} \mathrm{R} /{ }^{18} \mathrm{R}^{*}$ is $\left(\Delta_{18} / 1000+1\right)$ and is analogous to $\alpha_{\mathrm{CH} 4-\mathrm{H} 2 \mathrm{O}}$, except it is for a single phase.

The departure from in equilibrium in $\Delta_{18}$ and $\alpha_{\mathrm{CH} 4-\mathrm{H} 2 \mathrm{O}, \mathrm{iquid}}$ are compared in Figure 6. In this figure, a value of $0 \%$ indicates that the measured quantity is identical to that expected for isotopic equilibrium. The origin, therefore, represents methane that is both in internal isotopic equilibrium and in hydrogen-isotopic equilibrium with water. Two key observations can be made about the data plotted in Figure 6: (i) There are multiple points that plot in and around the origin, representing samples in equilibrium. And (ii) the degree of disequilibrium in $\Delta_{18}$ is correlated with that in $\alpha_{\mathrm{CH} 4 \mathrm{H} 2 \mathrm{O}, \mathrm{liquid}}$. Put another way, disequilibrium in isotopic clumping appears to be related to disequilibrium in bulk $\mathrm{D} / \mathrm{H}$ compositions. As discussed, above this relationship was first identified by Stolper et al. (2014c) and has recently been confirmed by Wang et al. (in press).

A simple interpretation of this data array is that when biogenic methane is in internal isotopic equilibrium (and $\Delta_{18}$ values yield sensible temperatures), it is in isotopic equilibrium with its source waters and plots at the origin of Figure 6. This was not an unforeseen result - we expect that it is unlikely at relatively low $\left(<100^{\circ} \mathrm{C}\right)$ temperatures that methane is capable of exchanging hydrogen solely with itself in order to attain internal isotopic equilibrium. Instead methane presumably exchanges hydrogen with some other phase in order to be in internal isotopic equilibrium. Although there are multiple sources of reduced $\mathrm{H}$ that are used by methanogens to reduce $\mathrm{CO}_{2}$ to $\mathrm{CH}_{4}$ (Thauer, 1998), it is generally assumed, based on many experimental results, that these hydrogen species are in rapid isotopic equilibrium with hydrogen in water and thus that the $\mathrm{D} / \mathrm{H}$ ratio of water ultimately controls the $\mathrm{D} / \mathrm{H}$ ratio of methane (Daniels et al., 1980; Schoell, 1980; Balabane et al., 1987; Sugimoto and Wada, 1995; Whiticar, 1999; Valentine et al., 2004; Yoshioka et al., 2008). Therefore, it may not be surprising that the $\Delta_{18}$ values and $\alpha_{\mathrm{CH} 4-}$ н2о,liquid are related. This is discussed in more detail in the Appendix (specifically A2).

We note that there is scatter around the origin in Figure 6, the point of mutual isotopic equilibrium between $\mathrm{CH}_{4}$ and $\mathrm{H}_{2} \mathrm{O}$ and internal isotopic equilibrium in $\mathrm{CH}_{4}$. This could result from the fact that the hydrogen isotopic composition of cellular waters, which actually controls the value of $\delta \mathrm{D}_{\mathrm{CH} 4}$, are not necessarily equivalent to the isotopic composition of the environmental waters (e.g., Kreuzer-Martin et al., 2005) or that our estimates for the $\delta \mathrm{D}_{\mathrm{H} 20 \text {, liquid }}$ for the environmental pore waters (e.g., we assume the $\delta \mathrm{D}_{\mathrm{H} 20 \text {,liquid }}$ value is $0 \%$ for all marine 
systems) is incorrect. A similar comparison for $\delta^{13} \mathrm{C}$ values is not possible because $\delta^{13} \mathrm{C}$ values of dissolved inorganic carbon or $\mathrm{CO}_{2}$ were not measured for any samples and are difficult to estimate for the environmental samples as they can vary strongly (up to $40 \%$ ) in sedimentary systems (Claypool and Kaplan, 1974).

\subsection{An isotopic model of methanogenesis}

To explore the relationship indicated by Figure 6, we created a model for kinetic and equilibrium isotope effects associated with microbial methanogenesis. This model follows the mathematical framework introduced by Rees (1973) to describe the bulk isotopic composition of sulfide generated by sulfate-reducing bacteria and is influenced by the ideas presented in Blair (1998), Valentine et al. (2004), and Penning et al. (2005) that hypothesized and provided evidence that the bulk isotopic composition of methane is controlled in part by the overall reversibility of the enzymes involved in methanogenesis. The model also follows the initial ideas raised in Stolper et al. (2014b) that the reversibility of these enzymes also controls the clumped isotopic composition of methane. A full derivation of the model and assumptions implicit to it are given in the appendix and follows the initial work presented by Eiler et al. (2014b). The model is similar in structure to that recently proposed by Yoshinaga et al. (2014) for anaerobic methane oxidation and, as discussed above, Wang et al. (in press) for methanogenesis.

Three key assumptions are made in the model: (i) Following the 'differential reversibility' hypothesis of Valentine et al. (2004), we assume that all metabolic intermediates between $\mathrm{CO}_{2}$ and $\mathrm{H}_{2}$ and a methyl group bound to a co-factor are in isotopic equilibrium (Figure A3). (ii) We assume that $\mathrm{H}_{2}$ and thus all methane precursors are in isotopic equilibrium with cellular $\mathrm{H}_{2} \mathrm{O}$ (Valentine et al., 2004). (iii) We assign the rate-limiting step in methane production to be the final hydrogenation step catalyzed by methyl-coenzyme M reductase (MCR; Figure A3). We note that the validity of the assumption $(i)$, that all metabolic intermediates between the methyl group and $\mathrm{CO}_{2}$ and $\mathrm{H}_{2}$ are in isotopic equilibrium, is most valid for natural environments in which $\mathrm{H}_{2}$ partial pressures are low and where there is a relatively small chemical potential contrast between the reactants and products of methanogenesis; however, as discussed in Valentine et al. (2004), in pure culture experiments where these chemical potential gradients are large, the metabolic intermediates may not be in isotopic equilibrium with $\mathrm{CO}_{2}$ and $\mathrm{H}_{2}$. In such a case, prior steps before MCR may be rate limiting. We discus this in more detail below in section 5.4 after the description of the model.

In the model, we vary the degree of reversibility of MCR to explore whether the trend seen in

Figure 6 can be reproduced (Figure A3). The capacity for MCR to catalyze both the addition and removal of a hydrogen from methane, i.e. that it is reversible, has been demonstrated using isotopic labeling techniques on MCR from the methanogen M. marburgensis (Scheller et al., 2010). Moreover, the capacity of anaerobic methanotrophs to synthesize MCR has led to the hypothesis that these organisms use the enzymes of methanogenesis (starting with MCR) in reverse to consume methane (e.g., Hallam et al., 2004; Thauer, 2011).

The required inputs for the model are given in Table 8. Rate constants are given in this table for individual isotopologues. When a rate constant directly constrains a specific bulk fractionation factor between two phases $(\alpha), \alpha$ is given as well. In the model, when MCR is assumed to be 
completely reversible, $\mathrm{CH}_{4}$ is required to be in isotopic equilibrium with $\mathrm{CO}_{2}$ and $\mathrm{H}_{2} \mathrm{O}$. The equilibrium isotopic fractionations between $\mathrm{CH}_{4}$ and $\mathrm{H}_{2} \mathrm{O}$ and $\mathrm{CO}_{2}$ were calculated using $\alpha_{\mathrm{CH} 4}$ H2O,liquid as described above and $\alpha_{\mathrm{CH} 4-\mathrm{CO} 2}$ values derived from Richet et al. (1977; Table 2). For the model, we assume an average temperature of $20^{\circ} \mathrm{C}$. Because the data in Figure 6 come from a variety of different environments and environmental temperatures, this is clearly an approximation. However, the purpose of the model is to gain first-order insight into the meaning of $\Delta_{18}$ values observed in biogenic samples, and thus we consider this approximation to be acceptable for the time being. We calculated the equilibrium constants for homogeneous-phase internal isotopic equilibrium between ${ }^{13} \mathrm{CH}_{3} \mathrm{D}$ and ${ }^{12} \mathrm{CH}_{2} \mathrm{D}_{2}$ with all other methane isotopologues (see appendix) using the statistical mechanical model described in Stolper et al., (2014a).

In the model, when the rate of methane production exceeds that of consumption (through the reversal of MCR), a kinetic isotope effect can be expressed. We assume that the maximum kinetic hydrogen isotope effect $\left(\alpha_{\mathrm{CH} 4-\mathrm{H} 2 \mathrm{O} \text {,liquid }}\right)$ is 0.528 . This value is based on data from our study and is similar in magnitude to that found by pure-culture experiments on hydrogenotrophic methanogens from Balabane et al. (1987), 0.567. For the maximum kinetic carbon isotope $\alpha_{\mathrm{CH} 4-}$ $\mathrm{CO}_{2}$, we assume a value of 0.92 . This is intermediate to the maximum value observed in pureculture experiments (0.93; Botz et al., 1996; Conrad, 2005), and from natural settings (up to 0.91; Whiticar, 1999). These values are fixed in the model. We then varied the rate constants for the kinetic isotope effect for ${ }^{13} \mathrm{CH}_{3} \mathrm{D}$ and ${ }^{12} \mathrm{CH}_{2} \mathrm{D}_{2}$ formation relative to ${ }^{12} \mathrm{CH}_{4}$ (Table 8) to achieve a best fit to the empirical data (Figure 6). To first order, the relationship observed between $\alpha_{\mathrm{CH} 4-}$ H2O,liquid and $\Delta_{18}$ can be reproduced by our model.

\subsection{Testing the Model}

The structure of our model and simple trend of the data in Figure 6 make it clear that some combination of rate constants for the formation of ${ }^{13} \mathrm{CH}_{3} \mathrm{D}$ and ${ }^{12} \mathrm{CH}_{2} \mathrm{D}_{2}$ relative to ${ }^{12} \mathrm{CH}_{4}$ will provide an adequate fit to the data. Nevertheless, the basic validity of the model can be tested by examining whether the required rate constants for ${ }^{13} \mathrm{CH}_{3} \mathrm{D}$ and ${ }^{12} \mathrm{CH}_{2} \mathrm{D}_{2}$ relative to ${ }^{12} \mathrm{CH}_{4}$ formation are chemically realistic. Thus we compared the isotope effects of ${ }^{13} \mathrm{C}$ and $\mathrm{D}$ addition to singly substituted isotopologue precursors to the primary isotope effects prescribed by the model (e.g., Bigeleisen and Wolfsberg, 1958). For example, the fitted relative difference in the rate constants for ${ }^{13} \mathrm{CH}_{3} \mathrm{D}$ vs. ${ }^{12} \mathrm{CH}_{3} \mathrm{D}$ formation is 0.916 . This is similar to the prescribed value for the relative rates of ${ }^{13} \mathrm{CH}_{4}$ vs. ${ }^{12} \mathrm{CH}_{4}$ formation, 0.92. Similarly, the relative formation rates for ${ }^{12} \mathrm{CH}_{2} \mathrm{D}_{2}$ vs. ${ }^{12} \mathrm{CH}_{3} \mathrm{D}$, (normalized for the symmetry numbers of the different isotopologues) was modeled to have a value of 0.6. Again, this is similar to the value used for the rate of ${ }^{12} \mathrm{CH}_{3} \mathrm{D}$ formation relative to ${ }^{12} \mathrm{CH}_{4}$ (again normalized for symmetry numbers), 0.528 . The modeled rate constants for ${ }^{13} \mathrm{CH}_{3} \mathrm{D}$ and ${ }^{12} \mathrm{CH}_{2} \mathrm{D}_{2}$ formation relative to ${ }^{12} \mathrm{CH}_{4}$ are thus chemically reasonable, and quite similar to the isotope effects required for a single ${ }^{13} \mathrm{C}$ or D substitution. Such a coincidence was not a forgone conclusion, and helps to demonstrate the self-consistency of our model. Furthermore, the model is testable through the independent measurement of the abundances of ${ }^{13} \mathrm{CH}_{3} \mathrm{D}$ and ${ }^{12} \mathrm{CH}_{2} \mathrm{D}_{2}$ because only specific trends, based on this model, are allowed (Figure 7). I.e., if their abundance can be measured independently this model can be

\subsection{Model Considerations}


The analysis above indicates that the model is plausible, makes testable predictions, and is consistent with the observed data (Figure 6). However, the model makes several simplifications that we consider more closely here:

(1) The model assumes that the final step of methanogenesis, the hydrogenation of a methyl group catalyzed by MCR, is the rate-limiting step, and that all previous steps are in isotopic equilibrium. However, in some pure-culture experiments it is thought that under high hydrogen partial pressures (at least $>400 \mathrm{~Pa}$ as in the experiments here), prior steps in the generation of methane may be rate limiting (Valentine et al., 2004; Penning et al., 2005) such that $\mathrm{CO}_{2}$ in the growth medium is not in isotopic equilibrium with the metabolic intermediates. This is sometimes evidenced by relatively small carbon isotope fractionation factors between methane and $\mathrm{CO}_{2}-$ for example $\alpha_{\mathrm{CH} 4-\mathrm{CO} 2}$ values range from 0.927 to 0.976 in pure-culture experiments (Valentine et al., 2004; Conrad, 2005). As the model presented here assumes that MCR is the rate-limiting step and that all isotope effects are 'normal,' i.e., that products are always isotopically lighter than the reactants, it requires that $\alpha_{\mathrm{CH} 4-\mathrm{CO} 2}$ will be between 0.92 and 0.932 . This indicates that for some pure-culture experiments, the model presented will be unlikely to fit the carbon isotope data. However, as we did not measure the $\delta^{13} \mathrm{C}$ values of the $\mathrm{CO}_{2}$ in our experiments nor in most of the environmental samples, it is difficult to evaluate whether this is an issue for the data presented here. A larger range of $\alpha_{\mathrm{CH} 4-\mathrm{CO} 2}$ can be modeled if steps prior to MCR are allowed to be rate limiting in some conditions. Though conceptually simple, incorporation of this step introduces up to 9 new and unconstrained variables: the reversibility of the step, two forward (or reverse) and two equilibrium isotope effects for bulk hydrogen and carbon isotopic compositions, and up to two forward (or reverse) and equilibrium isotope effects for clumping reactions between ${ }^{13} \mathrm{C}$ with $\mathrm{D}$ and $\mathrm{D}$ with $\mathrm{D}$. In contrast to this model, Wang et al. (in press) present a model with 6 potentially rate-limiting steps, the diffusion of $\mathrm{CO}_{2}$ into the cell, 4 hydrogenation steps, and the diffusion of $\mathrm{CH}_{4}$ out of the cell. To reduce the number of unconstrained free variables in the model, they assume that $\mathrm{CO}_{2}$ diffusion into the cell and $\mathrm{CH}_{4}$ diffusion out of the cell are not isotopically discriminating steps, that $\mathrm{CO}_{2}$ in the cell is in chemical equilibrium with $\mathrm{CO}_{2}$ outside of the cell, that all hydrogenation steps for methane precursors (i.e., $\mathrm{CO}_{2}, \mathrm{R}-\mathrm{CH}, \mathrm{R}-\mathrm{CH} 2, \mathrm{R}-\mathrm{CH} 3$, where $\mathrm{R}$ represents the molecule to which the carbon) have the same forward and reverse kinetic isotope effects for bulk carbon, bulk hydrogen, and clumped isotopic compositions (but with different values for bulk carbon-isotope vs. bulk hydrogen-isotope. vs. clumped-isotope effects), and that all hydrogenation steps have the same forward vs. reverse reaction rate, i.e., are equally reversible or irreversible. They predict that $\alpha_{\mathrm{CH} 4-\mathrm{CO} 2}$ values will be between 0.96 and 0.932 , but do not present or discuss $\delta^{13} \mathrm{C}$ measurements of $\mathrm{CO}_{2}$ in their environmental samples vs. the prediction of the model. Future models could attempt to calculate or experimentally constrain the various isotope effects involved with all species intermediate to $\mathrm{CH}_{4}$ and $\mathrm{CO}_{2}$ and $\mathrm{H}_{2}$. Additionally, a clear next step is to perform experiments and make measurements in natural systems in which the $\delta^{13} \mathrm{C}_{\mathrm{CO} 2}$ value is monitored along with $\delta \mathrm{D}_{\mathrm{H} 2 \mathrm{O}}, \delta \mathrm{D}_{\mathrm{CH} 4}, \delta^{13} \mathrm{C}_{\mathrm{CH} 4}$, and $\Delta_{18}$.

(2) The model implicitly requires that isotopic equilibrium between $\mathrm{CH}_{4}$ and both $\mathrm{CO}_{2}$ and $\mathrm{H}_{2} \mathrm{O}$ is reached at the same time. However, it is possible that MCR could catalyze exchange reactions more rapidly between $\mathrm{CH}_{4}$ and $\mathrm{H}_{2} \mathrm{O}$ than slower back reactions to $\mathrm{CO}_{2}$. In this case, isotopic 
928 equilibrium between $\mathrm{CH}_{4}$ and $\mathrm{H}_{2} \mathrm{O}$ and, as a consequence, internal isotopic (i.e., $\Delta_{18}$ ) equilibrium 929 could be achieved without carbon isotope equilibrium between $\mathrm{CH}_{4}$ and $\mathrm{CO}_{2}$. If so, a more

930 complex model that allows different rates of isotopic exchange for $\mathrm{H}$ and $\mathrm{C}$ would be required,

931 such as those used to describe the combined sulfur and oxygen isotope systematics of $\mathrm{SO}_{4}{ }^{2-}$

932 during dissimilatory sulfate reduction (e.g., Brunner et al., 2005). This consideration raises a

933 potentially interesting point related to possible effects on $\Delta_{18}$ values for anaerobic methane

934 oxidation. It has recently been suggested, based on both experimental data and model constraints, 935 that under low sulfate conditions ( $\sim 1$ to $2 \mathrm{mM}$ sulfate) anaerobic methane oxidizers can nearly

936 completely $(80 \%)$ isotopically equilibrate methane with dissolved $\mathrm{CO}_{2}$ (Yoshinaga et al., 2014).

937 As discussed above, this process is thought to be catalyzed through operation of MCR in reverse

938 (Hallam et al., 2004; Thauer, 2011), which itself, for the model of Yoshinaga et al. (2014), is up

939 to $80 \%$ reversible. This then suggests that hydrogen isotope exchange reactions between $\mathrm{CH}_{4}$ and

$940 \mathrm{H}_{2} \mathrm{O}$ should be at least as equilibrated if not more so than carbon isotopes between $\mathrm{CH}_{4}$ and $\mathrm{CO}_{2}$.

941 Consequently, anaerobic methane oxidation could result in $\Delta_{18}$ values of residual methane that

942 reflect the temperatures of methane oxidation at low sulfate levels. In such a scenario, the $\Delta_{18}$

943 values of gases from, for example, thermogenic systems, could potentially be reset to reflect

944 lower temperatures of methane oxidation. This appears not to be the case in the Antrim Shale,

945 indicating either limited amounts of anaerobic methane oxidation is occurring or that

946 thermogenic gases are sorbed to shales or otherwise inaccessible to microbial communities living

947 in fractures until active pumping in a well occurs.

948

(3), The model does not explicitly treat methylotrophic methanogenesis in which acetate or some other organic substrate (e.g. methanol or methylamine) is the precursor to methane. The $\Delta_{18}$ values of methane generated by this pathway, either in the lab or in nature, are unknown and will be important to constrain in future work. Nevertheless, we note that our pond sample likely contained aceticlastic methanogens, as they are commonly present in shallow, freshwater anoxic sediments (Whiticar et al., 1986), yet data from this sample are broadly consistent with the model. We speculate that - because aceticlastic methanogens also use MCR - our model may be more broadly generalizable.

Despite these model simplifications, the critical point is that clumped-isotope measurements from both culture-based and natural biogenic methane can be explained (Figure 6) in the context of a simple, plausible, and testable (Figure 7) model. Just as models to describe sulfate reduction in the context of isotopic measurements have evolved over the course of 40 years (Rees, 1973; Farquhar et al., 2003; Brunner and Bernasconi, 2005; Bradley et al., 2011; Wing and Halevy, 2014), we expect that more advanced and complex treatments of methanogenesis will address the issues presented above.

\subsection{Implications for clumped-isotope thermometry of biogenic methane}

971 observed are marine settings in the Santa Barbara and Santa Monica Basins, buried oil-degrading

972 methanogenic communities in the Gulf of Mexico (Stolper et al., 2014b), and organisms buried

973 in the Antrim Shale. In these, 'deep biosphere' systems and shallow marine settings, organic 
carbon has already been substantially degraded and even thermally altered before becoming available to methanogens and hydrogen partial pressures are likely very low (Burke, 1993). In such systems, growth and metabolic rates are slow compared to laboratory cultures of methanogens, and thus could allow internal isotopic equilibrium to be reached. For example, in the New Albany Shale, which is similar in age and depositional environment to the Antrim Shale, rates of methane generation are estimated based on accumulations of radiogenic ${ }^{4} \mathrm{He}$ to have been $10^{4}$ to $10^{6}$ slower than equivalent laboratory manipulations (Schlegel et al., 2011). In the context of the model, MCR would be almost entirely reversible in such settings and thus would generate methane in internal isotopic equilibrium. Additionally, this insight provides independent justification for the assumption that the methanogens in the Antrim Shale generate methane at internal isotopic equilibrium.

Fast metabolic rates in which methane is generated rapidly and MCR is not completely reversible would be expected to generate methane out of isotopic equilibrium. This is also consistent with current observations: In laboratory cultures, large partial pressures of hydrogen and $\mathrm{CO}_{2}$ are used to stimulate growth and generate methane rapidly. In the Caltech pond, plant litter is continually deposited at the sediment water interface that has undergone limited biodegradation, potentially stimulating rapid methanogenesis.

Based on these considerations, we predict that systems in nature where growth rates are slow, such as in marine sediments and deeply buried (many meters) continental systems, methane will form in internal isotopic equilibrium. Shallow sediments in terrestrial systems, on the other hand, where methane generation rates are high, will yield methane out of equilibrium. More broadly, this analysis indicates that $\Delta_{18}$ values of biogenic methane potentially reflect the metabolic state of methanogens and thus can be used to probe growth and metabolic rates of methanogenesis in the environment.

Additionally, our model potentially explains a long-standing discrepancy between the $\delta \mathrm{D}$ values of methane observed in culture experiments vs. in some natural settings. Specifically, in many natural settings, especially marine sediments, differences between $\delta \mathrm{D}_{\mathrm{CH} 4}$ and $\delta \mathrm{D}_{\mathrm{H} 20, \text {,iquid }}$ are significantly less (>100\%; Schoell, 1980; Whiticar et al., 1986; Burke Jr, 1993) than observed in cultures (e.g., Balabane et al., 1987; Valentine et al., 2004; Yoshioka et al., 2008; Hattori et al., 2012) and natural systems such as cow rumens (e.g., Bilek et al., 2001) and freshwater soils (e.g., Sugimoto and Wada, 1995). Explanations for this difference have included the incorporation of $\mathrm{H}$ from $\mathrm{H}_{2}$ into methane (Burke, 1993) and variability of isotopic fractionation (Valentine et al., 2004). Our model and the $\Delta_{18}$ values suggest an alternative, though not necessarily exclusive, explanation: specifically that in marine settings and 'deeply' buried continental systems isotopic equilibrium between methane and local waters is reached. This equilibrium results in an $\sim 160$ to $200 \%$ difference in $\delta \mathrm{D}$ between water and methane (Schoell, 1980; Whiticar et al., 1986). In contrast, in shallow, terrestrial systems, isotopic equilibrium is not reached and a larger kinetic isotope effect for $\mathrm{D} / \mathrm{H}$ ratios of methane is expressed.

Finally, the model, as inspired by the work of Blair (1998), Valentine et al. (2004), and Penning et al. (2005) and building on the initial ideas of Stolper et al. (2014b), Stolper et al. (2014c), and Eiler et al. (2014b), demonstrates the importance of considering both kinetic and equilibriumthermodynamics in the consideration of the controls on the isotopic compositions of reactants 
and products not only in methanogenesis, but a range of other metabolisms. This is not a novel idea and has been long considered in the studies of dissimilatory sulfate reduction (Rees, 1973; Farquhar et al., 2003; Brunner and Bernasconi, 2005; Bradley et al., 2011; Wing and Halevy, 2014). However, the use of clumped-isotope measurements to study microbial metabolisms provides a new, distinct avenue for studying the flow of metabolites in the metabolism or organisms by providing a reference frame that is grounded in equilibrium thermodynamics and fingerprint that remains with the molecule of interest even after separation from its formational environment.

\section{Conclusions}

We have demonstrated that clumped-isotope measurements of methane can be useful for quantifying the amount of biogenic vs. thermogenic methane in natural settings. In the Antrim Shale, significant quantities of both biogenic and thermogenic methane are present in different wells, with $\Delta_{18}$-based temperatures correlating with many other independent parameters such as $\mathrm{C}_{1} / \mathrm{C}_{2-4}$ ratios, $\delta \mathrm{D}_{\mathrm{H} 2 \mathrm{O} \text {,iquid }}$ and $\delta \mathrm{D}_{\mathrm{CH} 4}$. The mixing model results show that, in contrast to previous indications, biogenic and thermogenic methane are approximately equal in importance in the northern margin of the Michigan basin. Additionally, the Antrim Shale results support previous findings that biogenic gases in natural systems frequently yield low $\Delta_{18}$ temperatures consistent with their formation environments. This was also observed in samples from offshore seeps of biogenic gas. However, a pond sample and pure-culture experiments yield $\Delta_{18}$ temperatures that are strongly inconsistent with the known environmental or experimental temperatures. We present a metabolically based model that explicitly considers the reversibility of enzymes in methanogenesis. This model predicts that when rates of methanogenesis are slow, environmentally consistent temperatures result from the internal equilibration of methane with its metabolic precursors while the unrealistic temperatures result from the expression of kinetic isotope effects during rapid methane generation. Our model indicates that in many natural settings where methanogen growth rates are slow, such as in sedimentary basins and marine sediments, methane can be produced in or near isotopic equilibrium. By contrast, in settings that allow for high rates of methane generation such as ponds and near-surface environments, the methane is generated out of internal isotopic equilibrium. This potentially explains why methane from different environments can have drastically different $\mathrm{D} / \mathrm{H}$ fractionations relative to water, and indicates that methanogens in many natural settings live near thermodynamic equilibrium, eking out a slow living.

\section{Acknowledgements}

The idea to measure clumped-isotope compositions of methane from the Antrim shale resulted from a fortuitous meeting of DAS, JME, ALS, and AMM at the 2012 Gordon Research Conference on organic geochemistry. We wish to thank the conveners of that conference, Tim Eglinton and Erdem Idiz (and all other participants) for inviting us to the conference and creating a stimulating atmosphere for scientific discussion and collaboration. We additionally wish to thank Fenfang Wu for help measuring the $\delta D$ of water from the culturing experiments, Jared Leadbetter for aid in sampling methane from the Caltech pond, and the crew of the $R / V$ Atlantis. Finally, we would like to thank three anonymous reviewers and the associate editor, Ed Hornibrook, for their helpful comments. DAS was supported through the NSF GRFP. Research was supported by Caltech and an NSF EAR grant to JME, ACS-PRF grant to AMM, and NSF grants OCE-1046144, OCE-1155855 and EAR-0950600 to DLV and SSS. 
8. Tables

1068 Table 1 Antrim Shale sample locations.

\begin{tabular}{llll} 
Sample & County & Latitude & Longitude \\
\hline Butcher C3-24 & Ostego & 45.059931 & 84.375012 \\
Lake Horicon D4-15 & Ostego & 45.024263 & 84.692872 \\
Marlatt 1-7 & Montmorency & 45.008181 & 84.251409 \\
North Charlton A1-18 & Ostego & 45.083014 & 84.488447 \\
State Charlton C4-18 & Ostego & 44.906223 & 84.476438 \\
State Charlton C4-31 & Ostego & 45.059913 & 84.374974 \\
State Loud B4-28 & Montmorency & 44.878911 & 84.073628 \\
State Loud C2-31 & Oscoda & 44.860654 & 84.123699 \\
State Charlton A3-32 & Ostego & 44.906019 & 84.476079 \\
Weber A4-10 & Grand Traverse & 44.741218 & 85.641642 \\
${ }^{a}$ From the western margin. All else from the northern margin.
\end{tabular}

$1069{ }^{a}$ From the western margin. All else from the northern margin.

1070 
1071 Table 2: Theoretically derived temperature dependencies for $\alpha_{\mathrm{CH} 4-\mathrm{H} 2 \mathrm{O} \text {,vapor }}$ and $\alpha_{\mathrm{CH} 4-\mathrm{CO} 2}$.

Type $^{\mathrm{a}} \quad$ Equation $^{\mathrm{a}, \mathrm{b}}$

harmonic $\quad 1000 \ln \left(\alpha_{\text {CH4-H2O,vapor }}\right)=0.8576(1000 / T)^{4}-14.412(1000 / T)^{3}+88.483(1000 / T)^{2}-209.56(1000 / \mathrm{T})+60.553$

anharmonic $1000 \ln \left(\alpha_{\mathrm{CH} 4-\mathrm{H} 2 \mathrm{O}, \text { vapor }}\right)=1.1014(1000 / \mathrm{T})^{5}-11.537(1000 / \mathrm{T})^{4}+38.890(1000 / \mathrm{T})^{3}-20.448(1000 / \mathrm{T})^{2}-129.250(1000 / \mathrm{T})+21.701$

harmonic $\quad 1000 \ln \left(\alpha_{\mathrm{CH} 4-\mathrm{CO} 2}\right)=0.6196(1000 / \mathrm{T})^{3}-6.628(1000 / \mathrm{T})^{2}-6.025(1000 / \mathrm{T})+3.071$

1072 a Equations derived from Richet et al., (1977).

$1073{ }^{\mathrm{b}} \mathrm{T}$ is in Kelvin. 
1074 Table 3: Physical and isotopic measurements of Antrim Shale samples.

\begin{tabular}{|c|c|c|c|c|c|c|c|c|c|c|c|c|c|c|c|}
\hline Sample & Well T $\left({ }^{\circ} \mathrm{C}\right)$ & $\delta \mathrm{D}_{\mathrm{CH} 4}(\% o)^{\mathrm{a}}$ & \pm & $\delta^{13} \mathrm{C}_{\mathrm{CH} 4}(\% 0)^{\mathrm{b}}$ & \pm & $\Delta_{18}(\%)$ & \pm & $\mathrm{T}_{\Delta 18}\left({ }^{\circ} \mathrm{C}\right)^{\mathrm{c}}$ & \pm & $\begin{array}{c}\delta D_{\mathrm{H} 2 \mathrm{O}, \text { liquid }} \\
(\% \mathrm{o})^{\mathrm{a}}\end{array}$ & $\begin{array}{c}\delta^{18} \mathrm{O}_{\mathrm{H} 2 \mathrm{O}, \mathrm{liquid}} \\
(\%)^{\mathrm{a}}\end{array}$ & $\delta^{13} \mathrm{C}_{\mathrm{CO} 2}(\% o)^{\mathrm{b}}$ & ${ }^{b} C_{1} / C_{2-4}$ & $\delta^{13} \mathrm{C}_{\mathrm{C} 2 \mathrm{H} 6}(\% o)^{\mathrm{b}, \mathrm{d}}$ & $n$ \\
\hline Butcher C3-24 & 20 & -247.6 & 0.15 & -50.3 & 0.04 & 5.60 & 0.20 & 43 & 6 & -81.8 & -12.2 & 25.5 & 10225 & - & 3 \\
\hline Lake Horicon D4-15 & 16 & -240.4 & 0.01 & -53.0 & 0.05 & 4.80 & 0.05 & 72 & 2 & -76.1 & -11.4 & 22.8 & 46 & -45.6 & 2 \\
\hline Marlatt 1-7 & 23 & -240.4 & 0.13 & -50.9 & 0.05 & 5.30 & 0.28 & 53 & 10 & -62.4 & -10.5 & 26.9 & 782 & $-33.9^{\mathrm{e}}$ & 2 \\
\hline North Charlton A1-18 & 16 & -256.5 & 0.07 & -53.2 & 0.03 & 5.68 & 0.13 & 40 & 4 & -88.1 & -13.4 & 24.1 & 873 & $-36.2^{\mathrm{e}}$ & 3 \\
\hline State Charlton C4-18 & 16 & -233.4 & 0.22 & -52.2 & 0.02 & 4.65 & 0.00 & 78 & 0.1 & -46.5 & -7.3 & 22.5 & 27 & -45.6 & 2 \\
\hline State Charlton C4-31 & 16 & -247.4 & 0.14 & -51.1 & 0.04 & 5.30 & 0.11 & 53 & 4 & -77.7 & -11.9 & 23.9 & 393 & $-34.8^{\mathrm{e}}$ & 2 \\
\hline State Loud B4-28 & 24 & -225.8 & 0.20 & -52.8 & 0.03 & 4.09 & 0.19 & 104 & 9 & -31.9 & -5.1 & 23.1 & 9 & -52.9 & 2 \\
\hline State Loud C2-31 & 19 & -221.6 & 0.04 & -53.2 & 0.01 & 3.87 & 0.01 & 115 & 0.4 & -23.9 & -3.9 & 22.3 & 8 & -48.8 & 2 \\
\hline State Charlton A3-32 & 16 & -211.3 & 0.11 & -51.7 & 0.01 & 4.94 & 0.24 & 67 & 9 & -22.5 & -3.7 & 21.7 & 8 & -45.4 & 1 \\
\hline 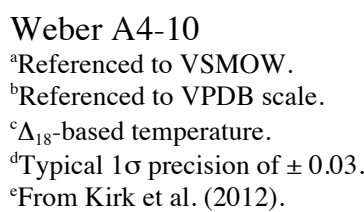 & 03. & -246.2 & 0.12 & -51.9 & 0.01 & 5.60 & 0.27 & 43 & 9 & -72.8 & -11.1 & 24.7 & 153 & - & 1 \\
\hline
\end{tabular}


1080 Table 4: Thermogenic and biogenic end member values for mixing calculation.

\begin{tabular}{l|cc} 
& Thermogenic end member & Biogenic end member \\
\hline$\delta \mathrm{D}_{\mathrm{CH} 4}(\% \circ)$ & $-207^{\mathrm{a}}$ & $-260^{\mathrm{b}}$ \\
$\delta^{13} \mathrm{C}_{\mathrm{CH} 4}(\% \circ)$ & $-55^{\mathrm{c}}$ & $-46^{\mathrm{c}}$ \\
$\delta \mathrm{D}_{\mathrm{H} 2 \mathrm{O}, \text { liquid }}(\% \circ)^{\mathrm{d}}$ & $-11^{\mathrm{e}}$ & $-102^{\mathrm{f}}$ \\
$\Delta_{18}$-based $\mathrm{T}\left({ }^{\circ} \mathrm{C}\right)$ & $144^{\mathrm{g}}$ & $18^{\mathrm{h}}$ \\
$\mathrm{C}_{1} / \mathrm{C}_{2-4}$ & $5.8^{\mathrm{i}}$ & $\infty^{\mathrm{j}}$
\end{tabular}

1081

1082 a Source: Maximum value of northern margin gases from the Antrim Shale (Martini et al., 2003).

083 'Source: Minimum value of northern margin gases from the Antrim Shale (Martini et al., 1998).

084 'Source: As discussed in the text.

$085{ }^{\mathrm{d}}$ Maximum and minimum $\delta \mathrm{D}_{\text {н2о.liquid }}$ were taken from units within the Antrim Shale, but outside of the northern margin. We have used samples from outside of the northern margin due to the large

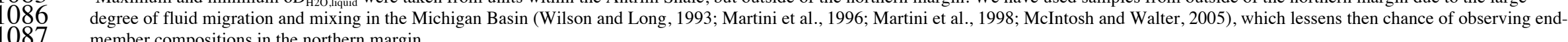

1087 member compositions in the northern margin.

1088 'Source: Maximum value of formation waters within the Antrim Shale (Wilson and Long, 1993). Specifically from the Berea Sandstone.

089 SSource: Minimum value of formation waters in the Antrim Shale (Martini et al., 2003). Specifically from the western margin.

090 'Source: Estimated as discussed in the text.

092 Source: Average temperature of wells measured in this study (Table 3).

1093 isource: Average value for thermogenic gases from the central basin of the Antrim Shale and from Silurian formation gases (Martini et al., 1998; Martini et al., 2003) 
1094 Table 5: Modeled relative concentrations of biogenic gas in Antrim Shale samples.

\begin{tabular}{lcc}
\multicolumn{1}{c}{ Sample } & Proportion of biogenic gas $(\%)$ & $\pm^{\mathrm{a}}(\%)$ \\
\hline Butcher C3-24 & 75 & 6.1 \\
Lake Horicon D4-15 & 49 & 1.5 \\
Marlatt 1-7 & 66 & 8.9 \\
North Charlton A1-18 & 77 & 4.1 \\
State Charlton C4-18 & 44 & 0.1 \\
State Charlton C4-31 & 65 & 3.4 \\
State Loud B4-28 & 26 & 6.4 \\
State Loud C2-31 & 18 & 0.2 \\
State Charlton A3-32 & 54 & 7.8 \\
Weber A4-10 & 75 & 8.4 \\
${ }^{\mathrm{a}}$ Errors are derived by propagating the 1 $\sigma$ errors of the $\Delta_{18}$ values of the samples through the calculation. They do not include the potential errors \\
associated with our estimates of the end-member compositions.
\end{tabular}

1095

1096

1097 
1098 Table 6: Environmental biogenic samples.

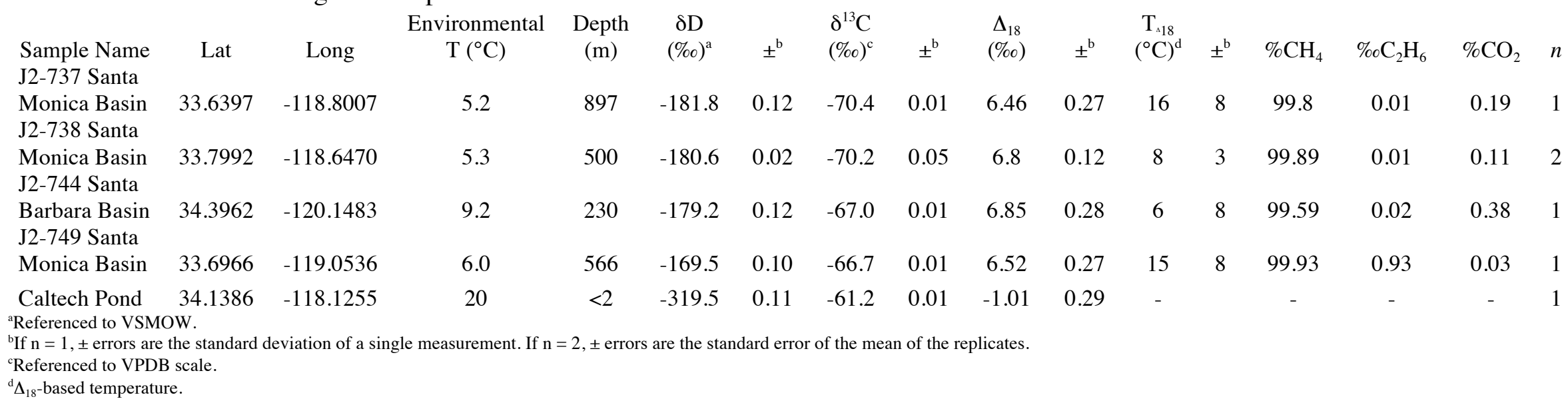


1103 Table 7: Pure-culture experiments.

$\begin{array}{lccccccc}\text { Species } & \begin{array}{c}\text { Growth } \mathrm{T} \\ \left({ }^{\circ} \mathrm{C}\right)\end{array} & \begin{array}{c}\delta \mathrm{D} \\ (\%)^{\mathrm{a}}\end{array} & \pm^{\mathrm{b}} & \begin{array}{c}\delta^{13} \mathrm{C} \\ (\%)^{\mathrm{c}}\end{array} & \pm^{\mathrm{b}} & \begin{array}{c}\Delta_{18} \\ (\% 0)\end{array} & \pm^{\mathrm{b}} \\ \text { M. marburgensis } & 70 & -317.2 & 0.12 & -54.7 & 0.01 & 1.16 & 0.25 \\ \text { M. marburgensis } & 65 & -367.3 & 0.11 & -44.7 & 0.01 & 0.89 & 0.27 \\ \text { M. marburgensis } & 50 & -356.7 & 0.12 & -40.1 & 0.01 & 0.78 & 0.26 \\ \text { M. marburgensis } & 45 & -317.9 & 0.1 & -48.1 & 0.01 & 1.85 & 0.29 \\ \text { M. marburgensis } & 30 & -476.0 & 0.1 & -65.1 & 0.01 & -1.59 & 0.25 \\ \text { M. barkeri } & 37 & -491.6 & 0.12 & -56.7 & 0.01 & -4.66 & 0.26\end{array}$

1104 a Referenced to VSMOW.

${ }^{b}$ Errors are standard deviation of a single measurement as all samples were only measured once.

1106 'Referenced to VPDB scale. 
1108 Table 8: Constants used for methanogenesis model.

$\begin{array}{cccc}\text { Isotopologue ratio } & \kappa_{\mathrm{f}}^{\mathrm{a}, \mathrm{b}} & \alpha^{\mathrm{c}} & \mathrm{K}_{\mathrm{eq}}{ }^{\mathrm{d}} \\ { }^{13} \mathrm{CH}_{4} /{ }^{12} \mathrm{CH}_{4} & 0.92(0.92) & 0.932 & - \\ { }^{12} \mathrm{CH}_{3} \mathrm{D} /{ }^{12} \mathrm{CH}_{4} & 2.112(0.528) & 0.816 & - \\ { }^{13} \mathrm{CH}_{3} \mathrm{D} /{ }^{12} \mathrm{CH}_{4} & 1.935 & - & 1.0061 \\ { }^{12} \mathrm{CH}_{2} \mathrm{D}_{2} /{ }^{12} \mathrm{CH}_{4} & 1.89 & - & 1.022\end{array}$

1109 at Ratio of rate constant that describes the relative rate of formation of the two isotopologues from a methyl

1110 precursor.

1111 b If a value is given inside a parenthetical, it refers to the equivalent bulk isotopic fractionation factor $(\alpha)$, which 1112 has been adjusted to take into the symmetry numbers of the isotopologues.

$1113{ }^{c}$ Fractionation factor for isotopic equilibrium at $20^{\circ} \mathrm{C}$ between $\mathrm{CH}_{4}$ and $\mathrm{CO}_{2}$ for ${ }^{13} \mathrm{C} /{ }^{12} \mathrm{C}$ ratios and between $\mathrm{CH}_{4}$ 1114 and $\mathrm{H}_{2} \mathrm{O}$ for $\mathrm{D} / \mathrm{H}$ ratios.

$1115{ }^{\mathrm{d}}$ Equilibrium constant for internal equilibrium amongst all isotopologues for the indicated multiply substituted 1116 isotopologue (normalized against the equilibrium constant for a random distribution of isotopologues).

1117 


\section{Figures}

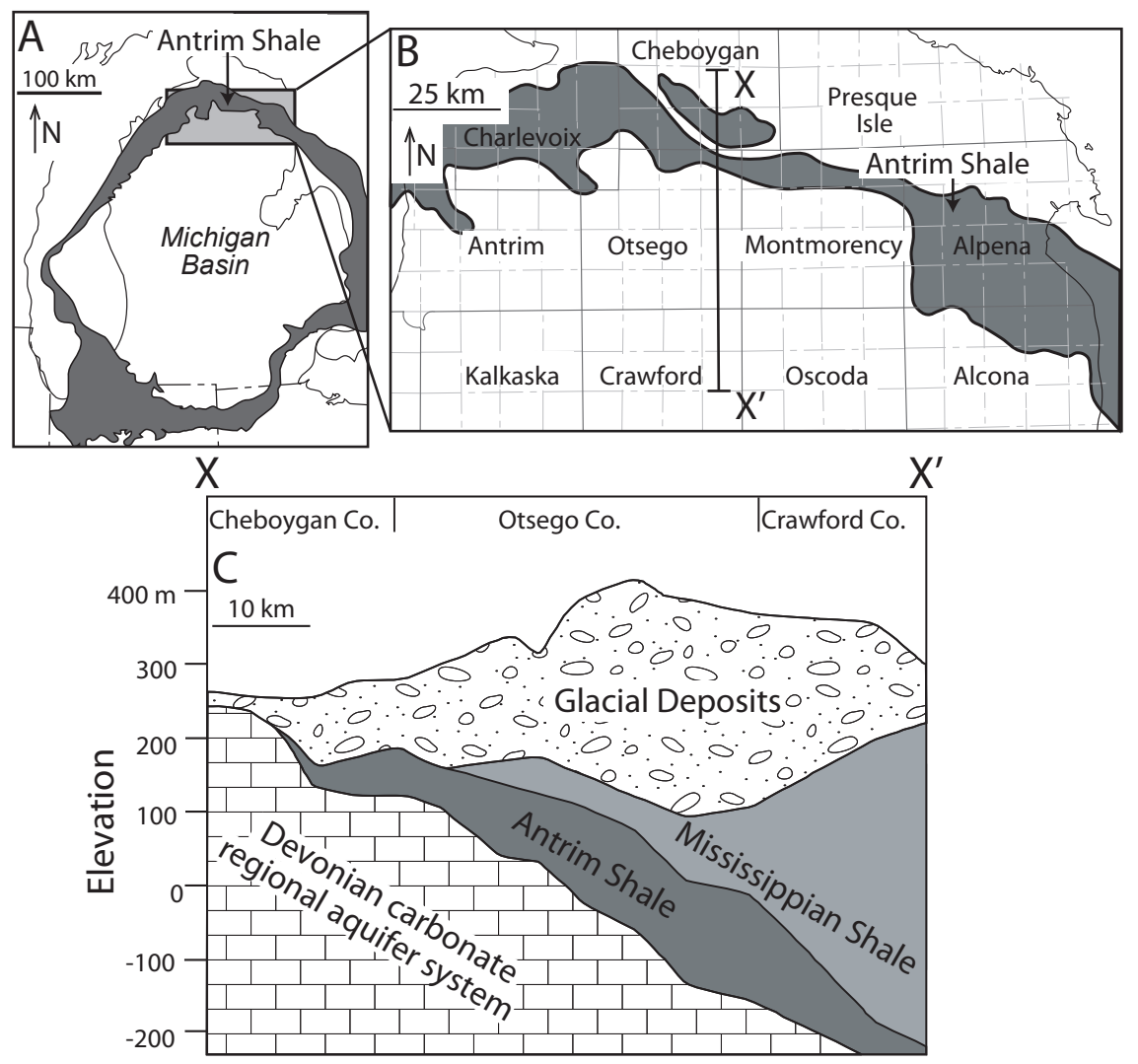

Figure 1: Geological map and cross section of the Antrim Shale. Modified after Martini et al. (1998) and Martini et al. (2008).

1122 A) Geological map of the Michigan Basin. In gray is the Antrim Shale. Note that it subcrops below glacial deposits. B)

1123 Zoom in of A where the Antrim Shale subcrops in the northern margin. County names are given. C) Cross section from X to $1124 \mathrm{X}$ ' given in B. 

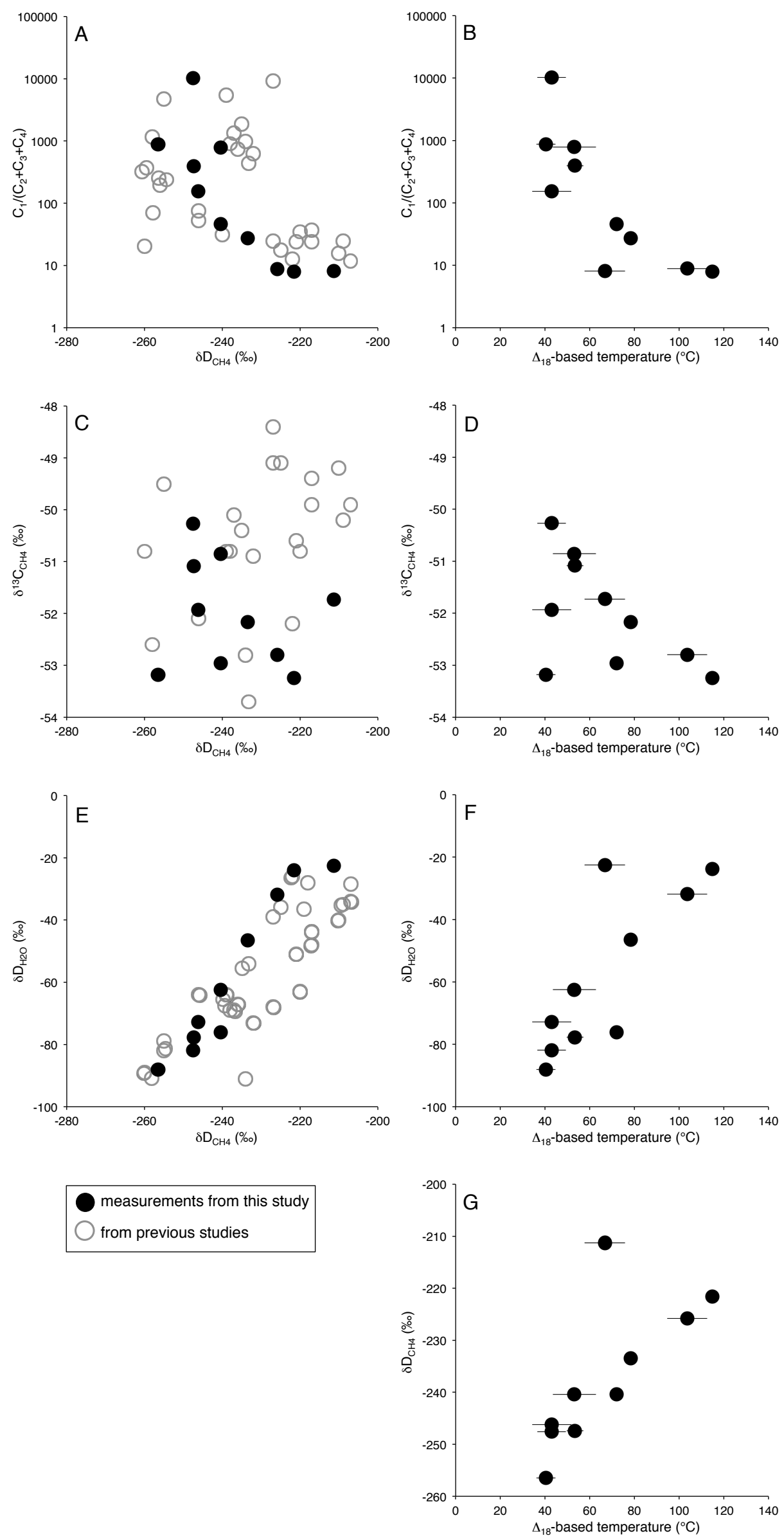
1128 Figure 2: Measured data from Antrim Shale samples. Error bars are all $1 \sigma$ and are not displayed if they are smaller than the 1129 symbol. Data from previous studies come from Martini et al. (1996), Martini et al. (1998), and Martini et al. (2003). Panels 1130 on the left plot properties vs. $\delta \mathrm{D}_{\mathrm{CH} 4}$. Panels on the right plot properties vs. $\Delta_{18}$-based temperatures.

1131 A) $\mathrm{C}_{1} / \mathrm{C}_{2-4}$ vs. $\delta \mathrm{D}_{\mathrm{CH} 4}$. B) $\mathrm{C}_{1} / \mathrm{C}_{2-4}$ vs. $\Delta_{18}$-based temperatures. C) $\delta^{13} \mathrm{C}$ vs. $\delta \mathrm{D}_{\mathrm{CH} 4}$. D) $\delta^{13} \mathrm{C}$ vs. $\Delta_{18}$-based temperatures. E) $1132 \delta D_{\mathrm{H} 2 \mathrm{O} \text {.liquid }}$ vs. $\delta \mathrm{D}_{\mathrm{CH} 4}$. F) $\delta \mathrm{D}_{\mathrm{H} 2 \mathrm{O}, \text { liquid }}$ vs. $\Delta_{18}$-based temperatures. G) $\delta \mathrm{D}_{\mathrm{CH} 4}$ vs. $\Delta_{18}$-based temperatures. 

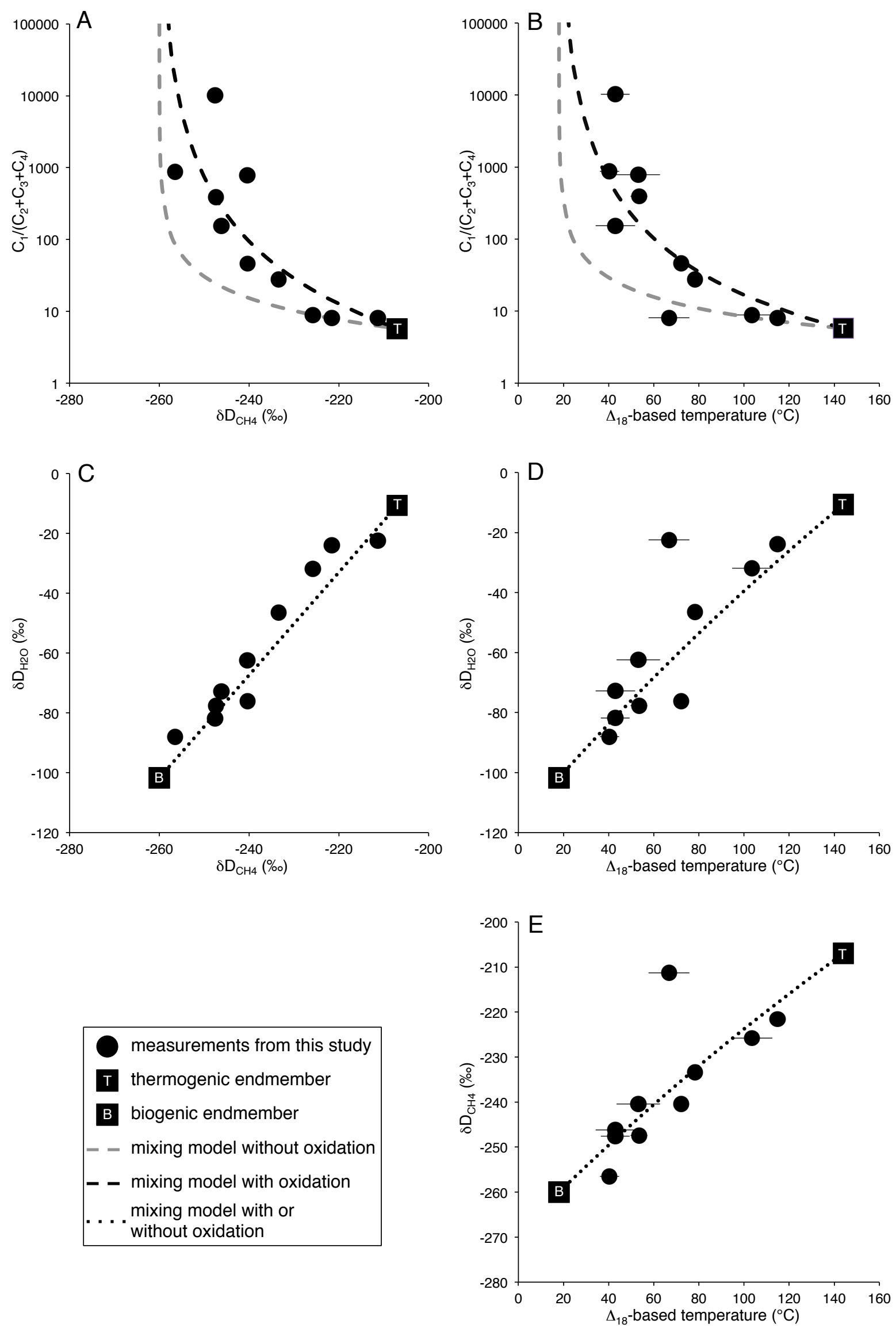

Figure 3: Comparison of the end member mixing models with or without oxidation of $\mathrm{C}_{2-4}$ hydrocarbons. Error bars are all 
1136 the oxidation of $\mathrm{C}_{2-4}$ hydrocarbons has no effect on methane or the formation water's isotopic composition. Panels on the left 1137 plot properties vs. $\delta \mathrm{D}_{\mathrm{CH} 4}$. Panels on the right plot properties vs. $\Delta_{18}$-based temperatures.

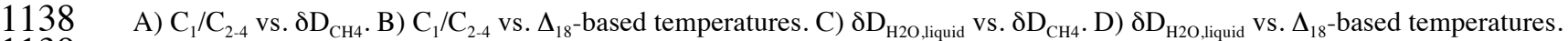
1139 For this mixing space, it is presumed that the mixing ratios of the gases are equivalent to the mixing ratios of the waters. E) $1140 \delta \mathrm{D}_{\mathrm{CH} 4}$ vs. $\Delta_{18}$-based temperatures. 


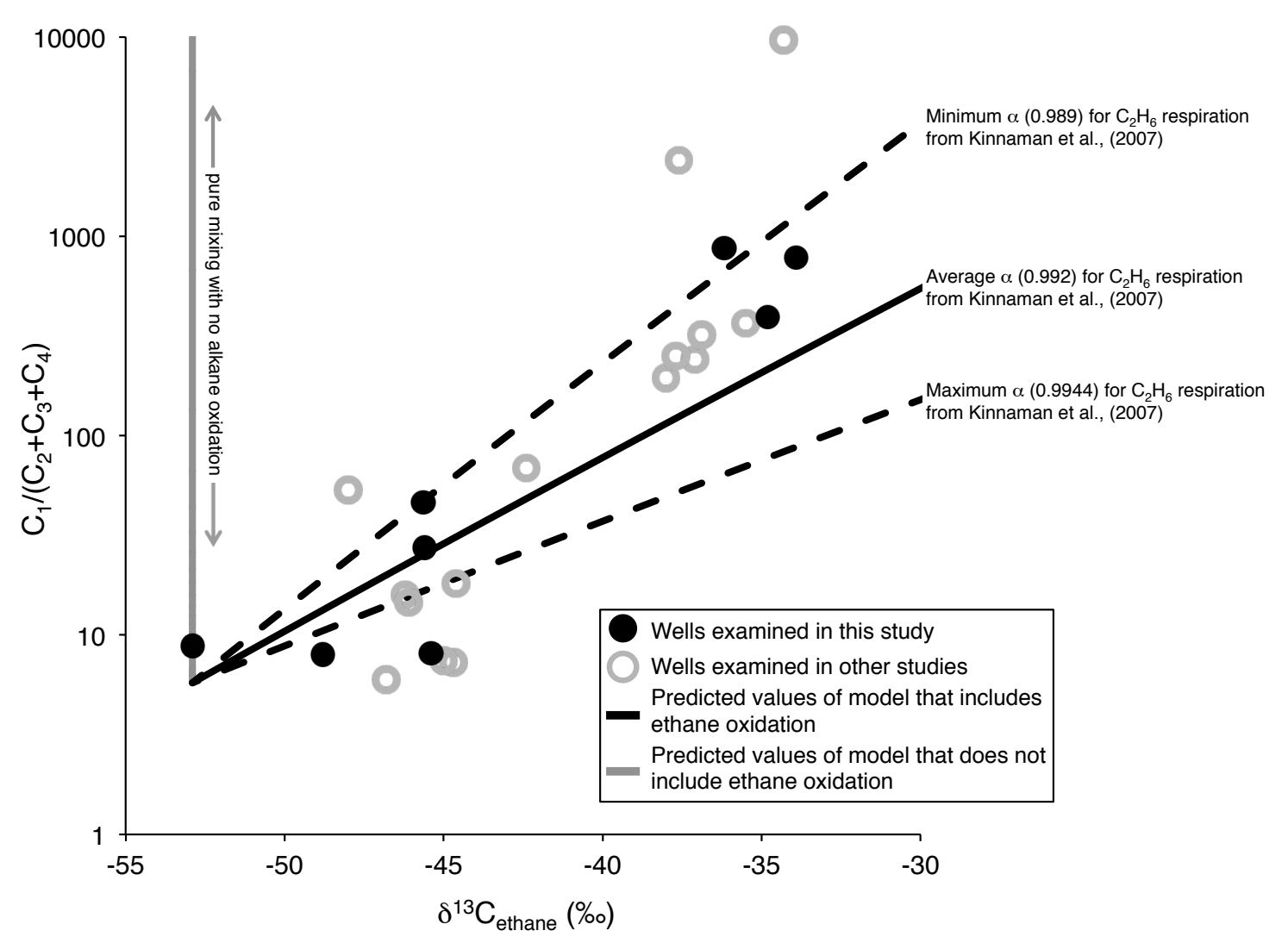

1141

1142

1143

1144

Figure 4: Mixing model's prediction of the $\delta^{13} \mathrm{C}$ of ethane as a function of the $\mathrm{C}_{1} / \mathrm{C}_{2-4}$ ratio. $\delta^{13} \mathrm{C}$ values of ethane are from this study and from previous measurements from Martini et al. (2003) and Kirk et al. (2012). Fractionation factors $(\alpha)$ for ethane oxidation are equal to $\left(1000+\delta^{13} \mathrm{C}_{\mathrm{C} 2 \mathrm{H} 6 \text {,respired }}\right) /\left(1000+\delta^{13} \mathrm{C}_{\mathrm{C} 2 \mathrm{H} 6 \text {,residual }}\right)$, where 'respired' refers to the ethane that is respired by microbes and 'residual' refers to the remaining ethane. $\alpha$ values for ethane oxidation are all from Kinnaman et al. (2007). The thermogenic end member is assumed to have a $\delta^{13} \mathrm{C}$ value of $-52.9 \%$ and $\mathrm{C}_{1} / \mathrm{C}_{2-4}$ of 5.8. See text for details. 


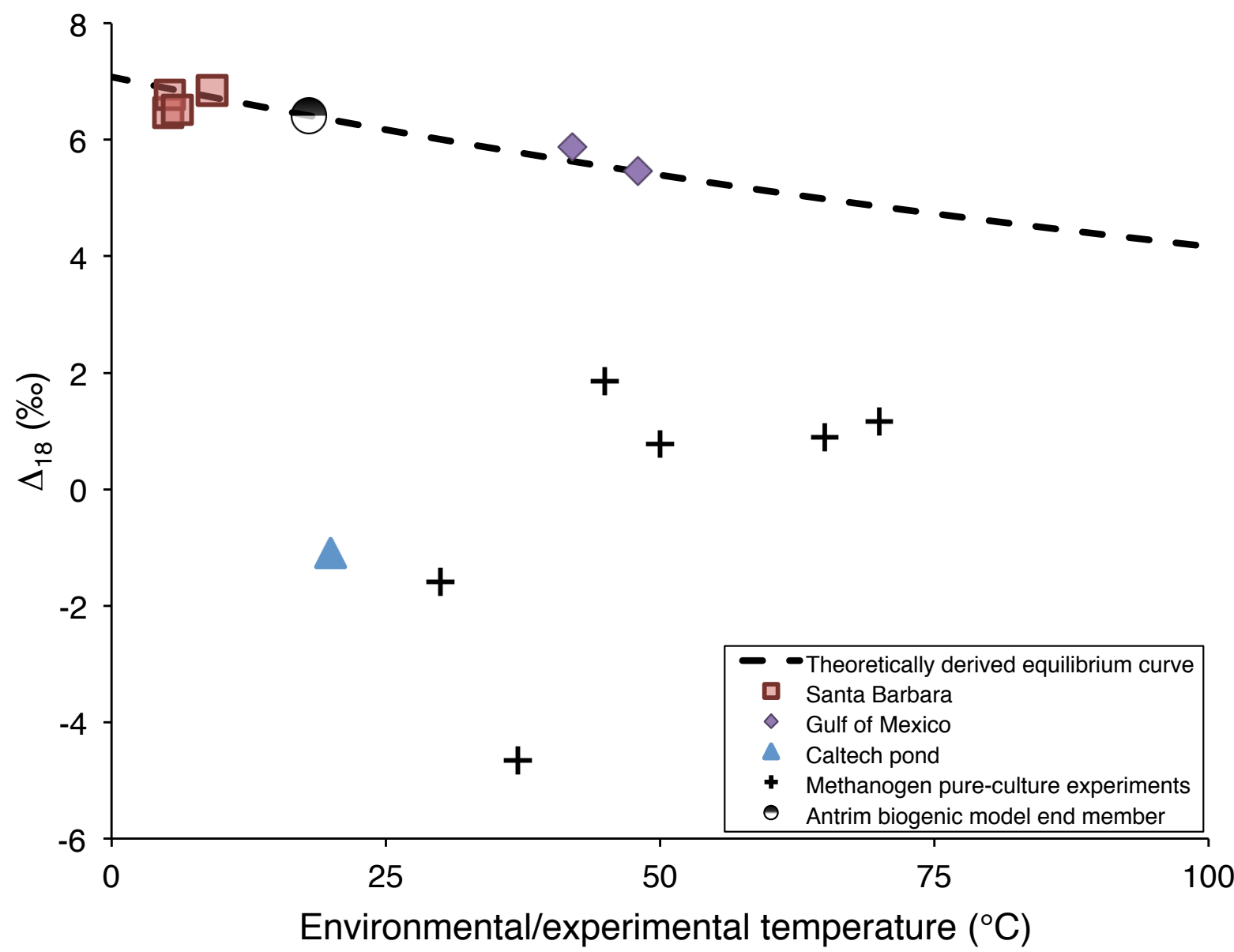

Figure 5: Measured or modeled $\Delta_{18}$ values of biogenic gases from natural or experimental systems. The theoretically derived curve describes the expected $\Delta_{18}$ value for methane isotopically equilibrated internally as a function of temperature and is from Stolper et al. (2014a). The Gulf of Mexico samples were reported in Stolper et al. (2014b). The Antrim biogenic model end member point is the value used in the mixing model of the Antrim Shale samples to describe the biogenic end member and is thus required to be on the equilibrium curve. 


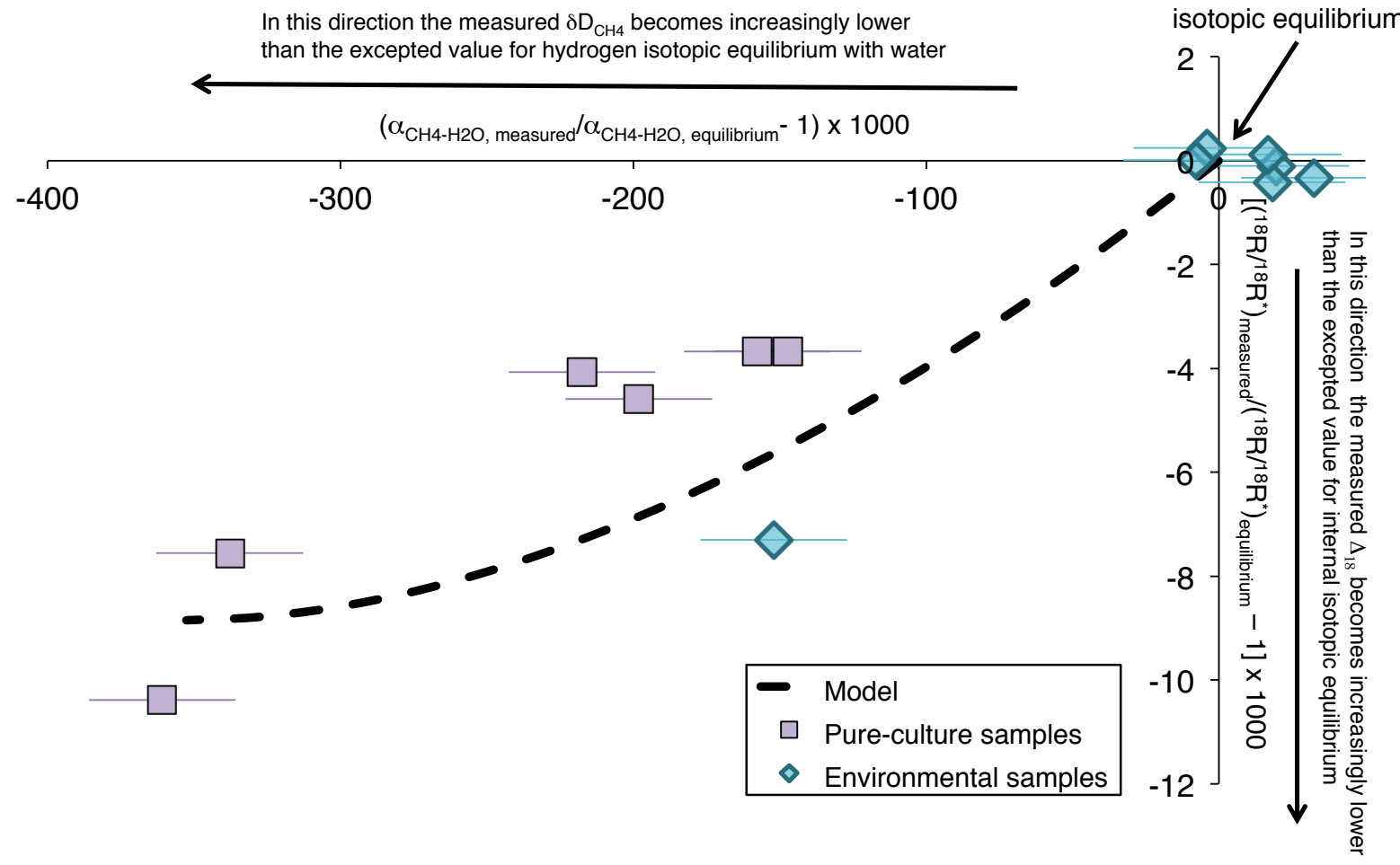

Figure 6: Comparison of measured $\Delta_{18}$ values to those expected if the methane formed in internal isotopic equilibrium vs. the difference in measured $\delta \mathrm{D}_{\mathrm{CH} 4}$ and $\delta \mathrm{D}_{\mathrm{H} 2 \mathrm{O}, \mathrm{liquid}}$ values (expressed as a difference in ratios, $\alpha_{\mathrm{CH} 4-\mathrm{H} 2 \mathrm{O}, \text { liquid }}$ ) compared to that expected for heterogeneous-phase isotopic equilibrium. Deviations in measured $\Delta_{18}$ values vs. those expected for equilibrium are represented in this figure through the comparison of ${ }^{18} \mathrm{R} /{ }^{18} \mathrm{R}^{*}$ values. As given in equation $1,{ }^{18} \mathrm{R} /{ }^{18} \mathrm{R}^{*}=\left(\Delta_{18} / 1000+1\right)$. All samples near the origin, which is the point at which methane is both internally isotopically equilibrated amongst all isotopologues and isotopically equilibrated for hydrogen isotopes with $\mathrm{H}_{2} \mathrm{O}$ are from marine samples and assumed to have a $\delta D_{\mathrm{H} 2 \mathrm{O} \text {,iquid }}=0 \%$. The Caltech pond sample, the only environmental sample not located near the origin, was measured to have a $\delta \mathrm{D}_{\mathrm{H} 2 \mathrm{O} \text { liquid }}$ of $-16 \%$. One pure-culture sample (the $65^{\circ} \mathrm{C}$ experiment) was measured to have a $\delta \mathrm{D}_{\mathrm{H} 2 \mathrm{O} \text { liquid }}=-37.8 \%$ for the culture media. We assume that this value is the same for all pure-culture experiments. We assume a conservative error for assignment of $\delta \mathrm{D}_{\mathrm{H} 2 \mathrm{O} \text {,liquid }}$ of $25 \%$ to account for our estimations and potential for differences in the $\delta \mathrm{D}_{\mathrm{H} 2 \mathrm{O}, \mathrm{liquid}}$ of the environmental waters vs. the intracellular waters of the methanogens. The model describes the isotopic composition of methane formed by methanogens as a function of the reversibility of methyl-coenzyme M reductase. It is described in the text and appendix. 


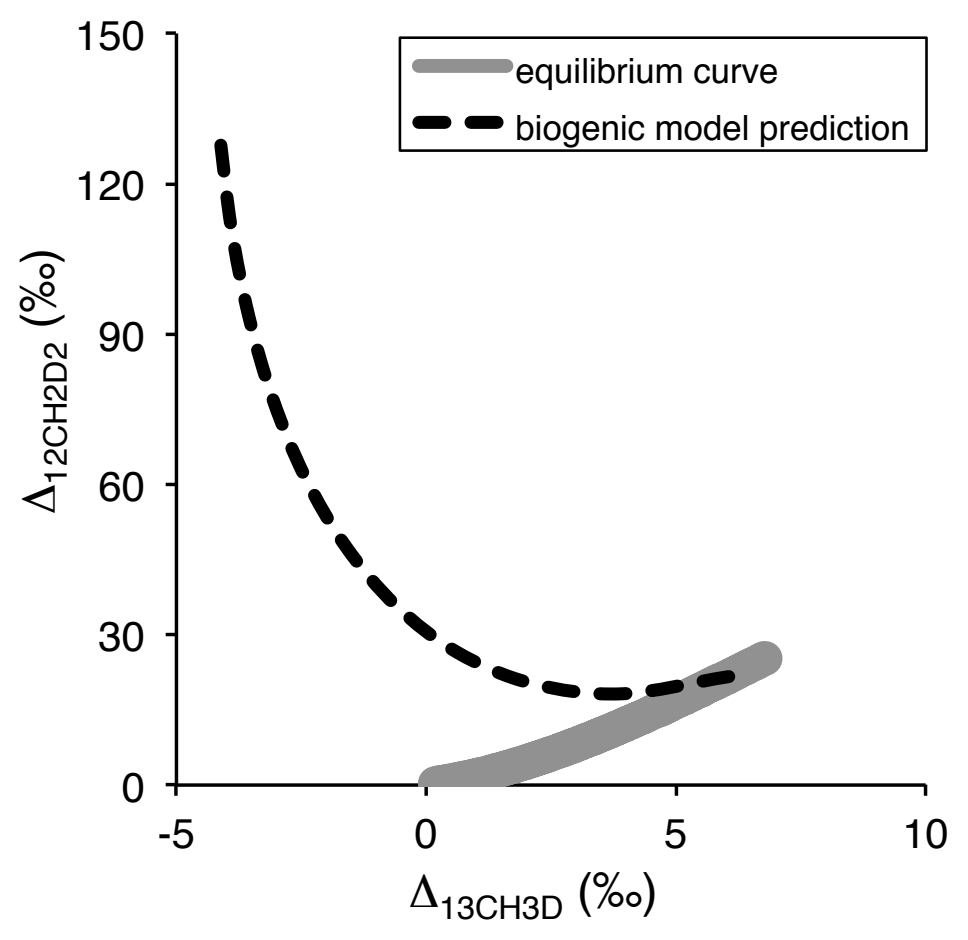

Figure 7: Comparison of the biogenic model (described in the text) vs. the expected values for internal isotopic equilibrium for $\Delta_{12 \mathrm{CH} 2 \mathrm{D} 2}$ and $\Delta_{13 \mathrm{CH} 3 \mathrm{D}}$ values. $\Delta_{12 \mathrm{CH} 2 \mathrm{D} 2}=\left[\left(\left[{ }^{12} \mathrm{CH}_{2} \mathrm{D}_{2}\right] /\left[{ }^{12} \mathrm{CH}_{4}\right] / /\left[{ }^{12} \mathrm{CH}_{2} \mathrm{D}_{2}\right]^{*} /\left[{ }^{12} \mathrm{CH}_{4}\right]^{*}\right)-1\right] \times 1000 . \Delta_{13 \mathrm{CH} 3 \mathrm{D}}=$ $\left[\left(\left[{ }^{13} \mathrm{CH}_{3} \mathrm{D}\right] /\left[{ }^{12} \mathrm{CH}_{4}\right]\right) /\left(\left[{ }^{13} \mathrm{CH}_{3} \mathrm{D}\right] / /\left[{ }^{12} \mathrm{CH}_{4}\right]^{*}\right)-1\right]$. * refers to the random isotopic distribution. If both $\Delta_{12 \mathrm{H} 2 \mathrm{D} 2}$ and $\Delta_{13 \mathrm{CH} 3 \mathrm{D}}$ can measured, the model can be tested.

1176 
1177

1178

1179

1180

1181

1182

1183

1184

1185

1186

1187

1188

1189

1190

1191

1192

1193

1194

1195

1196

1197

1198

1199

1200

1201

1202

1203

1204

1205

1206

1207

1208

1209

1210

1211

1212

1213

1214

1215

1216

1217

1218

1219

1220

1221

\section{Appendix}

\section{A1: Derivation of isotopically enabled methanogenesis model}

In this section we derive a model to describe the concentrations of various isotopologues of methane generated during microbial methanogenesis in order to calculate $\delta \mathrm{D}_{\mathrm{CH} 4}, \delta^{13} \mathrm{C}_{\mathrm{CH} 4}$, and $\Delta_{18}$ values. This model is based on the quantitative framework of Rees (1973) originally used to describe isotope fractionations of sulfur during dissmilatory sulfate reduction. We only deal with hydrogenotrophic methanogenesis here and do not incorporate aceticlastic or methylotrophic methanogenesis.

The generation of methane by methanogens involves many steps with 6 distinct metabolic intermediates between $\mathrm{CO}_{2}+\mathrm{H}_{2}$ and $\mathrm{CH}_{4}$ (Thauer, 1998). A full description of the isotopic fractionation factors of each individual step in both the forward and backward direction is desirable, and ultimately necessary for a complete description of the isotopic ratios observed for methane in nature. However, the individual fractionation factors for ${ }^{13} \mathrm{C}$ or $\mathrm{D}$ in the singly substituted isotopologues are not known for most steps, let alone for ${ }^{13} \mathrm{CH}_{3} \mathrm{D}$ and ${ }^{12} \mathrm{CH}_{2} \mathrm{D}_{2}$ (Scheller et al., 2013). We deal with this complexity by making a few simplifying assumptions regarding the metabolism of methanogens. We assume that the final step of methanogenesis in which a hydrogen atom is added to a methyl group attached to coenzyme $\mathrm{M}\left(\mathrm{CH}_{3}-\mathrm{S}-\mathrm{CoM}\right)$ is the rate-limiting step, and that this step proceeds sufficiently slowly compared to the previous steps that the precursor metabolites are in isotopic equilibrium (Figure A3). This follows arguments made in Valentine et al. (2004) based on the 'differential reversibility' hypothesis put forward there and discussed in the text above. We additionally assume, following Botz et al. (1996), that only a small proportion of $\mathrm{CO}_{2}$ is used for biomass generation ( $<10 \%$; Fuchs et al., 1979) as compared to methane production and therefore can be, to first order, neglected in the model. We note though that M. barkeri belongs to an order of methanogens that have significantly $(\sim 2-3 \mathrm{x})$ higher biomass yields than other orders (Thauer et al., 2008). This organism gave the most negative $\Delta_{18}$ value and may indicate that incorporation of biomass yields is important for understanding the isotopic composition of methane.

We can thus, in a simplified way, describe the overall generation of methane during methanogenesis with two reactions. The first reaction between $\mathrm{CO}_{2}$ and $\mathrm{CH}_{3}-\mathrm{S}-\mathrm{CoM}$ :

$$
\mathrm{CO}_{2}+3 \mathrm{H}_{2}+\mathrm{H}-\mathrm{S}-\mathrm{CoM} \leftrightarrows \mathrm{CH}_{3}-\mathrm{S}-\mathrm{CoM}+2 \mathrm{H}_{2} \mathrm{O}
$$

where all species are in isotopic equilibrium (Figure A3). S-CoM represents coenzyme M. The two-headed arrows indicate that the different species are at chemical and isotopic equilibrium. The rate-limiting step (where reduced $\mathrm{H}$ is donated from a reduced hydrogen pool) is then:

$$
\mathrm{CH}_{3}-\mathrm{S}-\mathrm{CoM}+2 \mathrm{H} \rightarrow \mathrm{CH}_{4}+\mathrm{H}-\mathrm{S}-\mathrm{CoM}
$$

In this derivation, the consequences of allowing equation A1.2 to proceed in the reverse direction will be explored. 


\section{A2: ${ }^{13} \mathrm{CH}_{4}$ Derivation}

The set of equations that describe the dependence of the ${ }^{13} \mathrm{CH}_{4} /{ }^{12} \mathrm{CH}_{4}$ ratio on the degree of reversibility of equation A1.2 are derived here for the following reactions:

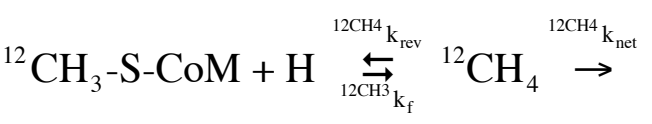

and

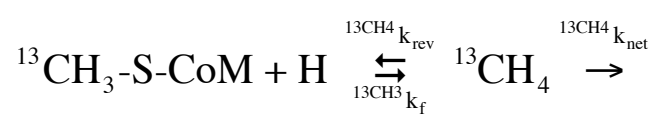

Here, for clarity, we have left off the additional reaction in which H-S-CoM is regenerated as written in equation A1.2. The rate constants describing each reaction are given next to the arrows for each step. The final step of the reaction in which methane leaves the system can be envisioned as diffusion or escape of methane out of the cell or environment such that it can no longer interact with the enzymes of the methanogens. It is assumed that all reactions follow the kinetic forms discussed in Rees (1973). Equations will only be developed for the system at steady state such that the concentrations of all metabolic intermediates are time invariant.

With this in mind, for the reaction in A2.1,

$$
\frac{\mathrm{d}\left[{ }^{12} \mathrm{CH}_{4}\right]}{\mathrm{dt}}=0={ }^{12} \mathrm{CH}_{3} \mathrm{k}_{\mathrm{f}}\left[{ }^{12} \mathrm{CH}_{3}-\mathrm{S}-\mathrm{CoM}\right][\mathrm{H}]-\left({ }^{12} \mathrm{CH}_{4} \mathrm{k}_{\text {rev }}+{ }^{12} \mathrm{CH}_{4} \mathrm{k}_{\text {net }}\right)\left[{ }^{12} \mathrm{CH}_{4}\right],
$$

such that, at steady state,

$$
\left[{ }^{12} \mathrm{CH}_{4}\right]=\frac{{ }^{12} \mathrm{CH}_{3} \mathrm{k}_{\mathrm{f}}\left[{ }^{12} \mathrm{CH}_{3}-\mathrm{S}-\mathrm{CoM}\right][\mathrm{H}]}{{ }^{12} \mathrm{CH}_{4} \mathrm{k}_{\mathrm{rev}}+{ }^{12} \mathrm{CH}_{4} \mathrm{k}_{\text {net }}} .
$$

Brackets denote concentrations of the species. In writing the equations in this form, we presume there exists some pool of hydrogen (and deuterium) that is used for all reactions. Multiple enzymes donate $\mathrm{H}$ to methane precursors, and thus this assumption is not strictly correct (Thauer, 1998; Valentine et al., 2004). Here, we assume that all pools of hydrogen are isotopically equilibrated with water. This is generally assumed and supported by a variety of experiments and observations (Daniels et al., 1980; Schoell, 1980; Balabane et al., 1987; Sugimoto and Wada, 1995; Whiticar, 1999; Valentine et al., 2004; Yoshioka et al., 2008). However, we note this assumption has recently been questioned by Kawagucci et al. (2014). Their results suggest, as proposed by Burke (1993), that the isotopic composition of hydrogen from $\mathrm{H}_{2}$, independent of the isotope composition of water, partially controls the isotopic composition of the resultant methane. Regardless, we will proceed with the assumption that all hydrogen in methane is ultimately derived from water. Similarly, for equation A2.2 we have, 


$$
\left[{ }^{13} \mathrm{CH}_{4}\right]=\frac{{ }^{13} \mathrm{CH}_{3} \mathrm{k}_{\mathrm{f}}\left[{ }^{13} \mathrm{CH}_{3}-\mathrm{S}-\mathrm{CoM}\right][\mathrm{H}]}{{ }^{13} \mathrm{CH}_{4} \mathrm{k}_{\mathrm{rev}}+{ }^{13} \mathrm{CH}_{4} \mathrm{k}_{\text {net }}} .
$$

1265

1266

1267

1268

1269

1270

1271

1272

1273

1274

1275

1276

1277

1278

1279

1280

1281

1282

1283

1284

1285

1286

1287

1288

1289

1290

1291

1292

1293

1294

1295

1296

1297

1298

An important approximation is used in equations A2.3 through A2.5: a small proportion of methyl groups have a deuterium added instead of a hydrogen (as written). These deuterium addition reactions are ignored as they represent $<0.1 \%$ of all methane groups generated for each reaction, which we consider an acceptable approximation.

Finally, we introduce here a 'degree of reversibility' term for equation A2.1. This term, ' $r$ ', introduced by Rees (1973), compares the rate of back reaction of methane into the metabolic intermediates vs. the forward generation rate of methane. In the form of an equation,

$$
\mathrm{r}=\frac{{ }^{12} \mathrm{CH}_{4} \mathrm{k}_{\mathrm{rev}}\left[{ }^{12} \mathrm{CH}_{4}\right]}{{ }^{12} \mathrm{CH}_{3} \mathrm{k}_{\mathrm{f}}\left[{ }^{12} \mathrm{CH}_{3}-\mathrm{S}-\mathrm{CoM}\right][\mathrm{H}]} .
$$

In this framework, $\mathrm{r}$ can vary from 0 to 1 . Combination of A2.6 with A2.4 results in:

$$
\mathrm{r}=\frac{{ }^{12} \mathrm{CH}_{4} \mathrm{k}_{\mathrm{rev}}}{{ }^{12} \mathrm{CH}_{4} \mathrm{k}_{\mathrm{rev}}+{ }^{12} \mathrm{CH}_{4} \mathrm{k}_{\text {net }}}
$$

Division of A2.5 by A2.4 yields

$$
\frac{\left[{ }^{13} \mathrm{CH}_{4}\right]}{\left[{ }^{12} \mathrm{CH}_{4}\right]}=\left(\frac{{ }^{13} \mathrm{CH}_{3} \mathrm{k}_{\mathrm{f}}\left[{ }^{13} \mathrm{CH}_{3}-\mathrm{S}-\mathrm{CoM}\right][\mathrm{H}]}{{ }^{12} \mathrm{CH}_{3} \mathrm{k}_{\mathrm{f}}\left[{ }^{12} \mathrm{CH}_{3}-\mathrm{S}-\mathrm{CoM}\right][\mathrm{H}]}\right) \times\left(\frac{{ }^{12} \mathrm{CH}_{4} \mathrm{k}_{\mathrm{rev}}+{ }^{12} \mathrm{CH}_{4} \mathrm{k}_{\text {net }}}{{ }^{13} \mathrm{CH}_{4} \mathrm{k}_{\text {rev }}+{ }^{13} \mathrm{CH}_{4} \mathrm{k}_{\text {net }}}\right) .
$$

This can be rewritten using the following notations:

$$
{ }^{13} \mathrm{CH}_{4} \mathrm{R}=\frac{\left[{ }^{13} \mathrm{CH}_{4}\right]}{\left[{ }^{12} \mathrm{CH}_{4}\right]} \text { and }{ }^{13} \mathrm{CH}_{3} \mathrm{R}=\frac{\left[{ }^{13} \mathrm{CH}_{3}-\mathrm{S}-\mathrm{CoM}\right]}{\left[{ }^{12} \mathrm{CH}_{3}-\mathrm{S}-\mathrm{CoM}\right]}
$$

and

$$
{ }^{\mathrm{i}} \kappa_{\mathrm{j}}=\frac{{ }^{\mathrm{i}} \mathrm{k}_{\mathrm{j}}}{\text { unsubstituted } \mathrm{k}_{\mathrm{j}}} .
$$

'Unsubstituted' refers to an isotopologue without ${ }^{13} \mathrm{C}$ or D: i.e., ${ }^{12} \mathrm{CH}_{3}-\mathrm{S}-\mathrm{CoM}$ or ${ }^{12} \mathrm{CH}_{4}$. Substituting equations A2.7, A2.9 and A2.10 into A2.8 and assuming that there is no isotopic fractionation during the net removal of methane (i.e., ${ }^{13 \mathrm{CH} 4} \alpha_{\text {net }}=1$ ) gives

$$
{ }^{13} \mathrm{CH}_{4} \mathrm{R}={ }^{13} \mathrm{CH}_{3} \mathrm{R} x{ }^{13} \mathrm{CH}_{3} \kappa_{\mathrm{f}} \times\left(\frac{1}{1+\mathrm{r}\left({ }^{13} \mathrm{CH}_{4} \kappa_{\text {rev }}-1\right)}\right) .
$$

It is inconvenient to describe ${ }^{13 \mathrm{CH} 4} \mathrm{R}$ in terms of ${ }^{13 \mathrm{CH} 3} \mathrm{R}$ because ${ }^{13 \mathrm{CH} 3} \mathrm{R}$ is not a measureable quantity. This term can be eliminated because it is assumed that in the system, at all times, all 
metabolites from $\mathrm{CO}_{2}$ and $\mathrm{H}_{2}$ through $\mathrm{CH}_{3}-\mathrm{S}-\mathrm{CoM}$ are in isotopic equilibrium. Thus we can write the following isotope-exchange reaction:

$$
{ }^{13} \mathrm{CO}_{2}+{ }^{12} \mathrm{CH}_{3}-\mathrm{S}-\mathrm{CoM} \leftrightarrows{ }^{12} \mathrm{CO}_{2}+{ }^{13} \mathrm{CH}_{3}-\mathrm{S}-\mathrm{CoM}
$$

The equilibrium constant for this reaction is:

$$
\underset{{ }^{13} \mathrm{CO}_{2} \leftrightarrows{ }^{13} \mathrm{CH}_{3} \text {-S-CoM }}{\mathrm{C}_{\mathrm{Cq}}}=\frac{{ }^{13} \mathrm{CH}_{3} \mathrm{R}}{{ }^{13} \mathrm{CO}_{2} \mathrm{R}}
$$

where

$$
{ }^{13} \mathrm{CO}_{2} \mathrm{R}=\frac{\left[{ }^{13} \mathrm{CO}_{2}\right]}{\left[{ }^{12} \mathrm{CO}_{2}\right]}
$$

Substituting A2.13 into A2.11 yields:

$$
{ }^{13} \mathrm{CH}_{4} \mathrm{R}={ }^{13} \mathrm{CO}_{2} \mathrm{R} x \underset{{ }^{13} \mathrm{CO}_{2} \leftrightarrows{ }^{-13} \mathrm{CH}_{3} \mathrm{~S}-\mathrm{CoM}}{\mathrm{K}} \times{ }^{13} \mathrm{CH}_{3} \kappa_{\mathrm{f}} \mathrm{x}\left(\frac{1}{1+\mathrm{r}\left({ }^{13} \mathrm{CH}_{4} \kappa_{\text {rev }}-1\right)}\right) .
$$

We define a new term such that:

$$
{ }^{13} \mathrm{CH}_{3} \kappa_{\mathrm{f}}^{*}=\underset{{ }^{13} \mathrm{CO}_{2} \dashv{ }^{-13} \mathrm{CH}_{3} \text {-S-CoM }}{\mathrm{K}_{\mathrm{eq}}} \times{ }^{13} \mathrm{CH}_{3} \kappa_{\mathrm{f}} .
$$

${ }^{13 \mathrm{CH} 3} \mathrm{~K}_{\mathrm{f}}^{*}$ is thus not strictly a ratio of rate constants (as kinetic isotope effects are usually defined), but instead incorporates the equilibrium fractionation between $\mathrm{CO}_{2}$ and $\mathrm{CH}_{3}-\mathrm{S}-\mathrm{CoM}$ and the rate-limiting step of hydrogen addition to $\mathrm{CH}_{3}$-S-CoM. Such 'combined,' multi-step fractionation factors are commonly described in models of this sort as often only the product and reactants are measureable (Hayes, 2001). Regardless, substitution of A2.16 into A2.15 yields:

$$
{ }^{13} \mathrm{CH}_{4} \mathrm{R}={ }^{13} \mathrm{CO}_{2} \mathrm{R} \times{ }^{13} \mathrm{CH}_{3} \kappa_{\mathrm{f}}^{*} \times\left(\frac{1}{1+\mathrm{r}\left({ }^{13} \mathrm{CH}_{4} \kappa_{\mathrm{rev}}-1\right)}\right) .
$$

When $\mathrm{r}=1, \mathrm{CH}_{4}$ and $\mathrm{CO}_{2}$ are in isotopic equilibrium (by definition). And we have:

$$
\frac{{ }^{13} \mathrm{CH}_{4} \mathrm{R}_{\text {eq }}}{{ }^{13} \mathrm{CO}_{2} \mathrm{R}_{\text {eq }}}=\frac{{ }^{13} \mathrm{CH}_{3} \kappa_{\mathrm{f}}^{*}}{{ }^{13} \mathrm{CH}_{4} \kappa_{\text {rev }}},
$$

where 'eq' signifies a value at isotopic equilibrium. We can write the following isotopeexchange reaction as well:

$$
{ }^{13} \mathrm{CO}_{2}+{ }^{12} \mathrm{CH}_{4} \leftrightarrows{ }^{12} \mathrm{CO}_{2}+{ }^{13} \mathrm{CH}_{4}
$$

This reaction has the following equilibrium constant, 


$$
\underset{{ }^{13} \mathrm{CO}_{2} \mathrm{~K}^{-13} \mathrm{CH}_{4}}{{ }^{13} \mathrm{CH}_{4} \mathrm{R}_{\mathrm{eq}}}=\frac{{ }^{13} \mathrm{CO}_{2} \mathrm{R}_{\mathrm{eq}}}{} .
$$

1337

1338

1339

1340

Combination of (A2.20) with (A2.18) yields:

$$
\underset{{ }^{13} \mathrm{CO}_{2} \longleftarrow{ }^{-13} \mathrm{CH}_{4}}{{ }^{13} \mathrm{CH}_{3} \kappa_{\mathrm{f}}^{*}}=\frac{{ }^{13} \mathrm{CH}_{4} \kappa_{\mathrm{rev}}}{} .
$$

1341

1342 This equilibrium constant is calculable using the theory of, for example, Richet et al. (1977). 1343 Thus, equation A2.21 removes a degree of freedom from equation A2.17. 
A3: ${ }^{12} \mathrm{CH}_{3} \mathrm{D}$ derivation.

1345 The set of equations that describe the dependence of the ${ }^{12} \mathrm{CH}_{3} \mathrm{D} /{ }^{12} \mathrm{CH}_{4}$ ratio on the degree of reversibility of equation A1.2 is derived in this section. The derivations, although similar to section A2, have a fundamental difference related to the fact that ${ }^{12} \mathrm{CH}_{3} \mathrm{D}$ can be made two different ways:

$$
{ }^{12} \mathrm{CH}_{3}-\mathrm{S}-\mathrm{CoM}+\mathrm{D} \underset{{ }^{12+\mathrm{D}} \mathrm{k}_{\mathrm{f}}}{\stackrel{12-\mathrm{D}}{\leftrightarrows} \mathrm{k}_{\mathrm{rev}}}{ }^{12} \mathrm{CH}_{3} \mathrm{D} \stackrel{12 \mathrm{CH} 3 \mathrm{D}}{\rightarrow} \mathrm{k}_{\text {net }}
$$

and

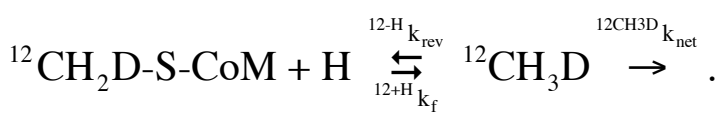

1355

1356

1357

1358

1359

Following section $\mathrm{A} 2$, we can write the steady state concentration of ${ }^{12} \mathrm{CH}_{3} \mathrm{D}$ as

$$
\left[{ }^{12} \mathrm{CH}_{3} \mathrm{D}\right]=\frac{{ }^{12+\mathrm{H}} \mathrm{k}_{\mathrm{f}}\left[{ }^{12} \mathrm{CH}_{2} \mathrm{D}-\mathrm{S}-\mathrm{CoM}\right][\mathrm{H}]+{ }^{12+\mathrm{D}} \mathrm{k}_{\mathrm{f}}\left[{ }^{12} \mathrm{CH}_{3}-\mathrm{S}-\mathrm{CoM}\right][\mathrm{D}]}{{ }^{12-\mathrm{H}} \mathrm{k}_{\mathrm{rev}}+{ }^{12-\mathrm{D}} \mathrm{k}_{\mathrm{rev}}+{ }^{12} \mathrm{CH}_{3} \mathrm{D} \mathrm{k}_{\text {net }}} .
$$

Division of A3.3 by A2.4 yields:

$$
\frac{\left[{ }^{12} \mathrm{CH}_{3} \mathrm{D}\right]}{\left[{ }^{12} \mathrm{CH}_{4}\right]}=\left(\frac{{ }^{12+\mathrm{H}} \mathrm{k}_{\mathrm{f}}\left[{ }^{12} \mathrm{CH}_{2} \mathrm{D}-\mathrm{S}-\mathrm{CoM}\right][\mathrm{H}]+{ }^{12+\mathrm{D}} \mathrm{k}_{\mathrm{f}}\left[{ }^{12} \mathrm{CH}_{3}-\mathrm{S}-\mathrm{CoM}\right][\mathrm{D}]}{{ }^{12} \mathrm{CH}_{3} \mathrm{k}_{\mathrm{f}}\left[{ }^{12} \mathrm{CH}_{3}-\mathrm{S}-\mathrm{CoM}\right][\mathrm{H}]}\right) \times\left(\frac{{ }^{12} \mathrm{CH}_{4} \mathrm{k}_{\mathrm{rev}}+{ }^{12} \mathrm{CH}_{4} \mathrm{k}_{\text {net }}}{{ }^{12-\mathrm{H}} \mathrm{k}_{\text {rev }}+{ }^{12-\mathrm{D}} \mathrm{k}_{\text {rev }}+{ }^{12} \mathrm{CH}_{3} \mathrm{D} \mathrm{k}_{\text {net }}}\right)
$$

We define the following ratios:

$$
{ }^{12} \mathrm{CH}_{3} \mathrm{D} \mathrm{R}=\frac{\left[{ }^{12} \mathrm{CH}_{3} \mathrm{D}\right]}{\left[{ }^{12} \mathrm{CH}_{4}\right]} ;{ }^{12} \mathrm{CH}_{2} \mathrm{D} \mathrm{R}=\frac{\left[{ }^{12} \mathrm{CH}_{2} \mathrm{D}-\mathrm{S}-\mathrm{CoM}\right]}{\left[{ }^{12} \mathrm{CH}_{3}-\mathrm{S}-\mathrm{CoM}\right]} ; \text { and }{ }^{\mathrm{D}} \mathrm{R}=\frac{[\mathrm{D}]}{[\mathrm{H}]}(\mathrm{A} 3.5 \mathrm{a}, \mathrm{b}, \text { and } \mathrm{c})
$$

Substituting A3.5a, b and c into A3.4 and utilization of the algebra and simplifications introduced in section $\mathrm{A} 2$ yields:

$$
{ }^{12} \mathrm{CH}_{3} \mathrm{D} \mathrm{R}=\left(\frac{{ }^{12+\mathrm{D}} \kappa_{\mathrm{f}} \times{ }^{\mathrm{D}} \mathrm{R}+{ }^{12+\mathrm{H}} \kappa_{\mathrm{f}} \times{ }^{12} \mathrm{CH}_{2} \mathrm{D} \mathrm{R}}{1+\mathrm{r}\left({ }^{12-\mathrm{D}} \kappa_{\text {rev }}+{ }^{12-\mathrm{H}} \kappa_{\text {rev }}-1\right)}\right) .
$$

At metabolic equilibrium, the following isotope-exchange reaction is in isotopic equilibrium:

$$
{ }^{12} \mathrm{CH}_{3}-\mathrm{S}-\mathrm{CoM}+\mathrm{D} \leftrightarrows{ }^{12} \mathrm{CH}_{2} \mathrm{D}-\mathrm{S}-\mathrm{CoM}+\mathrm{H}
$$

The equilibrium constant for this reaction is: 


$$
\underset{\mathrm{D} \leftrightarrows{ }^{12} \mathrm{CH}_{2} \mathrm{D}-\mathrm{S}-\mathrm{CoM}}{\mathrm{K}_{\mathrm{Cq}}}=\frac{{ }^{12} \mathrm{CH}_{2} \mathrm{D} \mathrm{R}}{{ }^{\mathrm{D}} \mathrm{R}} .
$$

Substituting A3.8 into A3.6 gives

1387

1388

1389

1390

1391

1392

1393

1394

1395

1396

1397

1398

1399

1400

1401

1402

1403

1404

1405

1406

1407

1408

1409

1410

1411

1412

1413

1414

1415

1416

1417

1418

1419

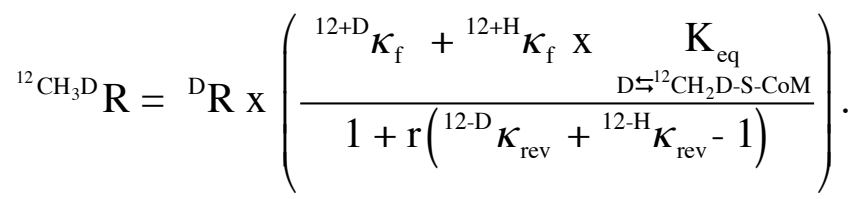

The fact that there are two pathways for making ${ }^{12} \mathrm{CH}_{3} \mathrm{D}$ may have implications for understanding what controls the $\delta \mathrm{D}$ value of methane as well as its clumped isotopic composition. This is because these two paths could have very different isotope effects as one is a primary isotope effect, the addition of $\mathrm{D}$, and the other is a secondary effect, the addition of $\mathrm{H}$ to an already deuterium-containing molecule. This could, perhaps, be recast as a mixing problem instead of a kinetic problem in which two distinct pools of ${ }^{12} \mathrm{CH}_{3} \mathrm{D}$ (or $\left.{ }^{13} \mathrm{CH}_{3} \mathrm{D}\right)$ are created at different rates and with different isotope effects. However, as there are few constraints on the sizes of these isotope effects (Scheller et al., 2013), we will simplify the problem by combing them into a single, amalgamated isotope effect:

$$
{ }^{12} \mathrm{CH}_{3} \mathrm{D} \kappa_{\mathrm{f}}^{*}={ }^{12+\mathrm{D}} \kappa_{\mathrm{f}}+{ }^{12+\mathrm{H}} \kappa_{\mathrm{f}} \mathrm{X} \underset{\mathrm{D}^{\mathrm{D}}{ }^{12} \mathrm{CH}_{2} \mathrm{D}-\mathrm{S}-\mathrm{CoM}}{\mathrm{K}_{\mathrm{eq}}}
$$

and

$$
{ }^{12} \mathrm{CH}_{3} \mathrm{D} \kappa_{\text {rev }}^{*}={ }^{12-\mathrm{D}} \kappa_{\text {rev }}+{ }^{12-\mathrm{H}} \kappa_{\text {rev }} .
$$

This yields the following simplified equation:

$$
{ }^{12} \mathrm{CH}_{3} \mathrm{D} \mathrm{R}={ }^{\mathrm{D}} \mathrm{R} x\left(\frac{{ }^{12} \mathrm{CH}_{3} \mathrm{D}}{\kappa_{\mathrm{f}}^{*}}\right) .
$$

This greatly simplifies the equation, but it is critical to note that this form of the equation

masks the true and interesting complexity of the reactions taking place. At equilibrium, $r=1$, and

$$
{ }^{12} \mathrm{CH}_{3} \mathrm{D} \mathrm{R}_{\text {eq }}={ }^{\mathrm{D}} \mathrm{R}_{\text {eq }} \times \frac{{ }^{12} \mathrm{CH}_{3} \mathrm{D} \kappa_{\mathrm{f}}^{*}}{{ }^{12} \mathrm{CH}_{3} \mathrm{D} \kappa_{\mathrm{rev}}^{*}} .
$$

Additionally at equilibrium, following section A2, we can write the following isotopeexchange reaction:

$$
{ }^{12} \mathrm{CH}_{4}+\mathrm{D} \leftrightarrows{ }^{12} \mathrm{CH}_{3} \mathrm{D}+\mathrm{H}
$$

The equilibrium constant for this reaction is 


$$
\frac{{ }^{12} \mathrm{CH}_{3} \mathrm{D} \mathrm{R}_{\mathrm{eq}}}{{ }^{\mathrm{D}} \mathrm{R}_{\mathrm{eq}}}=\frac{{ }^{12} \mathrm{CH}_{3} \mathrm{D}}{\kappa_{\mathrm{f}}^{*}}=\underset{{ }^{12} \mathrm{CH}_{3} \mathrm{D}}{\kappa_{\mathrm{rev}}^{*}}=\underset{\mathrm{D} \leftrightarrows{ }^{12} \mathrm{CH}_{3} \mathrm{D}}{\mathrm{K}_{2}} .
$$

1422 Problematically, ${ }^{\mathrm{D}} \mathrm{R}$ is not measureable. We will presume, for simplicity, as discussed above, 1423 that the hydrogen and deuterium pool accessible to methane and methane precursors is in rapid equilibrium with the hydrogen and deuterium in water and that there is a constant offset between ${ }^{\mathrm{D}} \mathrm{R}$ and ${ }^{\mathrm{D}} \mathrm{R}_{\mathrm{H} 2 \mathrm{O} \text {,liquid }}$ (the $\mathrm{D} / \mathrm{H}$ ratio of liquid $\mathrm{H}_{2} \mathrm{O}$ ). For simplicity, we will assume that they are equal. Any actual offset in this will be absorbed in ${ }^{12 \mathrm{CH} 3 \mathrm{D}} \kappa_{\mathrm{f}}{ }^{*}$, and thus mathematically is unimportant. However, if the actual kinetic isotope effects of each individual step for methanogenesis are known, then using the exact value of the $\mathrm{D} / \mathrm{H}$ ratio of the hydrogen donor to the methane precursor will be important. Regardless, for the derivation here, we assume,

$$
{ }^{\mathrm{D}} \mathrm{R}=\frac{[\mathrm{D}]_{\mathrm{H} 2 \mathrm{O}}}{[\mathrm{H}]_{\mathrm{H} 2 \mathrm{O}}}={ }^{\mathrm{H}_{2} \mathrm{O}} \mathrm{R}
$$

Inserting A3.15 into A3.14 yields:

$$
\frac{{ }^{12} \mathrm{CH}_{3} \mathrm{D} \mathrm{R}_{\mathrm{eq}}}{{ }^{\mathrm{H}_{2} \mathrm{O}} \mathrm{R}_{\mathrm{eq}}}=\frac{{ }^{12} \mathrm{CH}_{3} \mathrm{D} \kappa_{\mathrm{f}}^{*}}{{ }^{12} \mathrm{CH}_{3} \mathrm{D} \kappa_{\mathrm{rev}}^{*}} .
$$

1437 The ratio of $\frac{{ }^{12} \mathrm{CH}_{3} \mathrm{D} \mathrm{R}_{\mathrm{eq}}}{{ }_{\mathrm{H}_{2} \mathrm{O}} \mathrm{R}_{\mathrm{eq}}}$ is a calculable function of temperature (Richet et al., 1977; Horibe and 1438 Craig, 1995) and thus removes a degree of freedom from the model. 
1451

1452

1453

1454

1455

1456

1457

1458

1459

Section A4: ${ }^{13} \mathrm{CH}_{3} \mathrm{D}$.

This section derives the ${ }^{13} \mathrm{CH}_{3} \mathrm{D} /{ }^{12} \mathrm{CH}_{4}$ ratio as a function of the degree of reversibility of equation $\mathrm{A} 1$.2. Following sections $\mathrm{A} 2$ and $\mathrm{A} 3$, with similar symbology and assumptions, the following equation is found:

$$
{ }^{13} \mathrm{CH}_{3} \mathrm{D} \mathrm{R}=\left(\frac{{ }^{13+\mathrm{D}} \kappa_{\mathrm{f}} \times{ }^{\mathrm{D}} \mathrm{R} \mathrm{x}{ }^{13} \mathrm{CH}_{3} \mathrm{R}+{ }^{13+\mathrm{H}} \kappa_{\mathrm{f}} \times{ }^{13} \mathrm{CH}_{2} \mathrm{D} \mathrm{R}}{1+\mathrm{r}\left({ }^{13-\mathrm{D}} \kappa_{\mathrm{rev}}+{ }^{13-\mathrm{H}} \kappa_{\text {rev }}-1\right)}\right) .
$$

where

$$
{ }^{{ }^{13} \mathrm{CH}_{3} \mathrm{D} \mathrm{D}}=\frac{\left[{ }^{13} \mathrm{CH}_{3} \mathrm{D}\right]}{\left[{ }^{12} \mathrm{CH}_{4}\right]} \text { and }{ }^{1{ }^{13} \mathrm{C}_{2} \mathrm{D}} \mathrm{R}=\frac{\left[{ }^{13} \mathrm{CH}_{2} \mathrm{D}-\mathrm{S}-\mathrm{CoM}\right]}{\left[{ }^{12} \mathrm{CH}_{3}-\mathrm{S}-\mathrm{CoM}\right]} \text {. }
$$

Using the constraints from metabolic equilibrium, the following isotope-exchange reaction can be written:

$$
{ }^{13} \mathrm{CH}_{3}-\mathrm{S}-\mathrm{CoM}+\mathrm{D} \leftrightarrows{ }^{13} \mathrm{CH}_{2} \mathrm{D}-\mathrm{S}-\mathrm{CoM}+\mathrm{H}
$$

such that:

$$
\frac{\frac{{ }^{13} \mathrm{CH}_{2} \mathrm{D}-\mathrm{S}-\mathrm{CoM}}{{ }^{13} \mathrm{CH}_{3}-\mathrm{S}-\mathrm{CoM}}}{{ }^{\mathrm{D}} \mathrm{R}}=\underset{{ }^{13} \mathrm{CH}_{3}-\mathrm{S}-\mathrm{CoM}=5^{3} \mathrm{CH}_{2} \mathrm{D}-\mathrm{S}-\mathrm{CoM}}{\mathrm{K}_{\mathrm{eq}}} .
$$

Incorporating A4.4 and A2.13 into A4.1 yields,

As in section 3, we define the following 'combined' fractionation factors:

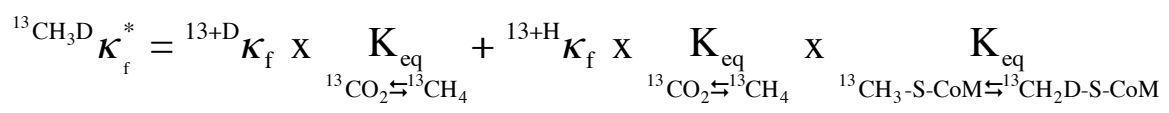

and

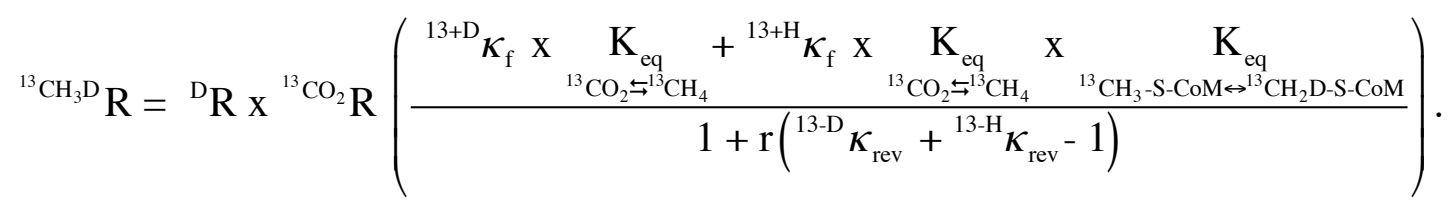

$$
{ }^{13} \mathrm{CH}_{3} \mathrm{D} \kappa_{\text {rev }}^{*}={ }^{13-\mathrm{D}} \kappa_{\text {rev }}+{ }^{13-\mathrm{H}} \kappa_{\text {rev }} .
$$

Substituting A4.6 into A4.5 gives 


$$
{ }^{13} \mathrm{CH}_{3} \mathrm{D} \mathrm{R}={ }^{\mathrm{D}} \mathrm{R} x{ }^{13} \mathrm{CO}_{2} \mathrm{R}\left(\frac{{ }^{13} \mathrm{CH}_{3} \mathrm{D} \kappa_{\mathrm{f}}^{*}}{1+\mathrm{r}\left({ }^{13} \mathrm{CH}_{3} \mathrm{D} \kappa_{\mathrm{rev}}^{*}-1\right)}\right) .
$$

1478

1479

1480

1481

1482

1483

1484

1485

1486

1487

1488

1489

1490

1491

1492

1493
At $r=1$, the following homogenous-phase equilibrium reaction occurs:

$$
{ }^{12} \mathrm{CH}_{3} \mathrm{D}+{ }^{13} \mathrm{CH}_{4} \leftrightarrows{ }^{12} \mathrm{CH}_{4}+{ }^{13} \mathrm{CH}_{3} \mathrm{D}
$$

The equilibrium constant for A4.8 is

$$
\underset{{ }^{13} \mathrm{CH}_{3} \mathrm{D}}{\mathrm{D}}=\frac{\left[{ }^{12} \mathrm{CH}_{4}\right]_{\mathrm{eq}}\left[{ }^{13} \mathrm{CH}_{3} \mathrm{D}\right]_{\mathrm{eq}}}{\left[{ }^{12} \mathrm{CH}_{3} \mathrm{D}\right]_{\mathrm{eq}}\left[{ }^{13} \mathrm{CH}_{4}\right]_{\mathrm{eq}}},
$$

which is a known function of temperature (Bottinga, 1969; Ma et al., 2008; Cao and Liu, 2012; Stolper et al., 2014a; Webb and Miller III, 2014; Ono et al., 2014a). Following some algebraic manipulations, we can write:

$$
\underset{{ }^{13} \mathrm{CH}_{3} \mathrm{D}}{\mathrm{K}_{\mathrm{eq}}} \times\left(\frac{{ }^{13} \mathrm{CH}_{3} \kappa_{\mathrm{f}}^{*}}{{ }^{13} \mathrm{CH}_{4} \kappa_{\text {rev }}}\right) \times\left(\frac{{ }^{12} \mathrm{CH}_{3} \mathrm{D} \kappa_{\mathrm{f}}^{*}}{{ }^{12} \mathrm{CH}_{3} \mathrm{D} \kappa_{\text {rev }}^{*}}\right)=\frac{{ }^{13} \mathrm{CH}_{3} \mathrm{D} \kappa_{\mathrm{f}}^{*}}{{ }^{13} \mathrm{CH}_{3} \mathrm{D} \kappa_{\text {rev }}^{*}},
$$

which removes a degree of freedom from the model. 
Section 5: ${ }^{12} \mathrm{CH}_{2} \mathrm{D}_{2}$.

This section derives the ${ }^{12} \mathrm{CH}_{2} \mathrm{D}_{2}{ }^{12} \mathrm{CH}_{4}$ ratio as a function of the degree of reversibility of equation $\mathrm{A} 1$.2. Following sections $\mathrm{A} 2, \mathrm{~A} 3$ and $\mathrm{A} 4$, with similar symbology and assumptions, the following equation is found:

$$
{ }^{12} \mathrm{CH}_{2} \mathrm{D}_{2} \mathrm{R}=\left(\frac{{ }^{\mathrm{H}_{2} \mathrm{D}+\mathrm{D}} \kappa_{\mathrm{f}} \times{ }^{\mathrm{D}} \mathrm{R} \mathrm{x}{ }^{12} \mathrm{CH}_{2} \mathrm{D} \mathrm{R}+{ }^{\mathrm{HD}_{2}+\mathrm{H}} \kappa_{\mathrm{f}} \times{ }^{12} \mathrm{CHD}_{2} \mathrm{R}}{1+\mathrm{r}\left({ }^{\mathrm{H}_{2} \mathrm{D}_{2}-\mathrm{D}} \kappa_{\text {rev }}+{ }^{\mathrm{H}_{2} \mathrm{D}_{2}-\mathrm{H}} \kappa_{\text {rev }}-1\right)}\right)
$$

where,

$$
{ }^{12} \mathrm{CHD}_{2} \mathrm{R}=\frac{\left[{ }^{12} \mathrm{CHD}_{2}-\mathrm{S}-\mathrm{CoM}\right]}{\left[{ }^{12} \mathrm{CH}_{3}-\mathrm{S}-\mathrm{CoM}\right]} .
$$

Using constraints from metabolic equilibrium, we write

$$
{ }^{12} \mathrm{CH}_{2} \mathrm{D}-\mathrm{S}-\mathrm{CoM}+\mathrm{D} \leftrightarrows{ }^{12} \mathrm{CHD}_{2}-\mathrm{S}-\mathrm{CoM}+\mathrm{H}
$$

with the following equilibrium constant:

$$
\frac{\frac{{ }^{12} \mathrm{CHD}_{2}-\mathrm{S}-\mathrm{CoM}}{{ }^{12} \mathrm{CH}_{2} \mathrm{D}-\mathrm{S}-\mathrm{CoM}}}{{ }^{\mathrm{D}} \mathrm{R}}=\underset{{ }^{12} \mathrm{CH}_{2} \mathrm{D}-\mathrm{S}-\mathrm{CoM}^{-12} \mathrm{CHD}_{2}-\mathrm{S}-\mathrm{CoM}}{\mathrm{K}_{\mathrm{eq}}} .
$$

Combination of (A5.4) with (A3.8) yields

$$
{ }^{12} \mathrm{CHD}_{2} \mathrm{R}=\left({ }^{\mathrm{D}} \mathrm{R}\right)^{2} \times \underset{{ }^{12} \mathrm{CH}_{2} \mathrm{D}-\mathrm{S}-\mathrm{CoM}^{-12} \mathrm{CHD}_{2}-\mathrm{S}-\mathrm{CoM}}{\mathrm{K}_{\mathrm{eq}}} \mathrm{X} \underset{\mathrm{D}^{5}{ }^{12} \mathrm{CH}_{2} \mathrm{D}-\mathrm{S}-\mathrm{CoM}}{\mathrm{K}_{\text {eq }}} .
$$

Combining (A5.5) and (A3.8) with (A5.1) yields

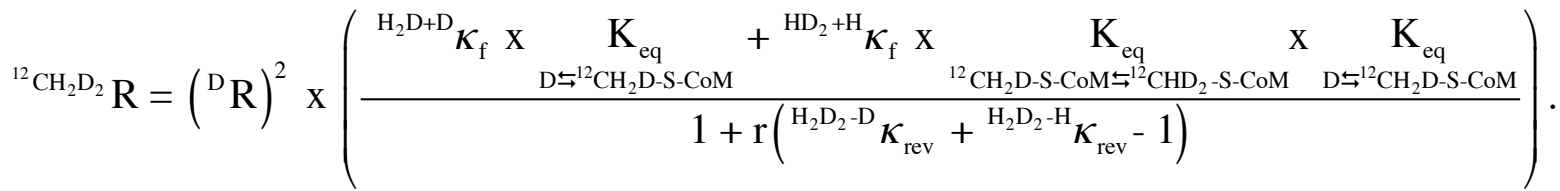

Rewriting with the following 'combined' fractionation factors:

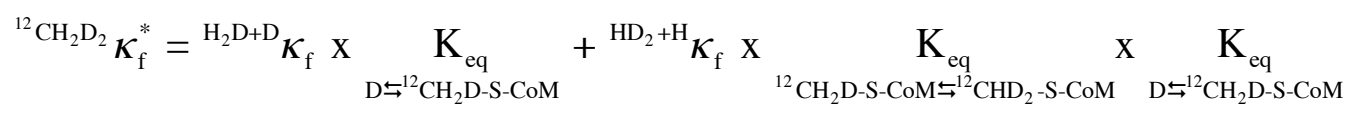

and

$$
{ }^{12} \mathrm{CH}_{2} \mathrm{D}_{2} \kappa_{\text {rev }}^{*}={ }^{\mathrm{H}_{2} \mathrm{D}_{2}-\mathrm{D}} \kappa_{\text {rev }}+{ }^{\mathrm{H}_{2} \mathrm{D}_{2}-\mathrm{H}} \kappa_{\text {rev }},
$$


1530 this equation becomes

1531

$$
{ }^{12} \mathrm{CH}_{2} \mathrm{D}_{2} \mathrm{R}=\left({ }^{\mathrm{D}} \mathrm{R}\right)^{2} \times\left(\frac{{ }^{12} \mathrm{CH}_{2} \mathrm{D}_{2} \kappa_{\mathrm{f}}^{*}}{1+\mathrm{r}\left({ }^{12} \mathrm{CH}_{2} \mathrm{D}_{2} \kappa_{\mathrm{rev}}^{*}-1\right)}\right) .
$$

1533

1534

1535

1536

1537

1538

1539

1540

At $r=1$, the following equilibrium reaction occurs:

$$
{ }^{12} \mathrm{CH}_{3} \mathrm{D}+{ }^{12} \mathrm{CH}_{3} \mathrm{D} \leftrightarrows{ }^{12} \mathrm{CH}_{4}+{ }^{12} \mathrm{CH}_{2} \mathrm{D}_{2},
$$

with the equilibrium constant

$$
\underset{{ }^{12} \mathrm{CH}_{2} \mathrm{D}_{2}}{\mathrm{~K}_{\mathrm{eq}}}=\frac{\left[{ }^{12} \mathrm{CH}_{4}\right]_{\mathrm{eq}}\left[{ }^{12} \mathrm{CH}_{2} \mathrm{D}_{2}\right]_{\mathrm{eq}}}{\left[{ }^{12} \mathrm{CH}_{3} \mathrm{D}\right]_{\mathrm{eq}}^{2}},
$$

1541

1542

1543

1544

1545

1546

1547

which, as discussed in section A4, is a function of temperature and thus removes a degree of freedom from the model.

With some algebraic manipulation, this can be rewritten for convenience as

1548

$$
\underset{{ }^{12} \mathrm{CH}_{2} \mathrm{D}_{2}}{\mathrm{~K}_{\mathrm{eq}}} \mathrm{X}\left(\frac{{ }^{12} \mathrm{CH}_{3} \mathrm{D} \kappa_{\mathrm{f}}^{*}}{{ }^{12} \mathrm{CH}_{3} \mathrm{D} \kappa_{\mathrm{rev}}^{*}}\right)^{2}=\frac{{ }^{12} \mathrm{CH}_{2} \mathrm{D}_{2} \kappa_{\mathrm{f}}^{*}}{{ }^{12} \mathrm{CH}_{2} \mathrm{D}_{2} \kappa_{\mathrm{rev}}^{*}} .
$$




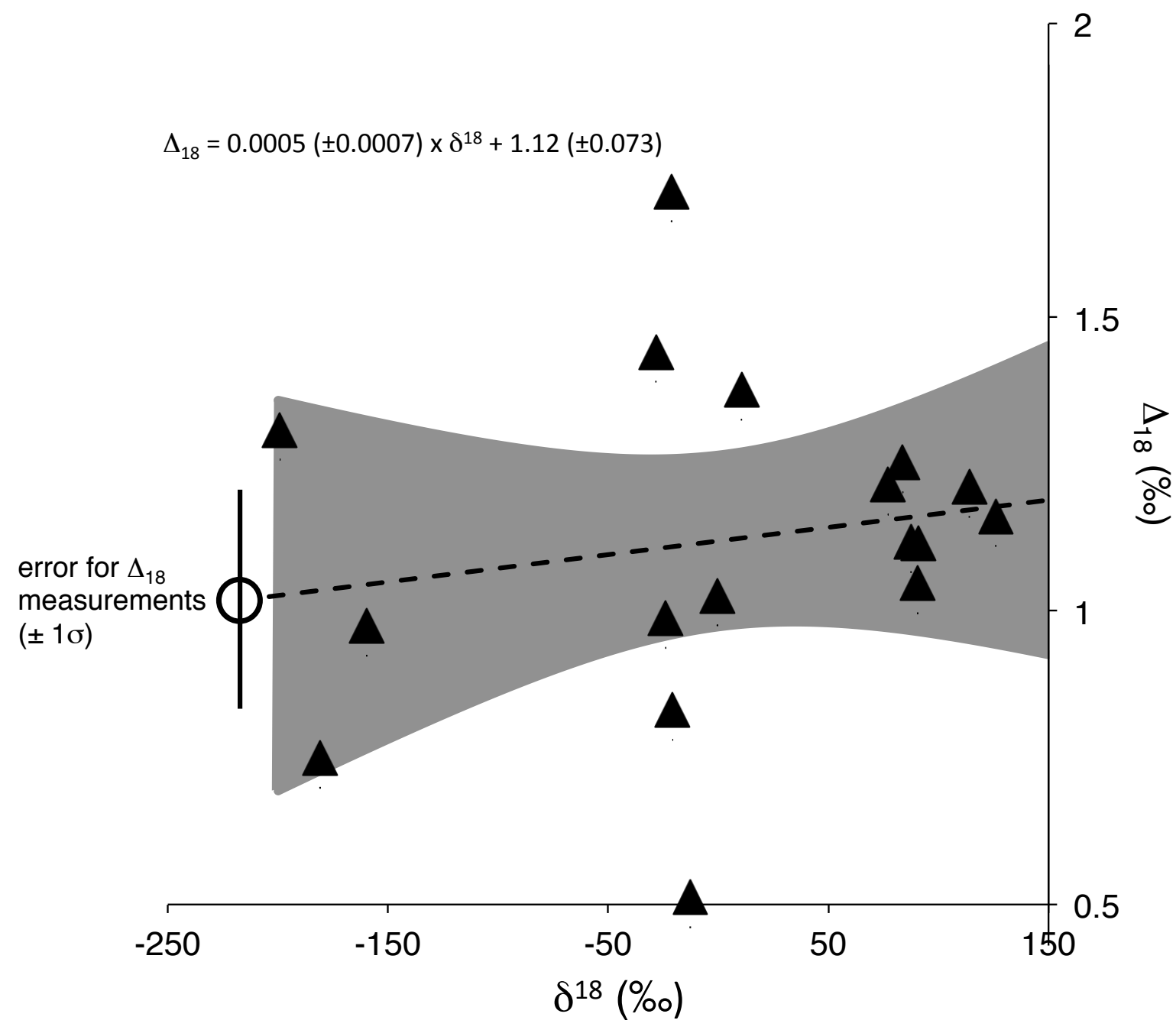

Figure A1: Comparison of measured $\Delta_{18}$ values vs. the average isotopic composition (tracked via $\delta^{18}$ values) for gases equilibrated at $500{ }^{\circ} \mathrm{C}$ in the lab using nickel catalysts as described in Stolper et al. (2014c). The $\delta^{18}$ values are dominantly controlled by variations in the $\delta \mathrm{D}$ value of the gas. No statistically significant dependence for $\Delta_{18}$ on $\delta^{18}$ is observed: the slope is $0.0005 \%$ and the $1 \sigma$ error of the slope is $0.0007 \%$. Additionally the intercept of the line, $1.12 \% \circ( \pm 0.073,1 \sigma)$, is points is $0.28 \%$, similar to the internal precision of each individual measurement $(\sim 0.25 \%$ ) . 

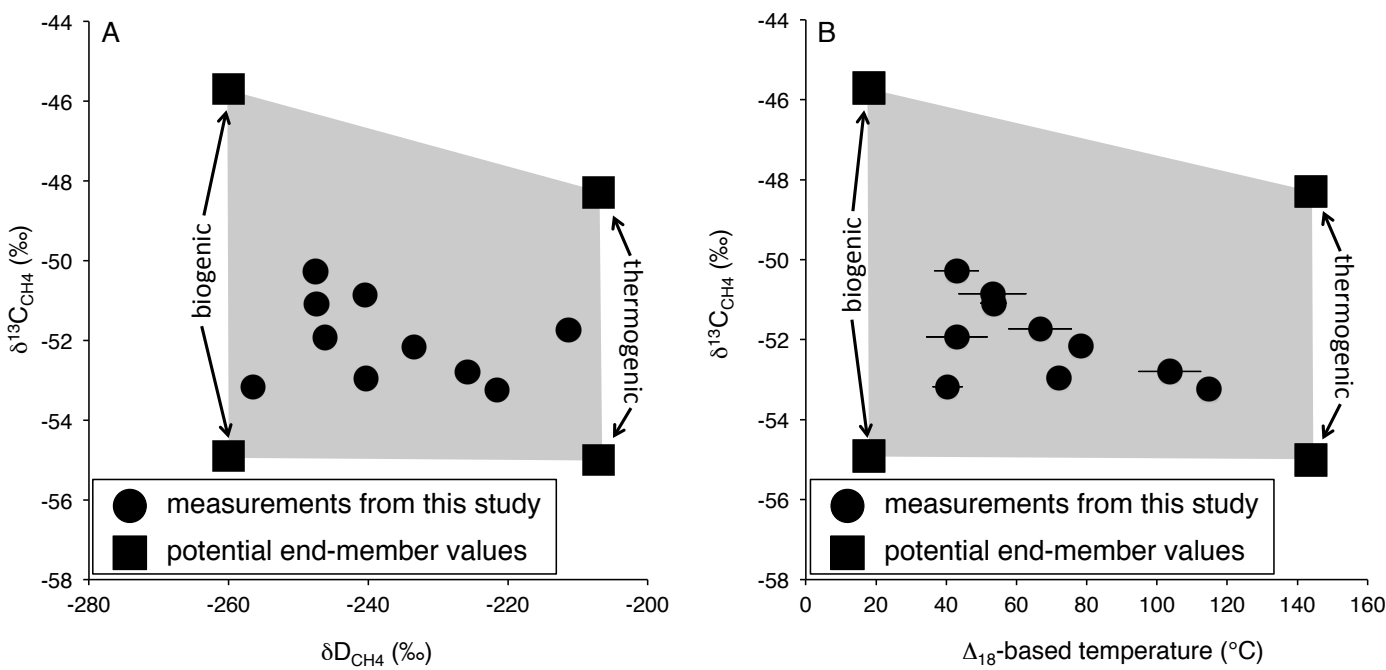

Figure A2: Comparison of potential $\delta^{13} \mathrm{C}_{\mathrm{CH} 4}$ values for the biogenic and thermogenic end members for the mixing model discussed in the main text for A) $\delta^{13} \mathrm{C}_{\mathrm{CH} 4}$ vs. $\delta D_{\mathrm{CH} 4}$ and B) $\delta^{13} \mathrm{C}_{\mathrm{CH} 4}$ vs. $\Delta_{18}$-based temperature. The range of biogenic end members were taken from the maximum and minimum $\delta^{13} \mathrm{C}_{\mathrm{CH} 4}$ values for gases from the northern margin of the Antrim shale with $C_{1} / C_{2-4}>500$. The maximum and minimum values are found in Martini et al. (1998). The thermogenic values were found by taking the maximum and minimum range of $\delta^{13} \mathrm{C}_{\mathrm{CH} 4}$ values for gases from the Antrim Shale with $\mathrm{C}_{1} / \mathrm{C}_{2-4}<$ 100, including those outside of the northern margin (Martini et al., 1998; Martini et al., 2003). Because the overall potential range of $\delta^{13} \mathrm{C}_{\mathrm{CH} 4}$ values is far larger than total range of $\delta^{13} \mathrm{C}_{\mathrm{CH} 4}$ values observed in this study (3\%), the leverage that the $\delta^{13} \mathrm{C}_{\mathrm{CH} 4}$ values provide for validating the model is low. 


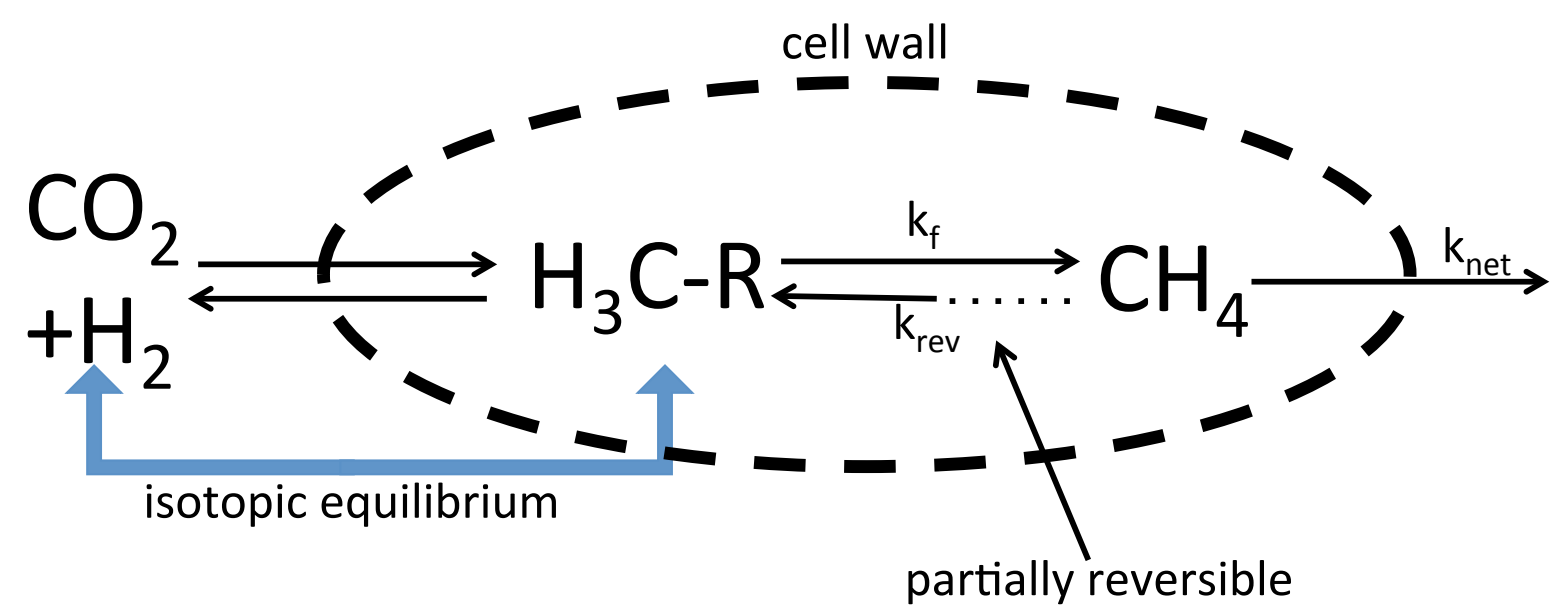

Figure A3: Cartoon of the isotopically enabled model of methane formation described in the main text and appendix. The dotted lines mark the boundary between the methanogen cell and extracellular water. In this model, $\mathrm{CO}_{2}$ and $\mathrm{H}_{2}$ are assumed to always be in isotopic equilibrium with a methyl group bound to coenzyme $M$ (here symbolized with the ' $R$ ') following the differential reversibility hypothesis of Valentine et al., (2004). Additionally, the $\mathrm{H}_{2}$ and hydrogen in the methyl group bound to coenzyme $\mathrm{M}$ are assumed to be in isotopic equilibrium with the intracellular $\mathrm{H}_{2} \mathrm{O}$. In the model, the reversibility of methyl-coenzyme $\mathrm{M}$ reductase (the relative rates of the steps symbolized by $\mathrm{k}_{\text {rev }} \mathrm{vs}_{\mathrm{f}} \mathrm{k}_{\mathrm{f}}$ ) is varied as discussed in the appendix. 
Apotria, T., Kaiser, C., 1994. Fracturing and stress history of the Devonian Antrim Shale, Michigan Basin, in: Nelson, P., Lauback, S. (Eds.), Rock Mechanics, pp. 809-816.

Balabane, M., Galimov, E., Hermann, M., Letolle, R., 1987. Hydrogen and carbon isotope fractionation during experimental production of bacterial methane. Organic Geochemistry 11, 115-119.

Bernard, B.B., Brooks, J.M., Sackett, W.M., 1976. Natural gas seepage in the Gulf of Mexico. Earth and Planetary Science Letters 31, 48-54.

Bigeleisen, J., Wolfsberg, M., 1958. Theoretical and experimental aspects of isotope effects in chemical kinetics. Advances in Chemical Physics, 15-76.

Bilek, R., Tyler, S., Kurihara, M., Yagi, K., 2001. Investigation of cattle methane production and emission over a 24 - hour period using measurements of $\delta{ }^{13} \mathrm{C}$ and $\delta \mathrm{D}$ of emitted $\mathrm{CH}_{4}$ and rumen water. Journal of Geophysical Research: Atmospheres (1984-2012) 106, 15405-15413.

Blair, N., 1998. The $\delta^{13} \mathrm{C}$ of biogenic methane in marine sediments: the influence of $\mathrm{C}$ org deposition rate. Chemical Geology 152, 139-150.

Boone, D.R., Johnson, R.L., Liu, Y., 1989. Diffusion of the interspecies electron carriers $\mathrm{H}_{2}$ and formate in methanogenic ecosystems and its implications in the measurement of $\mathrm{K}_{\mathrm{m}}$ for $\mathrm{H}_{2}$ or formate uptake. Applied and Environmental Microbiology 55, 1735-1741.

Bottinga, Y., 1969. Calculated fractionation factors for carbon and hydrogen isotope exchange in the system calcite-carbon dioxide-graphite-methane-hydrogen-water vapor. Geochimica et Cosmochimica Acta 33, 49-64.

Botz, R., Pokojski, H.-D., Schmitt, M., Thomm, M., 1996. Carbon isotope fractionation during bacterial methanogenesis by $\mathrm{CO}_{2}$ reduction. Organic Geochemistry 25, 255-262.

Bradley, A., Leavitt, W., Johnston, D., 2011. Revisiting the dissimilatory sulfate reduction pathway. Geobiology 9, 446-457.

Brunner, B., Bernasconi, S.M., 2005. A revised isotope fractionation model for dissimilatory sulfate reduction in sulfate reducing bacteria. Geochimica et Cosmochimica Acta 69, 4759-4771.

Brunner, B., Bernasconi, S.M., Kleikemper, J., Schroth, M.H., 2005. A model for oxygen and sulfur isotope fractionation in sulfate during bacterial sulfate reduction processes. Geochimica et Cosmochimica Acta 69, 4773-4785.

Burke Jr, R.A., 1993. Possible influence of hydrogen concentration on microbial methane stable hydrogen isotopic composition. Chemosphere 26, 55-67.

Cao, X., Liu, Y., 2012. Theoretical estimation of the equilibrium distribution of clumped isotopes in nature. Geochimica et Cosmochimica Acta 77, 292-303.

Cercone, K., Pollack, H., 1991. Thermal maturity of the Michigan Basin. Geological Society of America Special Papers 256, 1-12.

Chung, H., Gormly, J., Squires, R., 1988. Origin of gaseous hydrocarbons in subsurface environments: Theoretical considerations of carbon isotope distribution. Chemical Geology 71, 97-104.

Claypool, G.E., Kaplan, I., 1974. The origin and distribution of methane in marine sediments, Natural gases in marine sediments. Springer, pp. 99-139.

Clog, M., Martini, A., Lawson, M., Eiler, J., 2014. Doubly ${ }^{13} \mathrm{C}$-substituted ethane in shale gases, Goldschmidt Conference. Mineralogical Conference, Sacremento, CA, p. 435.

Conrad, R., 2005. Quantification of methanogenic pathways using stable carbon isotopic signatures: a review and a proposal. Organic Geochemistry 36, 739-752.

Criss, R.E., 1999. Principles of Stable Isotope Distribution. Oxford University Press New York.

Curtis, J.B., 2002. Fractured shale-gas systems. AAPG bulletin 86, 1921-1938.

Daniels, L., Fulton, G., Spencer, R., Orme-Johnson, W., 1980. Origin of hydrogen in methane produced by Methanobacterium thermoautotrophicum. Journal of Bacteriology 141, 694-698.

Duffy, M., Kinnaman, F.S., Valentine, D.L., Keller, E.A., Clark, J.F., 2007. Gaseous emission rates from natural petroleum seeps in the Upper Ojai Valley, California. Environmental Geosciences 14, 197-207.

Edwards, K.J., Becker, K., Colwell, F., 2012. The deep, dark energy biosphere: Intraterrestrial life on Earth. Annual Review of Earth and Planetary Sciences 40, 551-568.

Eiler, J.M., 2007. "Clumped-isotope" geochemistry - The study of naturally-occurring, multiply-substituted isotopologues. Earth and Planetary Science Letters 262, 309-327.

Eiler, J.M., 2013. The isotopic anatomies of molecules and minerals. Annual Review of Earth and Planetary Sciences 41, 411-441.

Eiler, J.M., Bergquist, B., Bourg, I., Cartigny, P., Farquhar, J., Gagnon, A., Guo, W., Halevy, I., Hofmann, A., Larson, T.E., Levin, N., Schauble, E.A., Stolper, D., 2014a. Frontiers of stable isotope geoscience. Chemical Geology 372, 119-143. 
Eiler, J.M., Clog, M., Kitchen, N., Stolper, D., 2014b. Mass spectrometric analysis of ${ }^{12} \mathrm{CH}_{2} \mathrm{D}_{2}, 2014$ ClumpedIstotope Workshop, Zurich, Switzerland.

Eiler, J.M., Clog, M., Magyar, P., Piasecki, A., Sessions, A., Stolper, D., Deerberg, M., Schlueter, H.-J., Schwieters, J., 2013. A high-resolution gas-source isotope ratio mass spectrometer. International Journal of Mass Spectrometry 335, 45-56.

Eiler, J.M., Schauble, E., 2004. ${ }^{18} \mathrm{O}^{13} \mathrm{C}^{16} \mathrm{O}$ in Earth's atmosphere. Geochimica et Cosmochimica Acta $68,4767-$ 4777.

England, W., Mackenzie, A., Mann, D., Quigley, T., 1987. The movement and entrapment of petroleum fluids in the subsurface. Journal of the Geological Society 144, 327-347.

Farquhar, J., Johnston, D.T., Wing, B.A., Habicht, K.S., Canfield, D.E., Airieau, S., Thiemens, M.H., 2003. Multiple sulphur isotopic interpretations of biosynthetic pathways: implications for biological signatures in the sulphur isotope record. Geobiology 1, 27-36.

Feakins, S.J., Sessions, A.L., 2010. Controls on the D/H ratios of plant leaf waxes in an arid ecosystem. Geochimica et Cosmochimica Acta 74, 2128-2141.

Formolo, M., Salacup, J., Petsch, S., Martini, A., Nüsslein, K., 2008. A new model linking atmospheric methane sources to Pleistocene glaciation via methanogenesis in sedimentary basins. Geology 36, 139-142.

Fuchs, G., Thauer, R., Ziegler, H., Stichler, W., 1979. Carbon isotope fractionation by Methanobacterium thermoautotrophicum. Archives of Microbiology 120, 135-139.

Gruen, D.S., Wang, D.T., Stewart, L., Holden, J., Ono, S., 2014. Clumped isotope systematics of biogenic methane, Goldschmidt Conference. Mineralogical Magazine, Sacramento, CA, p. 868.

Gutschick, R.C., Sandberg, C.A., 1991. Late Devonian history of Michigan basin. Geological Society of America Special Papers 256, 181-202.

Hallam, S.J., Putnam, N., Preston, C.M., Detter, J.C., Rokhsar, D., Richardson, P.M., DeLong, E.F., 2004. Reverse methanogenesis: Testing the hypothesis with environmental genomics. Science 305, 14571462.

Hattori, S., Nashimoto, H., Kimura, H., Koba, K., Yamada, K., Shimizu, M., Watanabe, H., Yoh, M., Yoshida, N., 2012. Hydrogen and carbon isotope fractionation by thermophilic hydrogenotrophic methanogens from a deep aquifer under coculture with fermenters. Geochemical Journal 46, 193-200.

Hayes, J.M., 2001. Fractionation of carbon and hydrogen isotopes in biosynthetic processes. Reviews in mineralogy and geochemistry 43, 225-277.

Horibe, Y., Craig, H., 1995. D/H fractionation in the system methane-hydrogen-water. Geochimica et Cosmochimica Acta 59, 5209-5217.

Horita, J., Wesolowski, D.J., 1994. Liquid-vapor fractionation of oxygen and hydrogen isotopes of water from the freezing to the critical temperature. Geochimica et Cosmochimica Acta 58, 3425-3437.

Hunt, J.M., 1996. Petroleum Geochemistry and Geology. W. H. Freeman and Company, New York.

Kawagucci, S., Kobayashi, M., Hattori, S., Yamada, K., Ueno, Y., Takai, K., Yoshida, N., 2014. Hydrogen isotope systematics among $\mathrm{H}_{2}-\mathrm{H}_{2} \mathrm{O}-\mathrm{CH}_{4}$ during the growth of the hydrogenotrophic methanogen Methanothermobacter thermoautotrophicus strain $\Delta \mathrm{H}$. Geochimica et Cosmochimica Acta.

Kinnaman, F.S., Valentine, D.L., Tyler, S.C., 2007. Carbon and hydrogen isotope fractionation associated with the aerobic microbial oxidation of methane, ethane, propane and butane. Geochimica et Cosmochimica Acta 71, 271-283.

Kirk, M.F., Martini, A.M., Breecker, D.O., Colman, D.R., Takacs-Vesbach, C., Petsch, S.T., 2012. Impact of commercial natural gas production on geochemistry and microbiology in a shale-gas reservoir. Chemical Geology 332, 15-25.

Kniemeyer, O., Musat, F., Sievert, S.M., Knittel, K., Wilkes, H., Blumenberg, M., Michaelis, W., Classen, A., Bolm, C., Joye, S.B., 2007. Anaerobic oxidation of short-chain hydrocarbons by marine sulphatereducing bacteria. Nature 449, 898-901.

Kreuzer-Martin, H.W., Ehleringer, J.R., Hegg, E.L., 2005. Oxygen isotopes indicate most intracellular water in log-phase Escherichia coli is derived from metabolism. Proceedings of the National Academy of Sciences of the United States of America 102,17337-17341.

Luczaj, J.A., Harrison III, W.B., Williams, N.S., 2006. Fractured hydrothermal dolomite reservoirs in the Devonian Dundee Formation of the central Michigan Basin. AAPG bulletin 90, 1787-1801.

Ma, L., Castro, M.C., Hall, C.M., Walter, L.M., 2005. Cross - formational flow and salinity sources inferred from a combined study of helium concentrations, isotopic ratios, and major elements in the Marshall aquifer, southern Michigan. Geochemistry, Geophysics, Geosystems 6.

Ma, Q., Wu, S., Tang, Y., 2008. Formation and abundance of doubly-substituted methane isotopologues $\left({ }^{13} \mathrm{CH}_{3} \mathrm{D}\right)$ in natural gas systems. Geochimica et Cosmochimica Acta 72, 5446-5456. 
1692

1693

1694

1695

1696

1697

1698

1699

1700

1701

1702

1703

1704

1705

1706

1707

1708

1709

1710

1711

1712

1713

1714

1715

1716

1717

1718

1719

1720

1721

1722

1723

1724

1725

1726

1727

1728

1729

1730

1731

1732

1733

1734

1735

1736

1737

1738

1739

1740

1741

1742

1743

1744

1745

1746

1747

1748

1749

1750

Martini, A., Walter, L., Budai, J., Ku, T., Kaiser, C., Schoell, M., 1998. Genetic and temporal relations between formation waters and biogenic methane: Upper Devonian Antrim Shale, Michigan Basin, USA. Geochimica et Cosmochimica Acta 62, 1699-1720.

Martini, A.M., Budai, J.M., Walter, L.M., Schoell, M., 1996. Microbial generation of economic accumulations of methane within a shallow organic-rich shale. Nature 383, 155-158.

Martini, A.M., Walter, L.M., Ku, T.C., Budai, J.M., McIntosh, J.C., Schoell, M., 2003. Microbial production and modification of gases in sedimentary basins: A geochemical case study from a Devonian shale gas play, Michigan basin. AAPG bulletin 87, 1355-1375.

Martini, A.M., Walter, L.M., McIntosh, J.C., 2008. Identification of microbial and thermogenic gas components from Upper Devonian black shale cores, Illinois and Michigan basins. Aapg Bulletin 92, 327-339.

McIntosh, J., Garven, G., Hanor, J., 2011. Impacts of Pleistocene glaciation on large - scale groundwater flow and salinity in the Michigan Basin. Geofluids 11, 18-33.

McIntosh, J., Walter, L., 2005. Volumetrically significant recharge of Pleistocene glacial meltwaters into epicratonic basins: Constraints imposed by solute mass balances. Chemical Geology 222, 292-309.

Ni, Y., Ma, Q., Ellis, G.S., Dai, J., Katz, B., Zhang, S., Tang, Y., 2011. Fundamental studies on kinetic isotope effect (KIE) of hydrogen isotope fractionation in natural gas systems. Geochimica et Cosmochimica Acta 75, 2696-2707.

Ono, S., Wang, D.T., Gruen, D.S., Sherwood Lollar, B., Zahniser, M.S., McManus, B.J., Nelson, D.D., 2014a. Measurement of a Doubly Substituted Methane Isotopologue, ${ }^{13} \mathrm{CH}_{3} \mathrm{D}$, by Tunable Infrared Laser Direct Absorption Spectroscopy. Analytical Chemistry 86, 6487-6494.

Ono, S., Wang, D., Gruen, D., Sherwood Lollar, B., Mcmanus, B., Zahniser, M., Nelson, D., 2014 b. Measurements of Clumped Methane Isotopologue $\left({ }^{13} \mathrm{CH}_{3} \mathrm{D}\right)$ by Tunable Mid-Infrared Laser Spectroscopy, Goldschmidt Conference. Mineralogical Magazine, Sacramento, CA, p. 1870.

Osborn, S.G., McIntosh, J.C., 2010. Chemical and isotopic tracers of the contribution of microbial gas in Devonian organic-rich shales and reservoir sandstones, northern Appalachian Basin. Applied Geochemistry 25, 456-471.

Penning, H., Plugge, C.M., Galand, P.E., Conrad, R., 2005. Variation of carbon isotope fractionation in hydrogenotrophic methanogenic microbial cultures and environmental samples at different energy status. Global Change Biology 11, 2103-2113.

Price, L.C., Schoell, M., 1995. Constraints on the origins of hydrocarbon gas from compositions of gases at their site of origin. Nature 378, 368-371.

Quigley, T., Mackenzie, A., 1988. The temperatures of oil and gas formation in the sub-surface. Nature 333, 549-552.

Rees, C., 1973. A steady-state model for sulphur isotope fractionation in bacterial reduction processes. Geochimica et Cosmochimica Acta 37, 1141-1162.

Richet, P., Bottinga, Y., Janoy, M., 1977. A review of hydrogen, carbon, nitrogen, oxygen, sulphur, and chlorine stable isotope enrichment among gaseous molecules. Annual Review of Earth and Planetary Sciences $5,65-110$.

Schauble, E.A., Ghosh, P., Eiler, J.M., 2006. Preferential formation of ${ }^{13} \mathrm{C}-{ }^{18} \mathrm{O}$ bonds in carbonate minerals, estimated using first-principles lattice dynamics. Geochimica et Cosmochimica Acta 70, 2510-2529.

Scheller, S., Goenrich, M., Boecher, R., Thauer, R.K., Jaun, B., 2010. The key nickel enzyme of methanogenesis catalyses the anaerobic oxidation of methane. Nature 465, 606-608.

Scheller, S., Goenrich, M., Thauer, R.K., Jaun, B.M., 2013. Methyl-Coenzyme M Reductase from Methanogenic Archaea: Isotope Effects on the Formation and Anaerobic Oxidation of Methane.

Schimmelmann, A., Sessions, A.L., Mastalerz, M., 2006. Hydrogen isotopic (D/H) composition of organic matter during diagenesis and thermal maturation. Annu. Rev. Earth Planet. Sci. 34, 501-533.

Schlegel, M.E., Zhou, Z., McIntosh, J.C., Ballentine, C.J., Person, M.A., 2011. Constraining the timing of microbial methane generation in an organic-rich shale using noble gases, Illinois Basin, USA. Chemical Geology 287, 27-40.

Schoell, M., 1980. The hydrogen and carbon isotopic composition of methane from natural gases of various origins. Geochimica et Cosmochimica Acta 44, 649-661.

Schoell, M., 1983. Genetic characterization of natural gases. AAPG Bulletin 67, 2225-2238.

Seewald, J.S., 2003. Organic-inorganic interactions in petroleum-producing sedimentary basins. Nature 426, 327-333.

Seewald, J.S., Benitez-Nelson, B.C., Whelan, J.K., 1998. Laboratory and theoretical constraints on the generation and composition of natural gas. Geochimica et Cosmochimica Acta 62, 1599-1617.

Stolper, D.A., Sessions, A.L., Ferreira, A., Santos Neto, E.V., Schimmelmann, A., Shusta, S.S., Valentine, D.L., Eiler, J.M., 2014a. Combined ${ }^{13} \mathrm{C}-\mathrm{D}$ and D-D clumping in methane: methods and preliminary results. Geochimica Et Cosmochimica Acta 126, 169-191. 
Stolper, D., Lawson, M., Davis, C., Ferreira, A., Neto, E.S., Ellis, G., Lewan, M., Martini, A., Tang, Y., Schoell, M., 2014b. Formation temperatures of thermogenic and biogenic methane. Science 344, 1500-1503.

Stolper, D.A., Davis, C.L., Eiler, J.M., Ellis, G.S., Ferreira, A.A., Lawson, M., Martini, A.M., Santos Neto, E.V., Schoell, M., Sessions, A.L., Shusta, S.S., Tang, Y., Valentine, D.L., 2014c. Clumped isotopes of methane: applications to both low and high temperature natural systems, Mineralogical Magazine, Sacremento, CA, p. 2393.

Sugimoto, A., Wada, E., 1995. Hydrogen isotopic composition of bacterial methane: $\mathrm{CO}_{2} / \mathrm{H}_{2}$ reduction and acetate fermentation. Geochimica et Cosmochimica Acta 59, 1329-1337.

Takai, K., Nakamura, K., Toki, T., Tsunogai, U., Miyazaki, M., Miyazaki, J., Hirayama, H., Nakagawa, S., Nunoura, T., Horikoshi, K., 2008. Cell proliferation at $122^{\circ} \mathrm{C}$ and isotopically heavy $\mathrm{CH}_{4}$ production by a hyperthermophilic methanogen under high-pressure cultivation. Proceedings of the National Academy of Sciences 105, 10949-10954.

Tang, Y., Perry, J., Jenden, P., Schoell, M., 2000. Mathematical modeling of stable carbon isotope ratios in natural gases. Geochimica et Cosmochimica Acta 64, 2673-2687.

Thauer, R.K., 1998. Biochemistry of methanogenesis: A tribute to Marjory Stephenson. Microbiology 144, 2377-2406.

Thauer, R.K., 2011. Anaerobic oxidation of methane with sulfate: on the reversibility of the reactions that are catalyzed by enzymes also involved in methanogenesis from $\mathrm{CO}_{2}$. Current opinion in microbiology 14, 292-299.

Thauer, R.K., Kaster, A.-K., Seedorf, H., Buckel, W., Hedderich, R., 2008. Methanogenic archaea: ecologically relevant differences in energy conservation. Nature Reviews Microbiology 6, 579-591.

Tissot, B.P., Welte, D.H., 1978. Petroleum formation and occurrence: A new approach to oil and gas exploration. Springer-Verlag, Berlin.

Tsuji, K., Teshima, H., Sasada, H., Yoshida, N., 2012. Spectroscopic isotope ratio measurement of doublysubstituted methane. Spectrochimica Acta Part A: Molecular and Biomolecular Spectroscopy 98, 4346.

Urey, H.C., Rittenberg, D., 1933. Some thermodynamic properties of the $\mathrm{H}^{1} \mathrm{H}^{1}, \mathrm{H}^{2} \mathrm{H}^{2}$ molecules and compounds containing the $\mathrm{H}^{2}$ atom. The Journal of Chemical Physics 1, 137.

Valentine, D.L., 2011. Emerging topics in marine methane biogeochemistry. Annu. Rev. Mar. Sci. 3, 147-171.

Valentine, D.L., Chidthaisong, A., Rice, A., Reeburgh, W.S., Tyler, S.C., 2004. Carbon and hydrogen isotope fractionation by moderately thermophilic methanogens. Geochimica et Cosmochimica Acta 68, 15711590 .

Valentine, D.L., Kessler, J.D., Redmond, M.C., Mendes, S.D., Heintz, M.B., Farwell, C., Hu, L., Kinnaman, F.S., Yvon-Lewis, S., Du, M., 2010. Propane respiration jump-starts microbial response to a deep oil spill. Science 330, 208-211.

Waldron, P.J., Petsch, S.T., Martini, A.M., Nüsslein, K., 2007. Salinity constraints on subsurface archaeal diversity and methanogenesis in sedimentary rock rich in organic matter. Applied and environmental microbiology 73, 4171-4179.

Wang, D.T., Gruen, D.S., Lollar, B.S., Hinrichs, K.-U., Stewart, L.C., Holden, J.F., Hristov, A.N., Pohlman, J.W., Morrill, P.L., Könneke, M., in press. Nonequilibrium clumped isotope signals in microbial methane. Science.

Wang, Z., Schauble, E.A., Eiler, J.M., 2004. Equilibrium thermodynamics of multiply substituted isotopologues of molecular gases. Geochimica et Cosmochimica Acta 68, 4779-4797.

Webb, M.A., Miller III, T.F., 2014. Position-Specific and Clumped Stable Isotope Studies: Comparison of the Urey and Path-Integral Approaches for Carbon Dioxide, Nitrous Oxide, Methane, and Propane. The Journal of Physical Chemistry A 118, 467-474.

Whiticar, M.J., 1999. Carbon and hydrogen isotope systematics of bacterial formation and oxidation of methane. Chemical Geology 161, 291-314.

Whiticar, M.J., Faber, E., Schoell, M., 1986. Biogenic methane formation in marine and freshwater environments: $\mathrm{CO}_{2}$ reduction vs acetate fermentation-Isotope evidence. Geochimica et Cosmochimica Acta 50, 693-709.

Wilhelms, A., Larter, S., Head, I., Farrimond, P., Di-Primio, R., Zwach, C., 2001. Biodegradation of oil in uplifted basins prevented by deep-burial sterilization. Nature 411, 1034-1037.

Wilson, T.P., Long, D.T., 1993. Geochemistry and isotope chemistry of Michigan Basin brines: Devonian formations. Applied Geochemistry 8, 81-100.

Wing, B.A., Halevy, I., 2014. Intracellular metabolite levels shape sulfur isotope fractionation during microbial sulfate respiration. Proceedings of the National Academy of Sciences, 201407502. 
Wuchter, C., Banning, E., Mincer, T.J., Drenzek, N.J., Coolen, M.J., 2013. Microbial diversity and methanogenic activity of Antrim Shale formation waters from recently fractured wells. Frontiers in microbiology 4.

Wuebbles, D.J., Hayhoe, K., 2002. Atmospheric methane and global change. Earth-Science Reviews 57, 177210

Yeung, L.Y., Young, E.D., Schauble, E.A., 2012. Measurements of ${ }^{18} \mathrm{O}^{18} \mathrm{O}$ and ${ }^{17} \mathrm{O}^{18} \mathrm{O}$ in the atmosphere and the role of isotope-exchange reactions. Journal of Geophysical Research 117, DOI: 10.1029/2012JD017992.

Yoshinaga, M.Y., Holler, T., Goldhammer, T., Wegener, G., Pohlman, J.W., Brunner, B., Kuypers, M.M., Hinrichs, K.-U., Elvert, M., 2014. Carbon isotope equilibration during sulphate-limited anaerobic oxidation of methane. Nature Geoscience.

Yoshioka, H., Sakata, S., Kamagata, Y., 2008. Hydrogen isotope fractionation by Methanothermobacter thermoautotrophicus in coculture and pure culture conditions. Geochimica et Cosmochimica Acta 72 , 2687-2694.

Zhang, Y., 1994. Reaction kinetics, geospeedometry, and relaxation theory. Earth and planetary science letters 122, 373-391. 


$$
\begin{aligned}
& \Delta_{18}=\left({ }^{18} \mathrm{R} /{ }^{18} \mathrm{R}^{*}-1\right) \times 1000, \\
& { }^{18} \mathrm{R}=\left(\left[{ }^{13} \mathrm{CH}_{3} \mathrm{D}\right]+\left[{ }^{12} \mathrm{CH}_{2} \mathrm{D}_{2}\right]\right) /\left[{ }^{12} \mathrm{CH}_{4}\right] \text {. } \\
& \Delta_{18}=-0.0117\left(\frac{10^{6}}{\mathrm{~T}^{2}}\right)^{2}+0.708\left(\frac{10^{6}}{\mathrm{~T}^{2}}\right)-0.337 \text {. } \\
& \mathrm{CO}_{2}+3 \mathrm{H}_{2}+\mathrm{H}-\mathrm{S}-\mathrm{CoM} \leftrightarrows \mathrm{CH}_{3}-\mathrm{S}-\mathrm{CoM}+2 \mathrm{H}_{2} \mathrm{O} \\
& \mathrm{CH}_{3}-\mathrm{S}-\mathrm{CoM}+2 \mathrm{H} \rightarrow \mathrm{CH}_{4}+\mathrm{H}-\mathrm{S}-\mathrm{CoM} \\
& { }^{12} \mathrm{CH}_{3}-\mathrm{S}-\mathrm{CoM}+\mathrm{H} \underset{{ }^{12 \mathrm{CH}_{3}} \mathrm{k}_{\mathrm{f}}}{\stackrel{12 \mathrm{CH} 4}{\leftrightarrows} \mathrm{k}_{\text {rev }}}{ }^{12} \mathrm{CH}_{4} \stackrel{{ }^{12 \mathrm{CH} 4} \mathrm{k}_{\text {net }}}{\rightarrow} \\
& { }^{13} \mathrm{CH}_{3}-\mathrm{S}-\mathrm{CoM}+\mathrm{H} \underset{13 \mathrm{CH}_{3}}{\stackrel{13 \mathrm{k}_{\mathrm{f}}}{\leftrightarrows} \mathrm{k}_{\text {rev }}}{ }^{13} \mathrm{CH}_{4} \stackrel{13 \mathrm{CH} 4 \mathrm{k}_{\text {net }}}{\rightarrow} \\
& \frac{\mathrm{d}\left[{ }^{12} \mathrm{CH}_{4}\right]}{\mathrm{dt}}=0={ }^{12} \mathrm{CH}_{3} \mathrm{k}_{\mathrm{f}}\left[{ }^{12} \mathrm{CH}_{3}-\mathrm{S}-\mathrm{CoM}\right][\mathrm{H}]-\left({ }^{12} \mathrm{CH}_{4} \mathrm{k}_{\text {rev }}+{ }^{12} \mathrm{CH}_{4} \mathrm{k}_{\text {net }}\right)\left[{ }^{12} \mathrm{CH}_{4}\right] \\
& {\left[{ }^{12} \mathrm{CH}_{4}\right]=\frac{{ }^{12} \mathrm{CH}_{3} \mathrm{k}_{\mathrm{f}}\left[{ }^{12} \mathrm{CH}_{3}-\mathrm{S}-\mathrm{CoM}\right][\mathrm{H}]}{{ }^{12} \mathrm{CH}_{4} \mathrm{k}_{\text {rev }}+{ }^{12} \mathrm{CH}_{4} \mathrm{k}_{\text {net }}}} \\
& {\left[{ }^{13} \mathrm{CH}_{4}\right]=\frac{{ }^{13} \mathrm{CH}_{3} \mathrm{k}_{\mathrm{f}}\left[{ }^{13} \mathrm{CH}_{3}-\mathrm{S}-\mathrm{CoM}\right][\mathrm{H}]}{{ }^{13} \mathrm{CH}_{4} \mathrm{k}_{\mathrm{rev}}+{ }^{13} \mathrm{CH}_{4} \mathrm{k}_{\text {net }}}} \\
& \mathrm{r}=\frac{{ }^{12} \mathrm{CH}_{4} \mathrm{k}_{\mathrm{rev}}\left[{ }^{12} \mathrm{CH}_{4}\right]}{{ }^{12} \mathrm{CH}_{3} \mathrm{k}_{\mathrm{f}}\left[{ }^{12} \mathrm{CH}_{3}-\mathrm{S}-\mathrm{CoM}\right][\mathrm{H}]} \\
& \mathrm{r}=\frac{{ }^{12} \mathrm{CH}_{4} \mathrm{k}_{\mathrm{rev}}}{{ }^{12} \mathrm{CH}_{4} \mathrm{k}_{\mathrm{rev}}+{ }^{12} \mathrm{CH}_{4} \mathrm{k}_{\text {net }}} \\
& \frac{\left[{ }^{13} \mathrm{CH}_{4}\right]}{\left[{ }^{12} \mathrm{CH}_{4}\right]}=\left(\frac{{ }^{13} \mathrm{CH}_{3} \mathrm{k}_{\mathrm{f}}\left[{ }^{13} \mathrm{CH}_{3}-\mathrm{S}-\mathrm{CoM}\right][\mathrm{H}]}{{ }^{12} \mathrm{CH}_{3} \mathrm{k}_{\mathrm{f}}\left[{ }^{12} \mathrm{CH}_{3}-\mathrm{S}-\mathrm{CoM}\right][\mathrm{H}]}\right) \times\left(\frac{{ }^{12} \mathrm{CH}_{4} \mathrm{k}_{\mathrm{rev}}+{ }^{12} \mathrm{CH}_{4} \mathrm{k}_{\mathrm{net}}}{{ }^{13} \mathrm{CH}_{4} \mathrm{k}_{\mathrm{rev}}+{ }^{13} \mathrm{CH}_{4} \mathrm{k}_{\mathrm{net}}}\right) \\
& { }^{13} \mathrm{CH}_{4} \mathrm{R}=\frac{\left[{ }^{13} \mathrm{CH}_{4}\right]}{\left[{ }^{12} \mathrm{CH}_{4}\right]} \text { and }{ }^{13} \mathrm{CH}_{3} \mathrm{R}=\frac{\left[{ }^{13} \mathrm{CH}_{3}-\mathrm{S}-\mathrm{CoM}\right]}{\left[{ }^{12} \mathrm{CH}_{3}-\mathrm{S}-\mathrm{CoM}\right]} \\
& { }^{\mathrm{i}} \kappa_{\mathrm{j}}=\frac{{ }^{\mathrm{i}} \mathrm{k}_{\mathrm{j}}}{\text { unsubstituted } \mathrm{k}_{\mathrm{j}}} \\
& { }^{13} \mathrm{CH}_{4} \mathrm{R}={ }^{13} \mathrm{CH}_{3} \mathrm{R} \times{ }^{13} \mathrm{CH}_{3} \kappa_{\mathrm{f}} \times\left(\frac{1}{1+\mathrm{r}\left({ }^{13} \mathrm{CH}_{4} \kappa_{\text {rev }}-1\right)}\right) \\
& { }^{13} \mathrm{CO}_{2}+{ }^{12} \mathrm{CH}_{3}-\mathrm{S}-\mathrm{CoM} \leftrightarrows{ }^{12} \mathrm{CO}_{2}+{ }^{13} \mathrm{CH}_{3}-\mathrm{S}-\mathrm{CoM} \\
& \underset{{ }^{13} \mathrm{CO}_{2} \leftrightarrows{ }^{13} \mathrm{CH}_{3} \text {-S-CoM }}{\mathrm{K}_{\text {eq }}}=\frac{{ }^{13} \mathrm{CH}_{3} \mathrm{R}}{{ }^{13} \mathrm{CO}_{2} \mathrm{R}}
\end{aligned}
$$




$$
\begin{aligned}
& { }^{13} \mathrm{CO}_{2} \mathrm{R}=\frac{\left[{ }^{13} \mathrm{CO}_{2}\right]}{\left[{ }^{12} \mathrm{CO}_{2}\right]} \\
& { }^{13} \mathrm{CH}_{4} \mathrm{R}={ }^{13} \mathrm{CO}_{2} \mathrm{R} x \underset{{ }^{13} \mathrm{CO}_{2} \longleftarrow{ }^{13} \mathrm{CH}_{3} \text {-S-CoM }}{\mathrm{K}_{\mathrm{eq}}} \times{ }^{13} \mathrm{CH}_{3} \kappa_{\mathrm{f}} \mathrm{x}\left(\frac{1}{1+\mathrm{r}\left({ }^{13} \mathrm{CH}_{4} \kappa_{\text {rev }}-1\right)}\right) \\
& { }^{13} \mathrm{CH}_{3} \kappa_{\mathrm{f}}^{*}=\underset{{ }^{13} \mathrm{CO}_{2} \leftrightarrows{ }^{13} \mathrm{CH}_{3} \text {-S-CoM }}{\mathrm{K}_{\text {- }}} \mathrm{X}{ }^{13} \mathrm{CH}_{3} \kappa_{\mathrm{f}} \\
& { }^{13} \mathrm{CH}_{4} \mathrm{R}={ }^{13} \mathrm{CO}_{2} \mathrm{R} \times{ }^{13} \mathrm{CH}_{3} \kappa_{\mathrm{f}}^{*} \times\left(\frac{1}{1+\mathrm{r}\left({ }^{13} \mathrm{CH}_{4} \kappa_{\text {rev }}-1\right)}\right) \\
& \frac{{ }^{13} \mathrm{CH}_{4} \mathrm{R}_{\mathrm{eq}}}{{ }^{13} \mathrm{CO}_{2} \mathrm{R}_{\mathrm{eq}}}=\frac{{ }^{13} \mathrm{CH}_{3} \boldsymbol{\kappa}_{\mathrm{f}}^{*}}{{ }^{13} \mathrm{CH}_{4} \kappa_{\mathrm{rev}}} \\
& { }^{13} \mathrm{CO}_{2}+{ }^{12} \mathrm{CH}_{4} \leftrightarrows{ }^{12} \mathrm{CO}_{2}+{ }^{13} \mathrm{CH}_{4} \\
& \underset{{ }^{13} \mathrm{CO}_{2} \leftrightarrows{ }^{13} \mathrm{CH}_{4}}{\mathrm{~K}}=\frac{{ }^{13} \mathrm{CH}_{4} \mathrm{R}_{\mathrm{eq}}}{{ }^{13} \mathrm{CO}_{2} \mathrm{R}_{\mathrm{eq}}} \\
& \underset{{ }^{13} \mathrm{CO}_{2} \leftrightarrows{ }^{-13} \mathrm{CH}_{4}}{\mathrm{~K}}=\frac{{ }^{13} \mathrm{CH}_{3} \kappa_{\mathrm{f}}^{*}}{{ }^{13} \mathrm{CH}_{4} \kappa_{\mathrm{rev}}} \\
& { }^{12} \mathrm{CH}_{3}-\mathrm{S}-\mathrm{CoM}+\mathrm{D} \underset{{ }_{12+\mathrm{D}} \mathrm{k}_{\mathrm{f}}}{\stackrel{12-\mathrm{D}}{\leftrightarrows} \mathrm{k}_{\text {rev }}}{ }^{12} \mathrm{CH}_{3} \mathrm{D} \stackrel{12 \mathrm{CH} 3 \mathrm{D}}{\rightarrow} \mathrm{k}_{\text {net }} \\
& { }^{12} \mathrm{CH}_{2} \mathrm{D}-\mathrm{S}-\mathrm{CoM}+\mathrm{H} \underset{12+\mathrm{k}_{\mathrm{f}}}{\stackrel{{ }^{12-\mathrm{H}} \mathrm{k}_{\text {rev }}}{\leftrightarrows}}{ }^{12} \mathrm{CH}_{3} \mathrm{D} \stackrel{12 \mathrm{CH3D} \mathrm{k}_{\text {net }}}{\rightarrow} \\
& {\left[{ }^{12} \mathrm{CH}_{3} \mathrm{D}\right]=\frac{{ }^{12+\mathrm{H}} \mathrm{k}_{\mathrm{f}}\left[{ }^{12} \mathrm{CH}_{2} \mathrm{D}-\mathrm{S}-\mathrm{CoM}\right][\mathrm{H}]+{ }^{12+\mathrm{D}} \mathrm{k}_{\mathrm{f}}\left[{ }^{12} \mathrm{CH}_{3}-\mathrm{S}-\mathrm{CoM}\right][\mathrm{D}]}{{ }^{12-\mathrm{H}} \mathrm{k}_{\mathrm{rev}}+{ }^{12-\mathrm{D}} \mathrm{k}_{\mathrm{rev}}+{ }^{12} \mathrm{CH}_{3} \mathrm{D} \mathrm{k}_{\mathrm{net}}}} \\
& \frac{\left[{ }^{12} \mathrm{CH}_{3} \mathrm{D}\right]}{\left[{ }^{12} \mathrm{CH}_{4}\right]}=\left(\frac{{ }^{12+\mathrm{H}} \mathrm{k}_{\mathrm{f}}\left[{ }^{12} \mathrm{CH}_{2} \mathrm{D}-\mathrm{S}-\mathrm{CoM}\right][\mathrm{H}]+{ }^{12+\mathrm{D}} \mathrm{k}_{\mathrm{f}}\left[{ }^{12} \mathrm{CH}_{3}-\mathrm{S}-\mathrm{CoM}\right][\mathrm{D}]}{{ }^{12} \mathrm{CH}_{3} \mathrm{k}_{\mathrm{f}}\left[{ }^{12} \mathrm{CH}_{3}-\mathrm{S}-\mathrm{CoM}\right][\mathrm{H}]}\right) \times\left(\frac{{ }^{12} \mathrm{CH}_{4} \mathrm{k}_{\mathrm{rev}}+{ }^{12} \mathrm{CH}_{4} \mathrm{k}_{\text {net }}}{{ }^{12-\mathrm{H}} \mathrm{k}_{\mathrm{rev}}+{ }^{12 \mathrm{D}} \mathrm{k}_{\text {rev }}+{ }^{12} \mathrm{CH}_{3} \mathrm{D} \mathrm{k}_{\text {net }}}\right) \\
& \text { (A3.4) } \\
& { }^{12} \mathrm{CH}_{3} \mathrm{D} \mathrm{R}=\frac{\left[{ }^{12} \mathrm{CH}_{3} \mathrm{D}\right]}{\left[{ }^{12} \mathrm{CH}_{4}\right]} ;{ }^{12} \mathrm{CH}_{2} \mathrm{D} \mathrm{R}=\frac{\left[{ }^{12} \mathrm{CH}_{2} \mathrm{D}-\mathrm{S}-\mathrm{CoM}\right]}{\left[{ }^{12} \mathrm{CH}_{3}-\mathrm{S}-\mathrm{CoM}\right]} ; \text { and }{ }^{\mathrm{D}} \mathrm{R}=\frac{[\mathrm{D}]}{[\mathrm{H}]} \\
& { }^{12} \mathrm{CH}_{3} \mathrm{D} \mathrm{R}=\left(\frac{{ }^{12+\mathrm{D}} \kappa_{\mathrm{f}} \times{ }^{\mathrm{D}} \mathrm{R}+{ }^{12+\mathrm{H}} \kappa_{\mathrm{f}} \times{ }^{12} \mathrm{CH}_{2} \mathrm{D} \mathrm{R}}{1+\mathrm{r}\left({ }^{12-\mathrm{D}} \kappa_{\mathrm{rev}}+{ }^{12-\mathrm{H}} \kappa_{\text {rev }}-1\right)}\right) \\
& { }^{12} \mathrm{CH}_{3}-\mathrm{S}-\mathrm{CoM}+\mathrm{D} \leftrightarrows{ }^{12} \mathrm{CH}_{2} \mathrm{D}-\mathrm{S}-\mathrm{CoM}+\mathrm{H} \\
& \underset{\mathrm{D} \Im^{12} \mathrm{CH}_{2} \mathrm{D}-\mathrm{S}-\mathrm{CoM}}{\mathrm{K}_{\mathrm{eq}}}=\frac{{ }^{12} \mathrm{CH}_{2} \mathrm{D} \mathrm{R}}{{ }^{\mathrm{D}} \mathrm{R}}
\end{aligned}
$$




$$
\begin{aligned}
& { }^{12} \mathrm{CH}_{3} \mathrm{D} \mathrm{R}={ }^{\mathrm{D}} \mathrm{R} \times\left(\frac{{ }^{12+\mathrm{D}} \kappa_{\mathrm{f}}+{ }^{12+\mathrm{H}} \kappa_{\mathrm{f}} \mathrm{X} \quad \mathrm{K}_{\text {eq }}}{1+\mathrm{r}\left({ }^{12-\mathrm{D}} \kappa_{\text {rev }}+{ }^{12-\mathrm{H}} \boldsymbol{K}_{\text {rev }}-1\right)}\right) \\
& { }^{12} \mathrm{CH}_{3} \mathrm{D} \kappa_{\mathrm{f}}^{*}={ }^{12+\mathrm{D}} \kappa_{\mathrm{f}}+{ }^{12+\mathrm{H}} \kappa_{\mathrm{f}} \mathrm{X} \underset{\mathrm{D}^{12} \mathrm{CH}_{2} \mathrm{D}-\mathrm{S}-\mathrm{CoM}}{\mathrm{K}_{\mathrm{eq}}} \\
& { }^{12} \mathrm{CH}_{3} \mathrm{D} \kappa_{\text {rev }}^{*}={ }^{12-\mathrm{D}} \kappa_{\text {rev }}+{ }^{12-\mathrm{H}} \kappa_{\text {rev }} \\
& { }^{12} \mathrm{CH}_{3} \mathrm{D} \mathrm{R}={ }^{\mathrm{D}} \mathrm{R} x\left(\frac{{ }^{12} \mathrm{CH}_{3} \mathrm{D} \kappa_{\mathrm{f}}^{*}}{1+\mathrm{r}\left({ }^{12} \mathrm{CH}_{3} \mathrm{D} \kappa_{\mathrm{rev}}^{*}-1\right)}\right) \\
& { }^{12} \mathrm{CH}_{3} \mathrm{D} \mathrm{R}_{\mathrm{eq}}={ }^{\mathrm{D}} \mathrm{R}_{\mathrm{eq}} \times \frac{{ }^{12} \mathrm{CH}_{3} \mathrm{D}}{\kappa_{\mathrm{f}}^{*}} \\
& { }^{12} \mathrm{CH}_{4}+\mathrm{D} \leftrightarrows{ }^{12} \mathrm{CH}_{3} \mathrm{D}+\mathrm{H}
\end{aligned}
$$

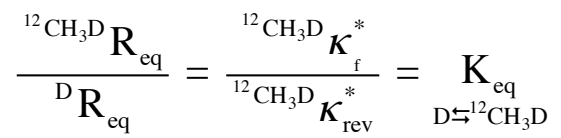

$$
\begin{aligned}
& { }^{\mathrm{D}} \mathrm{R}=\frac{[\mathrm{D}]_{\mathrm{H} 2 \mathrm{O}}}{[\mathrm{H}]_{\mathrm{H} 2 \mathrm{O}}}={ }^{\mathrm{H}_{2} \mathrm{O}} \mathrm{R} \\
& \frac{{ }^{12} \mathrm{CH}_{3} \mathrm{D}}{\mathrm{R}_{\mathrm{eq}}}=\frac{{ }^{12} \mathrm{CH}_{3} \mathrm{D}}{\kappa_{\mathrm{f}}^{*}} \\
& { }^{13} \mathrm{CH}_{3} \mathrm{D} \mathrm{R}=\left(\frac{{ }^{13+\mathrm{D}} \kappa_{\mathrm{f}} \times{ }^{\mathrm{D}} \mathrm{R} \mathrm{x}{ }^{13} \mathrm{CH}_{3} \mathrm{R}+{ }^{13+\mathrm{H}} \kappa_{\mathrm{f}} \times{ }^{13} \mathrm{CH}_{2} \mathrm{D} \mathrm{R}}{1+\mathrm{r}\left({ }^{13-\mathrm{D}} \kappa_{\mathrm{rev}}+{ }^{13-\mathrm{H}} \kappa_{\text {rev }}-1\right)}\right) \\
& { }^{13} \mathrm{CH}_{3} \mathrm{D} \mathrm{R}=\frac{\left[{ }^{13} \mathrm{CH}_{3} \mathrm{D}\right]}{\left[{ }^{12} \mathrm{CH}_{4}\right]} \text { and }{ }^{13} \mathrm{CH}_{2} \mathrm{D} \mathrm{R}=\frac{\left[{ }^{13} \mathrm{CH}_{2} \mathrm{D}-\mathrm{S}-\mathrm{CoM}\right]}{\left[{ }^{12} \mathrm{CH}_{3}-\mathrm{S}-\mathrm{CoM}\right]} \\
& { }^{13} \mathrm{CH}_{3}-\mathrm{S}-\mathrm{CoM}+\mathrm{D} \leftrightarrows{ }^{13} \mathrm{CH}_{2} \mathrm{D}-\mathrm{S}-\mathrm{CoM}+\mathrm{H} \\
& { }^{13} \mathrm{CH}_{2} \mathrm{D}-\mathrm{S}-\mathrm{CoM} \\
& \frac{{ }^{13} \mathrm{CH}_{3}-\mathrm{S}-\mathrm{CoM}}{{ }^{\mathrm{D}} \mathrm{R}}=\underset{{ }^{13} \mathrm{CH}_{3} \text {-S-CoM- }{ }^{13} \mathrm{CH}_{2} \mathrm{D}-\mathrm{S}-\mathrm{CoM}}{\mathrm{K}_{\mathrm{H}}}
\end{aligned}
$$

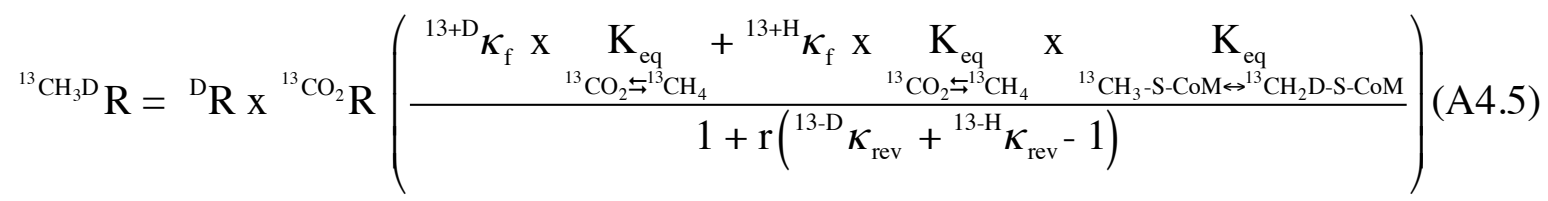

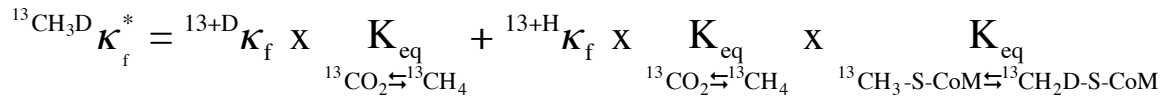

$$
\begin{aligned}
& { }^{13} \mathrm{CH}_{3} \mathrm{D} \kappa_{\text {rev }}^{*}={ }^{13-\mathrm{D}} \kappa_{\text {rev }}^{*}+{ }^{13-\mathrm{H}} \kappa_{\text {rev }}^{*}
\end{aligned}
$$




$$
\begin{aligned}
& { }^{13} \mathrm{CH}_{3} \mathrm{D} \mathrm{R}={ }^{\mathrm{D}} \mathrm{R} x{ }^{13} \mathrm{CO}_{2} \mathrm{R}\left(\frac{{ }^{13} \mathrm{CH}_{3} \mathrm{D} \kappa_{\mathrm{f}}^{*}}{1+\mathrm{r}\left({ }^{13} \mathrm{CH}_{3} \mathrm{D} \kappa_{\text {rev }}^{*}-1\right)}\right) \\
& { }^{12} \mathrm{CH}_{3} \mathrm{D}+{ }^{13} \mathrm{CH}_{4} \leftrightarrows{ }^{12} \mathrm{CH}_{4}+{ }^{13} \mathrm{CH}_{3} \mathrm{D} \\
& \underset{\mathrm{K}_{\mathrm{eq}}}{{ }^{13} \mathrm{CH}_{3} \mathrm{D}}=\frac{\left[{ }^{12} \mathrm{CH}_{4}\right]_{\mathrm{eq}}\left[{ }^{13} \mathrm{CH}_{3} \mathrm{D}\right]_{\mathrm{eq}}}{\left[{ }^{12} \mathrm{CH}_{3} \mathrm{D}\right]_{\mathrm{eq}}\left[{ }^{13} \mathrm{CH}_{4}\right]_{\mathrm{eq}}} \\
& \underset{{ }^{13} \mathrm{~K}_{3} \mathrm{D}}{\mathrm{eq}} \times\left(\frac{{ }^{13} \mathrm{CH}_{3} \kappa_{\mathrm{f}}^{*}}{{ }^{13} \mathrm{CH}_{4} \kappa_{\text {rev }}}\right) \times\left(\frac{{ }^{12} \mathrm{CH}_{3} \mathrm{D} \kappa_{\mathrm{f}}^{*}}{{ }^{12} \mathrm{CH}_{3} \mathrm{D} \kappa_{\text {rev }}^{*}}\right)=\frac{{ }^{13} \mathrm{CH}_{3} \mathrm{D} \kappa_{\mathrm{f}}^{*}}{{ }^{13} \mathrm{CH}_{3} \mathrm{D} \kappa_{\text {rev }}^{*}} \\
& { }^{12} \mathrm{CH}_{2} \mathrm{D}_{2} \mathrm{R}=\left(\frac{{ }^{\mathrm{H}_{2} \mathrm{D}+\mathrm{D}} \kappa_{\mathrm{f}} \times{ }^{\mathrm{D}} \mathrm{R} \mathrm{X}{ }^{12} \mathrm{CH}_{2} \mathrm{D} \mathrm{R}+{ }^{\mathrm{HD}_{2}+\mathrm{H}} \kappa_{\mathrm{f}} \times{ }^{12} \mathrm{CHD}_{2} \mathrm{R}}{1+\mathrm{r}\left({ }^{\mathrm{H}_{2} \mathrm{D}_{2}-\mathrm{D}} \kappa_{\text {rev }}+{ }^{\mathrm{H}_{2} \mathrm{D}_{2}-\mathrm{H}} \boldsymbol{\kappa}_{\text {rev }}-1\right)}\right) \\
& { }^{12} \mathrm{CHD}_{2} \mathrm{R}=\frac{\left[{ }^{12} \mathrm{CHD}_{2}-\mathrm{S}-\mathrm{CoM}\right]}{\left[{ }^{12} \mathrm{CH}_{3}-\mathrm{S}-\mathrm{CoM}\right]} \\
& { }^{12} \mathrm{CH}_{2} \mathrm{D}-\mathrm{S}-\mathrm{CoM}+\mathrm{D} \leftrightarrows{ }^{12} \mathrm{CHD}_{2}-\mathrm{S}-\mathrm{CoM}+\mathrm{H} \\
& { }^{12} \mathrm{CHD}_{2}-\mathrm{S}-\mathrm{CoM} \\
& \frac{\overline{{ }^{12} \mathrm{CH}_{2} \mathrm{D}-\mathrm{S}-\mathrm{CoM}}}{{ }^{\mathrm{D}} \mathrm{R}}=\underset{{ }_{\text {eq }}}{{ }^{12} \mathrm{CH}_{2} \mathrm{D}-\mathrm{S}-\mathrm{CoM} \leftrightarrows{ }^{12} \mathrm{CHD}_{2}-\mathrm{S}-\mathrm{CoM}} \\
& { }^{12} \mathrm{CHD}_{2} \mathrm{R}=\left({ }^{\mathrm{D}} \mathrm{R}\right)^{2} \mathrm{X} \underset{{ }^{12} \mathrm{CH}_{2} \mathrm{D}-\mathrm{S}-\mathrm{CoM}^{-12} \mathrm{CHD}_{2}-\mathrm{S}-\mathrm{CoM}}{\mathrm{K}_{\text {eq }}} \mathrm{X} \underset{\mathrm{D} \leftrightarrows{ }^{12} \mathrm{CH}_{2} \mathrm{D}-\mathrm{S}-\mathrm{CoM}}{\mathrm{K}_{\text {eq }}}
\end{aligned}
$$

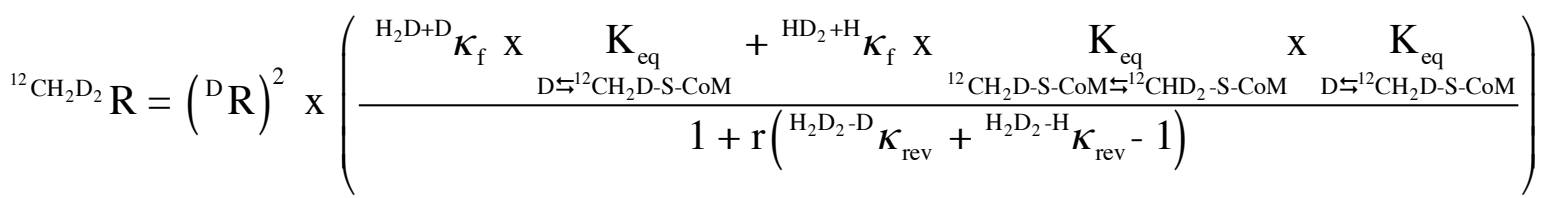

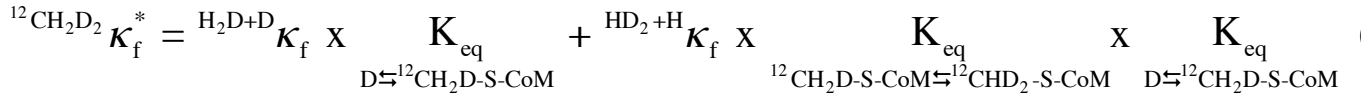

$$
\begin{aligned}
& { }^{12} \mathrm{CH}_{2} \mathrm{D}_{2} \kappa_{\text {rev }}^{*}={ }^{\mathrm{H}_{2} \mathrm{D}_{2}-\mathrm{D}} \kappa_{\text {rev }}+{ }^{\mathrm{H}_{2} \mathrm{D}_{2}-\mathrm{H}} \kappa_{\text {rev }} \\
& \left.{ }^{12} \mathrm{CH}_{2} \mathrm{D}_{2} \mathrm{R}=\left({ }^{\mathrm{D}} \mathrm{R}\right)\right)^{2} \times\left(\frac{{ }^{12} \mathrm{CH}_{2} \mathrm{D}_{2} \kappa_{\mathrm{f}}^{*}}{1+\mathrm{r}\left({ }^{12} \mathrm{CH}_{2} \mathrm{D}_{2} \kappa_{\text {rev }}^{*}-1\right)}\right) \\
& { }^{12} \mathrm{CH}_{3} \mathrm{D}+{ }^{12} \mathrm{CH}_{3} \mathrm{D} \leftrightarrows{ }^{12} \mathrm{CH}_{4}+{ }^{12} \mathrm{CH}_{2} \mathrm{D}_{2} \\
& \underset{{ }^{12} \mathrm{CH}_{2} \mathrm{D}_{2}}{\mathrm{~K}_{\mathrm{eq}}}=\frac{\left[{ }^{12} \mathrm{CH}_{4}\right]_{\mathrm{eq}}\left[{ }^{12} \mathrm{CH}_{2} \mathrm{D}_{2}\right]_{\mathrm{eq}}}{\left[{ }^{12} \mathrm{CH}_{3} \mathrm{D}\right]_{\mathrm{eq}}^{2}} \\
& \underset{{ }^{12} \mathrm{CH}_{2} \mathrm{D}_{2}}{\mathrm{~K}_{\mathrm{eq}}} \times\left(\frac{{ }^{12} \mathrm{CH}_{3} \mathrm{D} \kappa_{\mathrm{f}}^{*}}{{ }^{12} \mathrm{CH}_{3} \mathrm{D} \kappa_{\mathrm{rev}}^{*}}\right)^{2}=\frac{{ }^{12} \mathrm{CH}_{2} \mathrm{D}_{2} \boldsymbol{\kappa}_{\mathrm{f}}^{*}}{{ }^{12} \mathrm{CH}_{2} \mathrm{D}_{2} \kappa_{\mathrm{rev}}^{*}}
\end{aligned}
$$




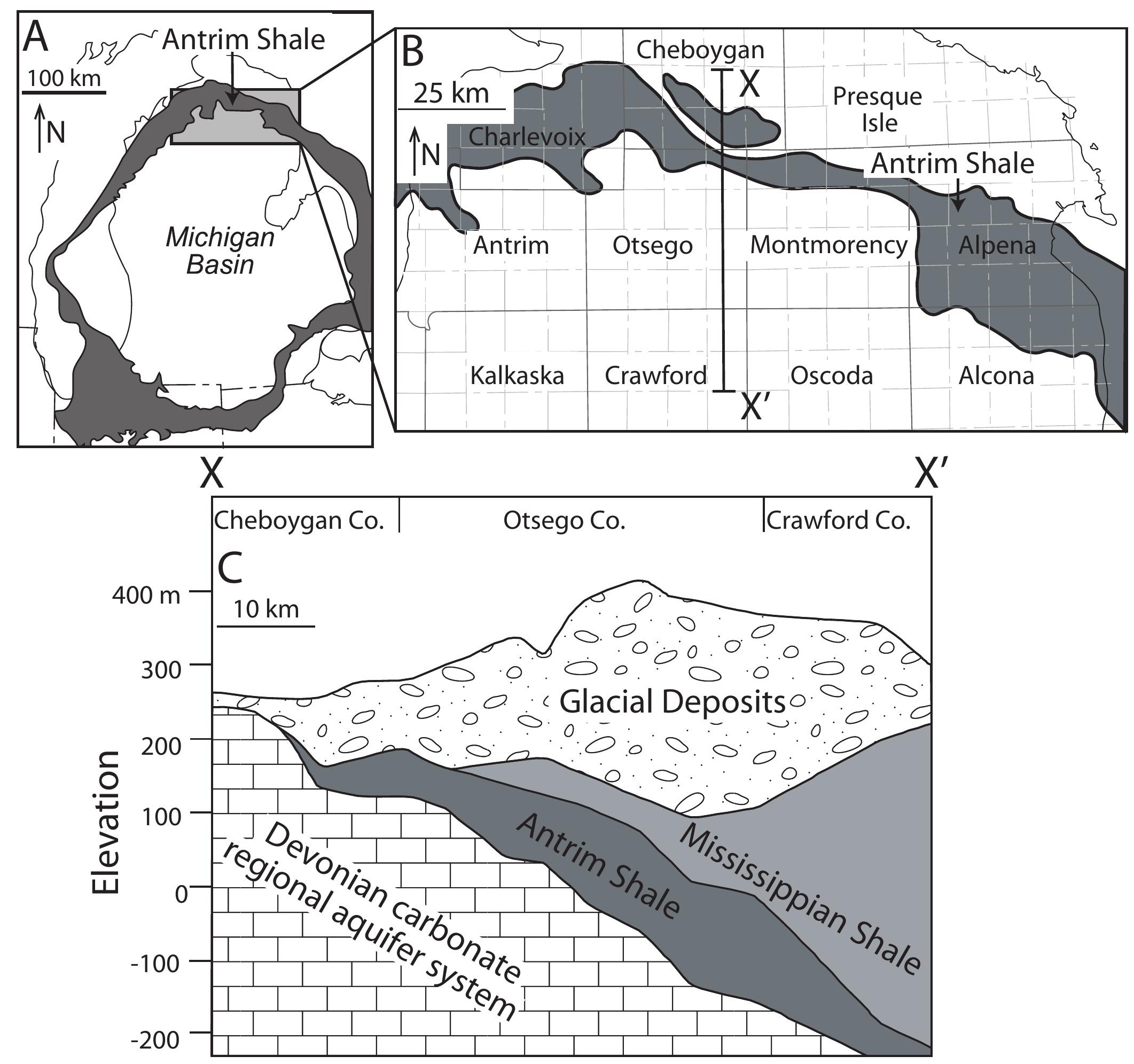


Figuręzo
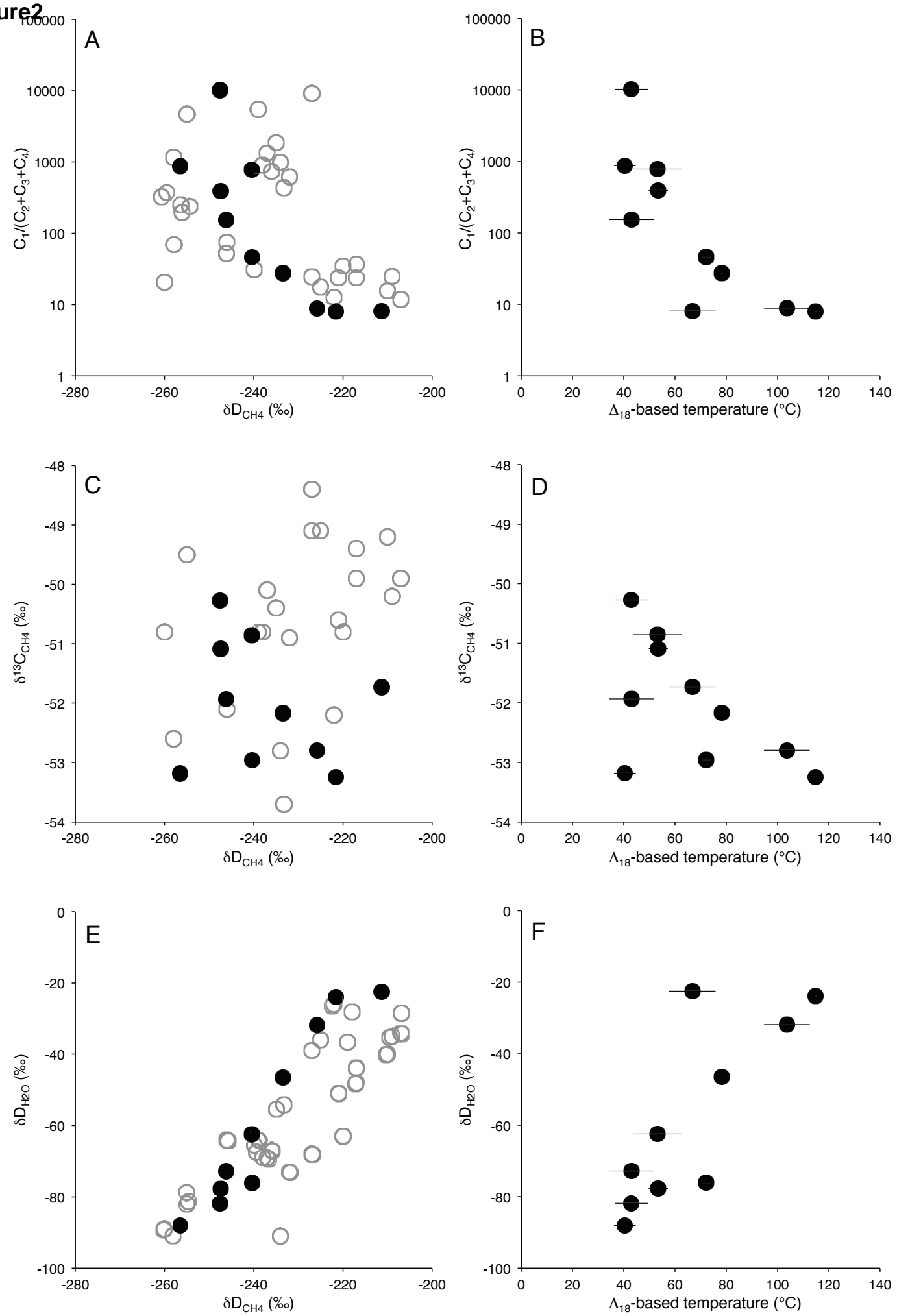

measurements from this study from previous studies

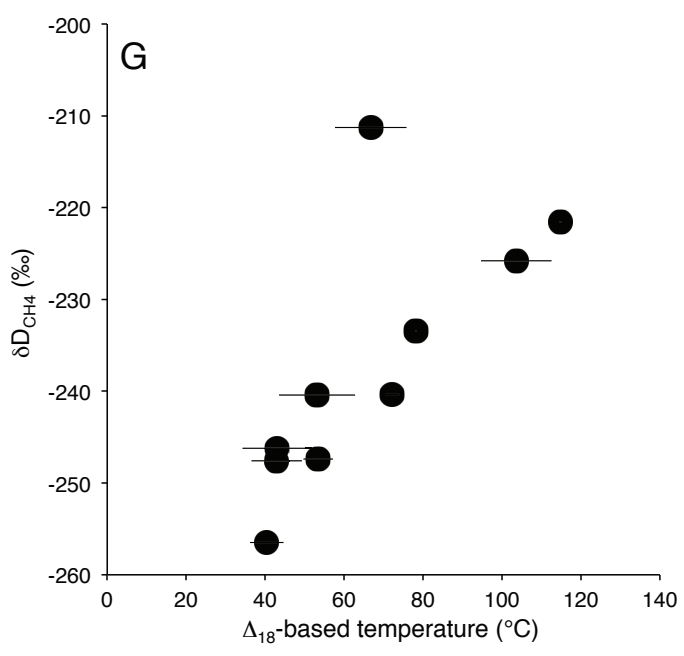


Figure3
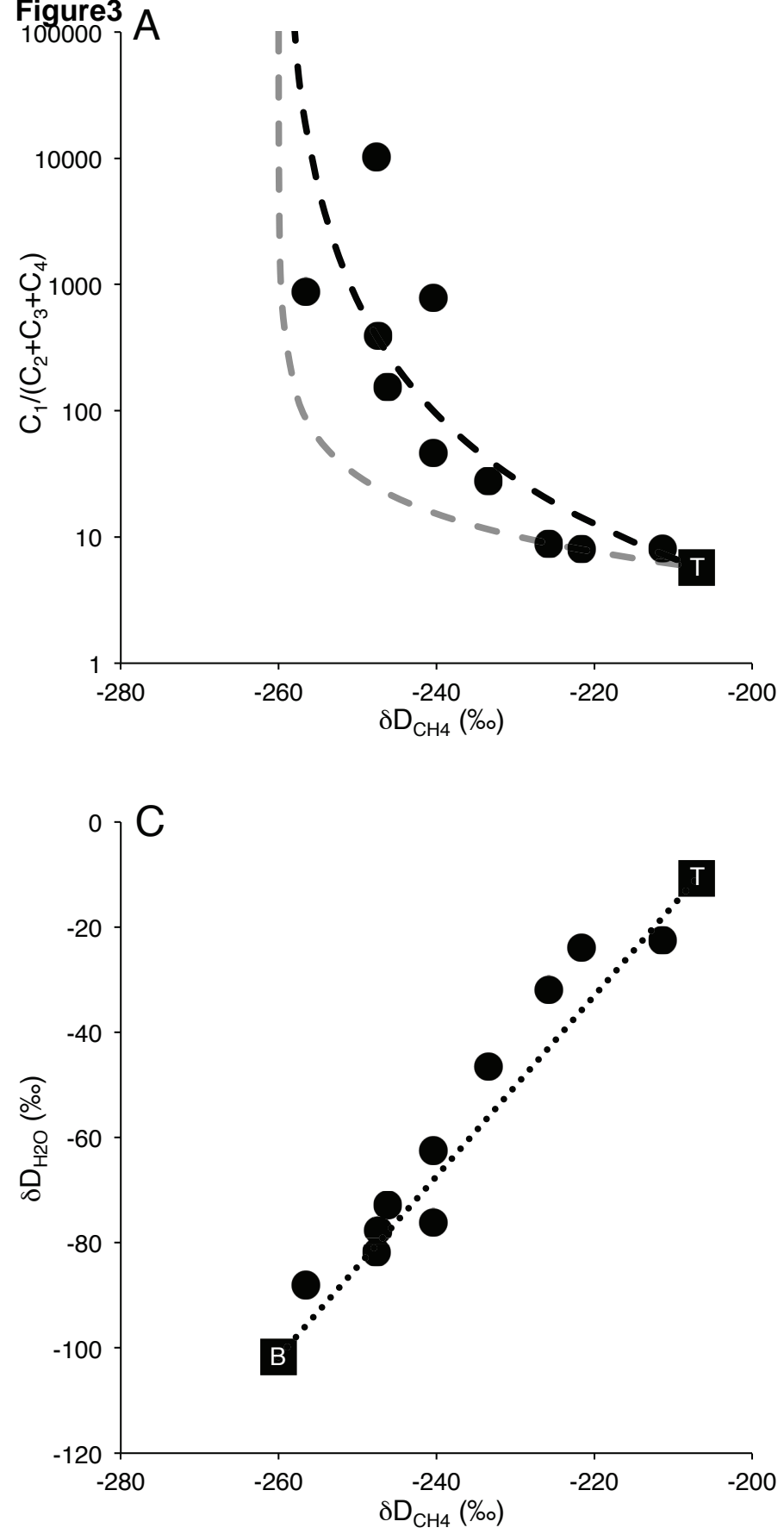
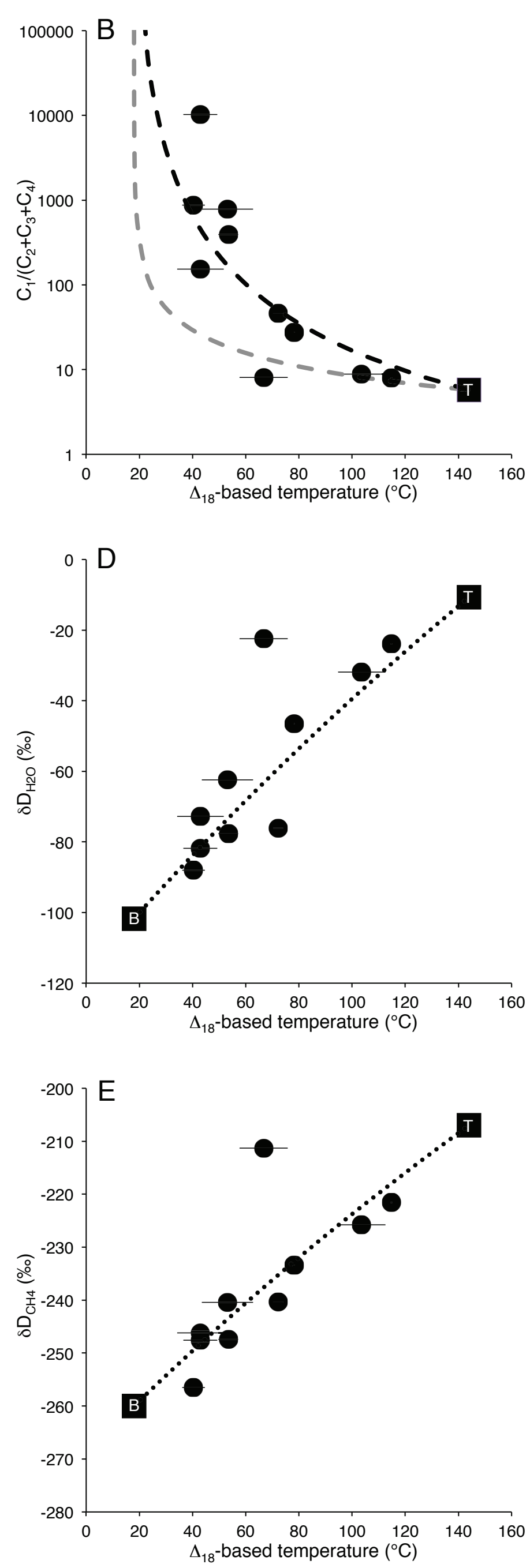

$\mathrm{T}$ thermogenic endmember

B biogenic endmember

- - mixing model without oxidation

- - mixing model with oxidation

... mixing model with or without oxidation 


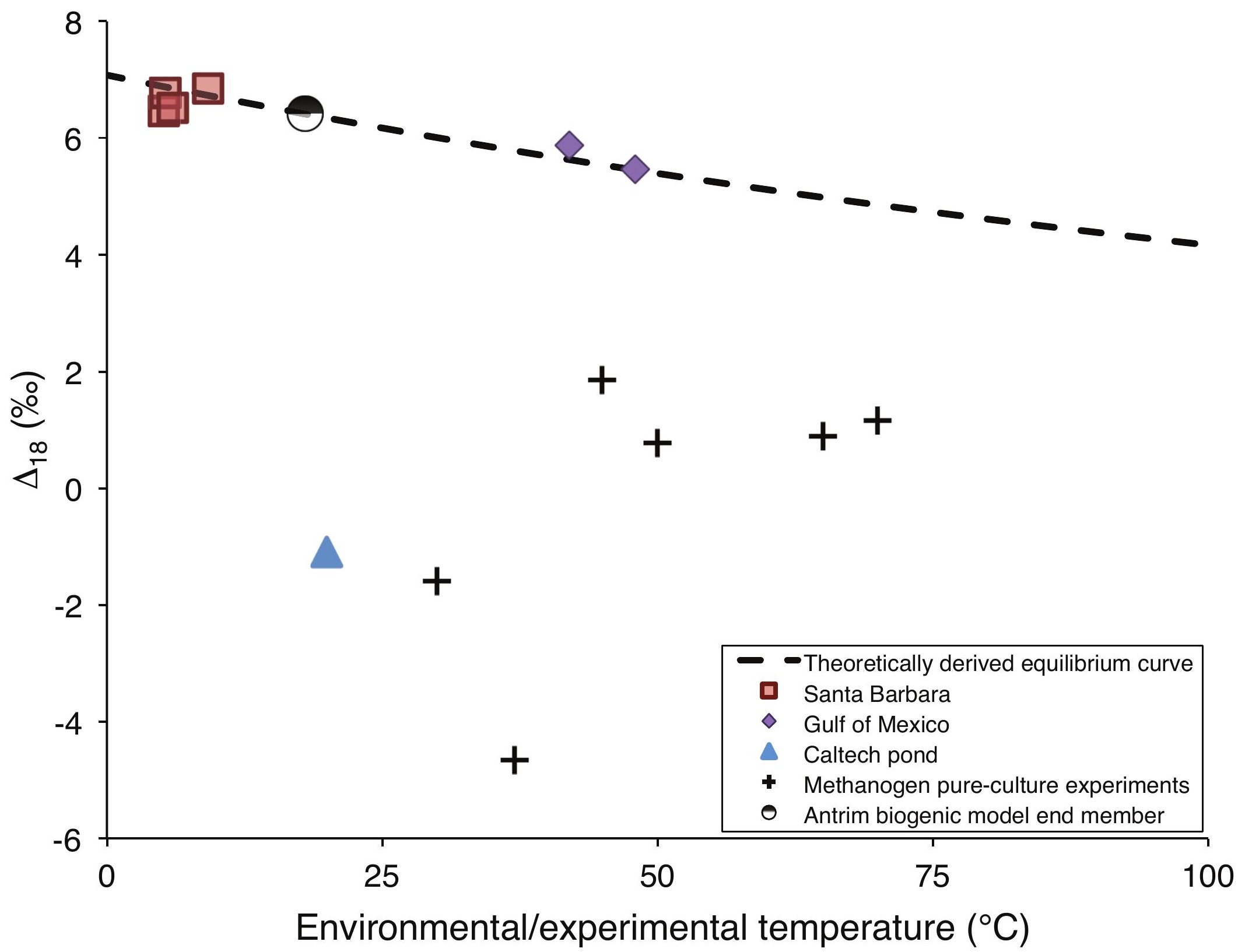


In this direction the measured $\delta \mathrm{D}_{\mathrm{CH} 4}$ becomes increasingly lower than the excepted value for hydrogen isotopic equilibrium with water isotopic equilibrium

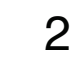

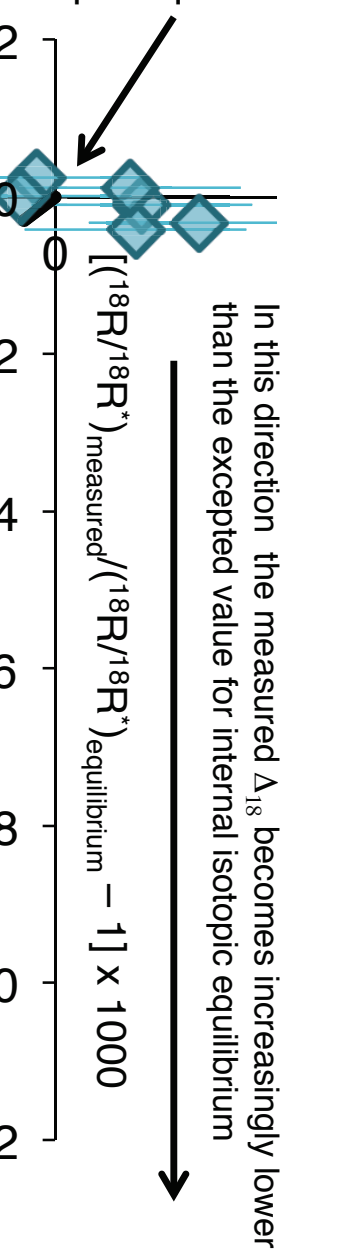




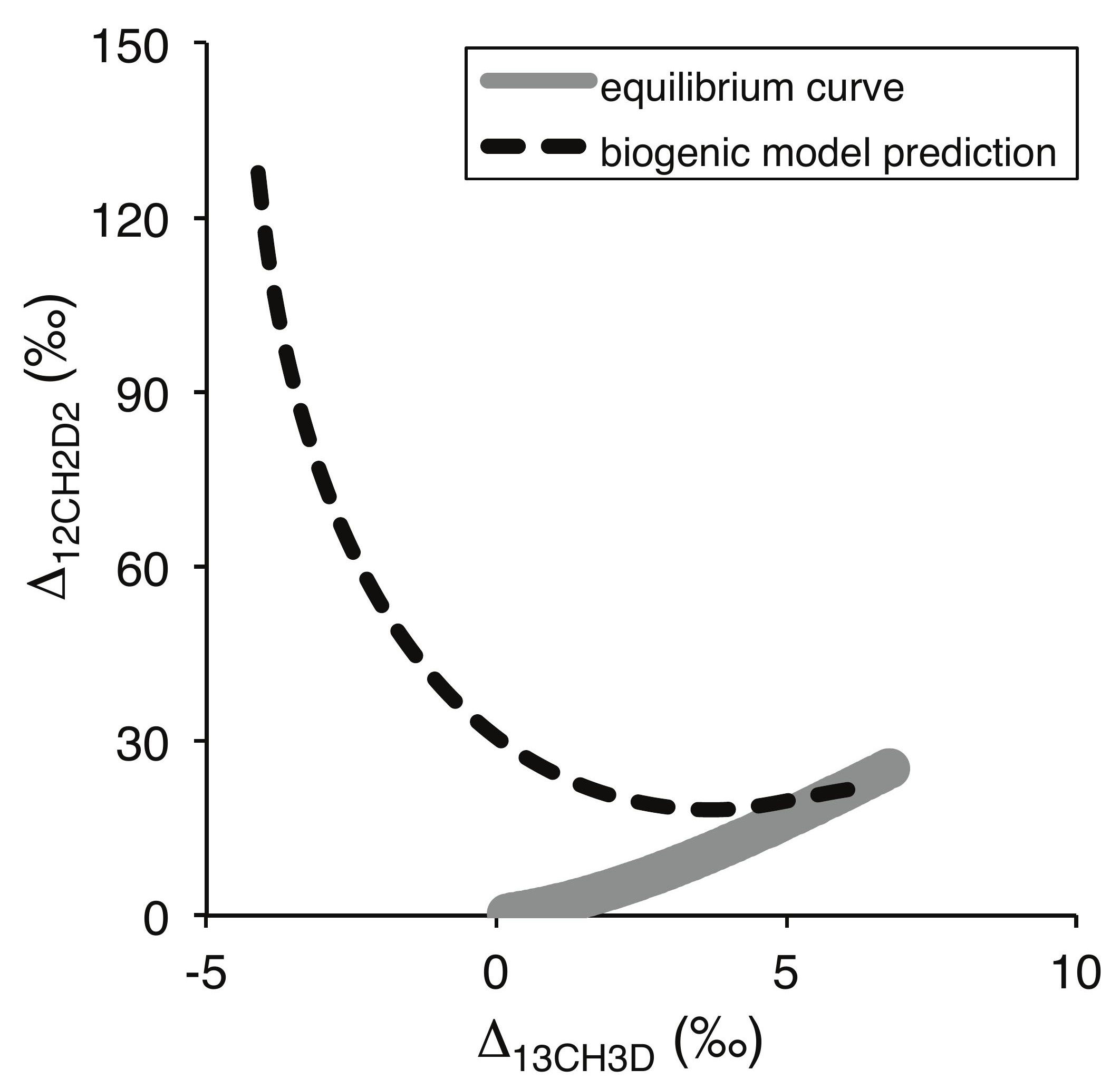

Figure7
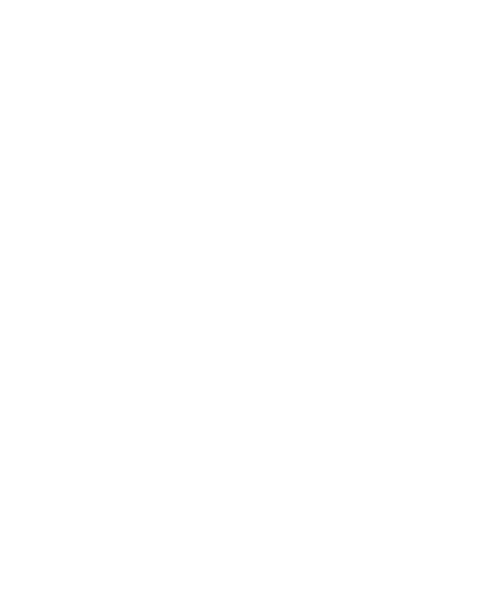

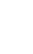

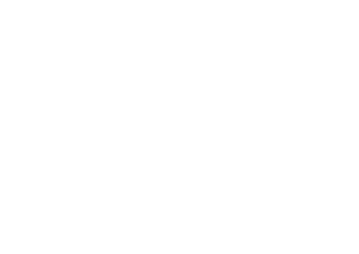

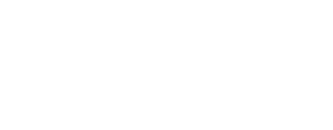




$$
\Delta_{18}=0.0005( \pm 0.0007) \times \delta^{18}+1.12( \pm 0.073)
$$

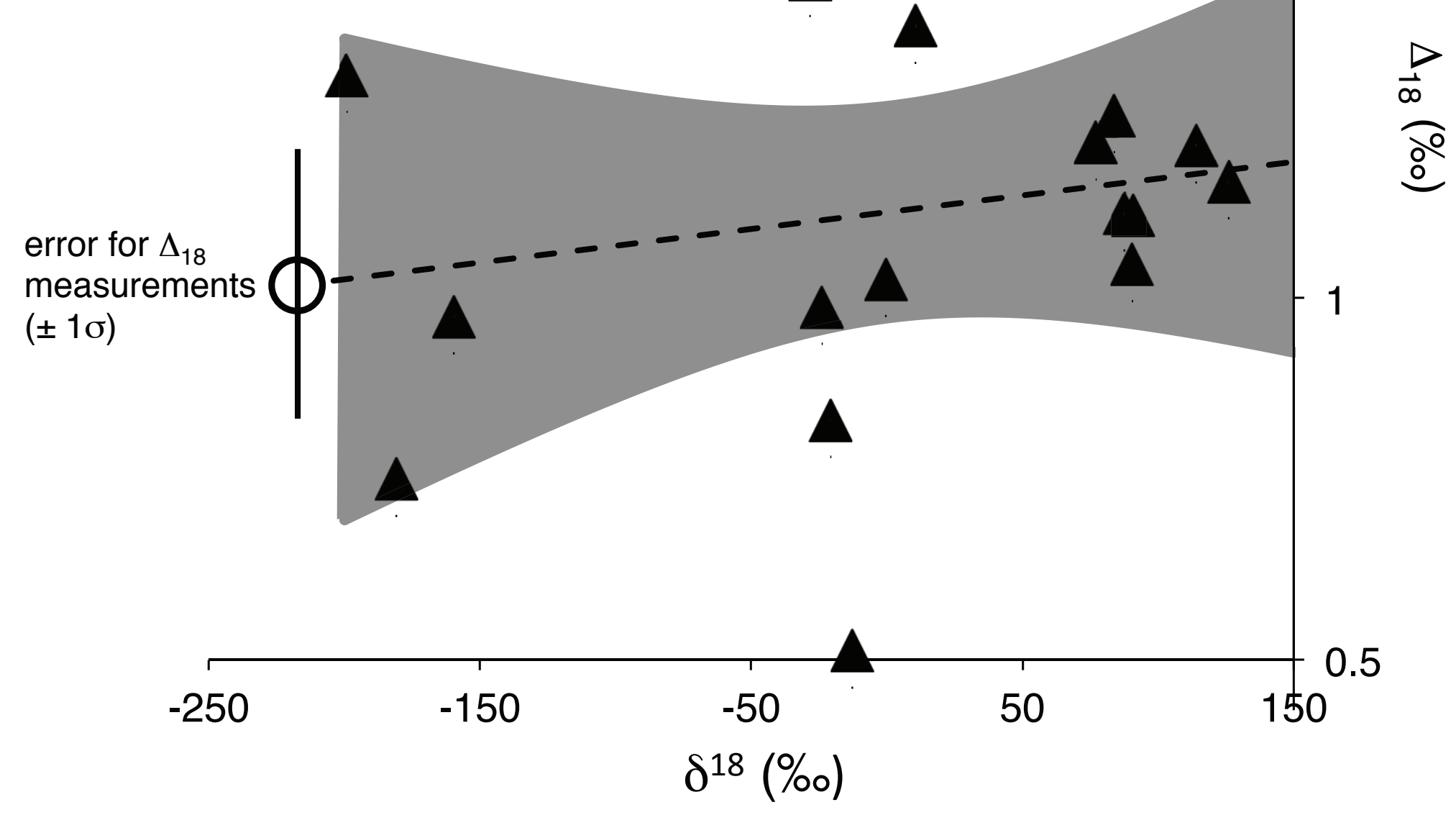



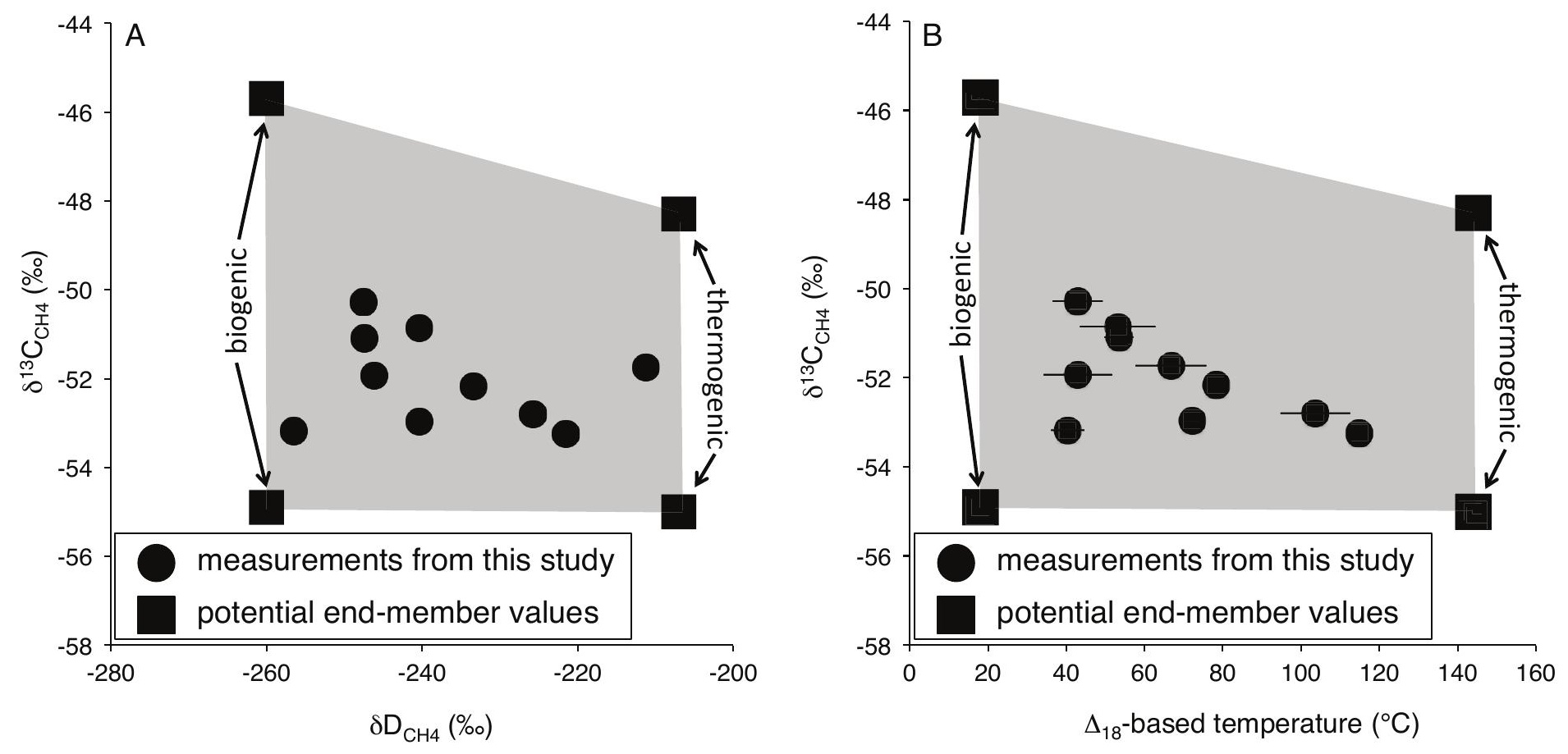
